\title{
Total Synthesis and Stereochemical Assignment of Callyspongiolide
}

\author{
Jingjing Zhou, Bowen Gao, Zhengshuang Xu,* and Tao Ye* \\ Laboratory of Chemical Genomics, Engineering Laboratory for Chiral Drug Synthesis, \\ School of Chemical Biology and Biotechnology, Peking University Shenzhen Graduate \\ School, Xili, Nanshan District, Shenzhen, 518055, China
}

Supporting Information 
Index

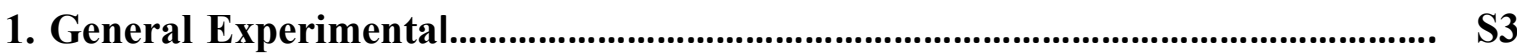

2. Experimental procedures................................................ S4

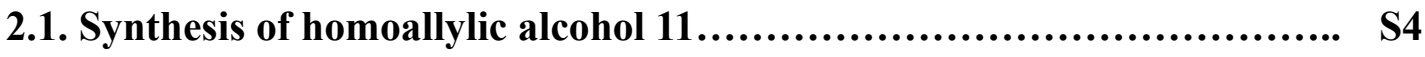

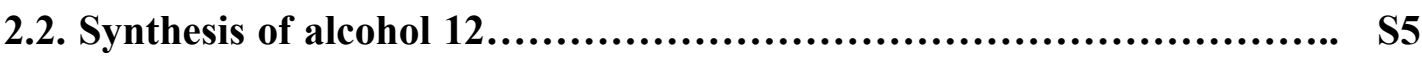

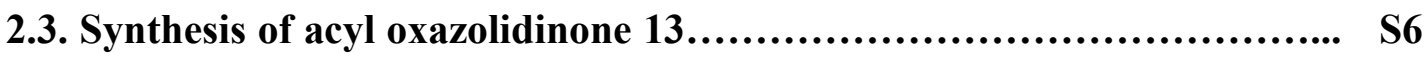

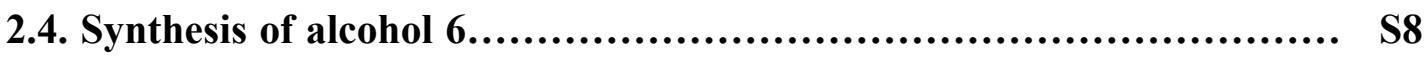

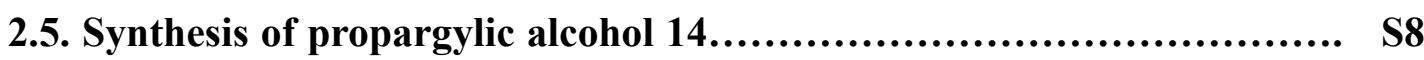

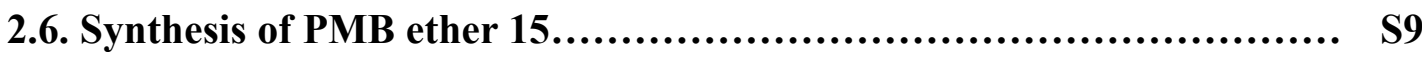

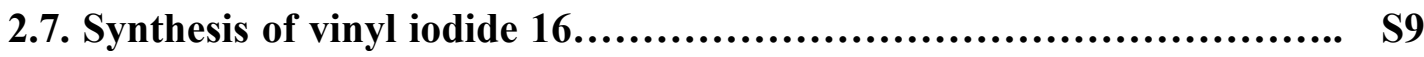

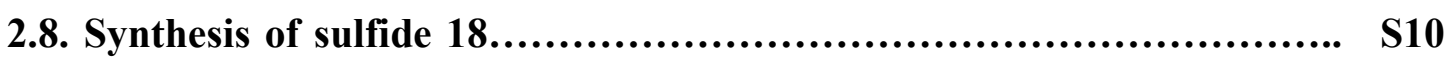

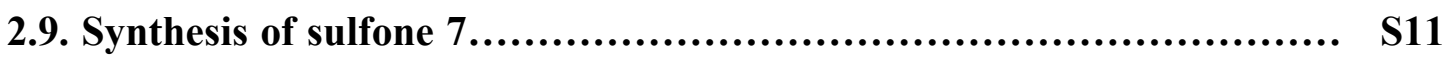

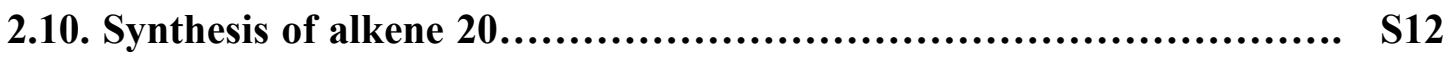

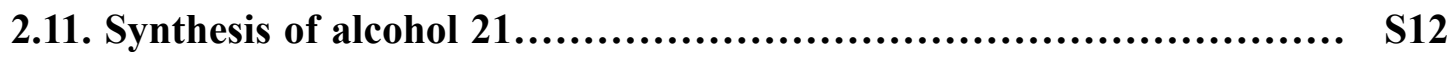

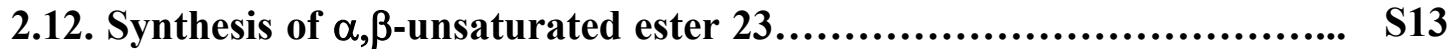

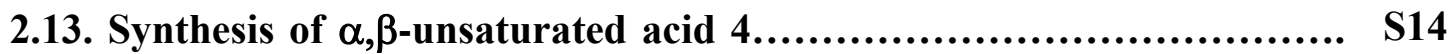

2.14. Synthesis of macrolactone 2 ..................................... S15

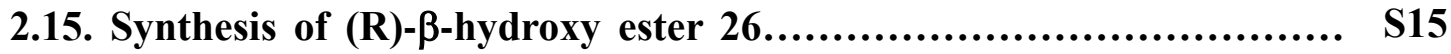

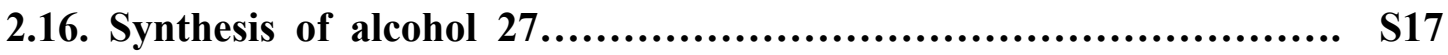

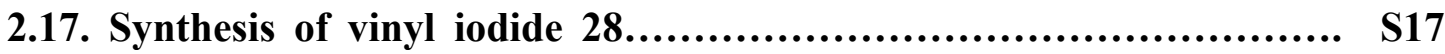

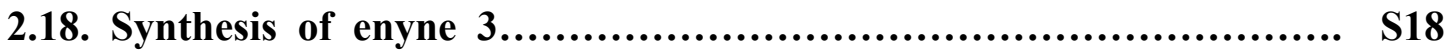

2.19. Synthesis of enyne ent-3......................................... S19

2.20. Synthesis of 1 a................................................... S19

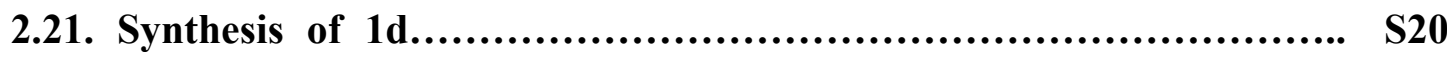

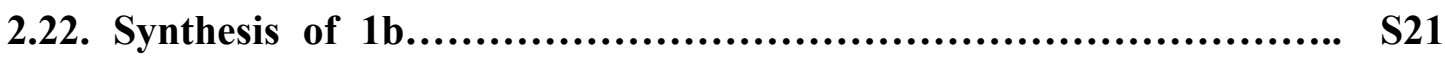

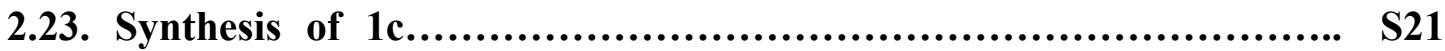

3. Biological Evaluation of Synthetic Compounds........................... S22

4. Comparison of NMR Spectra of Natural and Synthetic Callyspongiolides..... S25

4.1. ${ }^{1}$ H NMR Spectra of Natural and Synthetic Callyspongiolides.......... S25

4.2. ${ }^{13} \mathrm{C}$ NMR Spectra of Natural and Synthetic Callyspongiolides........... S29

4.3. Comparison of ${ }^{13} \mathrm{C}$ NMR Data of Natural, Synthetic Samples........... S33

$5 .{ }^{1} \mathrm{H} \&{ }^{13} \mathrm{C}$ NMR Spectra...................................................... S35 


\section{General Experimental}

All reactions were conducted in flame-dried or oven-dried glassware under an atmosphere of dry nitrogen or argon. Oxygen and/or moisture sensitive solids and liquids were transferred appropriately. Concentration of solutions in vacuo was accomplished using a rotary evaporator fitted with a water aspirator. Residual solvents were removed under high vacuum (0.1-0.2 mm Hg). All reaction solvents were purified before use: Tetrahydrofuran were distilled from sodium benzophenone ketyl. Toluene was distilled over molten sodium metal. Dichloromethane, dimethylformamide, diethylamine, triethylamine and diisoproylethylamine were distilled from $\mathrm{CaH}_{2}$. Methanol was distilled from $\mathrm{Mg} / \mathrm{I}_{2}$. Flash column chromatography was performed using the indicated solvents on E. Qingdao silica gel 60 (230 - 400 mesh ASTM). TLC was carried out using pre-coated sheets (Qingdao silica gel 60-F250, $0.2 \mathrm{~mm}$ ). Compounds were visualized with UV light, iodine, $p$-anisaldehyde stain, ceric ammonium molybdate stain, or phosphomolybdic acid in EtOH. ${ }^{1} \mathrm{H}$ NMR spectra were recorded on Bruker DPX $300 \mathrm{MHz}$, AV $500 \mathrm{MHz}$ or AV $600 \mathrm{MHz}$ spectrometers. Chemical shifts were reported in parts per million (ppm), relative to either a tetramethylsilane (TMS) internal standard or the signals due to the solvent. The following abbreviations are used to describe spin multiplicity: $\mathrm{s}=$ singlet, $\mathrm{d}=$ doublet, $\mathrm{t}=$ triplet, $\mathrm{q}=$ quartet, $\mathrm{qn}=$ quintet, $\mathrm{m}=$ multiplet, $\mathrm{br}=$ broad, $\mathrm{dd}=$ doublet of doublets, $\mathrm{dt}=$ doublet of triplets, $\mathrm{dq}=$ doublet of quartets, $\mathrm{ddd}=$ doublet of doublet of doublets; other combinations are derived from those listed above. Coupling constants (J) are reported in Hertz. ${ }^{13} \mathrm{C}$ NMR spectra were completely heterodecoupled and measured at 75, 125, or $150 \mathrm{MHz}$. High resolution mass spectra were measured on ABI Q-star Elite. Optical rotations were recorded on a Perkin-Elmer 351 polarimeter at $589 \mathrm{~nm}, 100 \mathrm{~mm}$ cell. Data were reported as follow: optical rotation $(c(\mathrm{~g} / 100 \mathrm{~mL})$, solvent). 


\section{Experimental procedures}

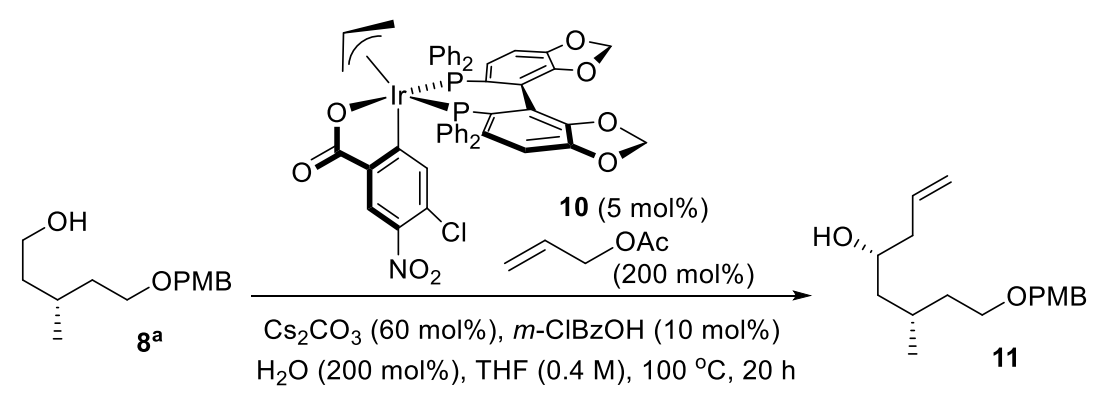

To an oven-dried sealed tube under one atmosphere of nitrogen charged with alcohol $\mathbf{8}$ (200 mg, 0.84 $\mathrm{mmol}$ ), catalyst 10 (44 mg, $0.04 \mathrm{mmol}), \mathrm{Cs}_{2} \mathrm{CO}_{3}(85 \mathrm{mg}, 0.50 \mathrm{mmol}), m-\mathrm{ClBzOH}$ (13 mg, $0.08 \mathrm{mmol}$ ), and $\mathrm{H}_{2} \mathrm{O}(30 \mathrm{mg}, 1.68 \mathrm{mmol})$ was added THF (2.0 mL, 0.4 M) followed by allyl acetate (168 mg, 1.68 mmol). The reaction mixture was allowed to stir at $100{ }^{\circ} \mathrm{C}$ for $20 \mathrm{~h}$, at which point the reaction mixture was evaporated. The residue was purified by silica gel flash chromatography to produce $\mathbf{1 1}$ $(210 \mathrm{mg}, 90 \%)$ as a colorless oil. $\mathrm{R}_{f}=0.2$ (silica gel, $10 \%$ ethyl acetate in hexane); $[\alpha]_{\mathbf{D}}{ }^{20}=-9.4(c 1.0$, $\left.\mathrm{CHCl}_{3}\right) ;{ }^{1} \mathbf{H}$ NMR $\left(500 \mathrm{MHz}, \mathrm{CDCl}_{3}\right) \delta 7.25(\mathrm{~d}, J=8.2 \mathrm{~Hz}, 2 \mathrm{H}), 6.87(\mathrm{~d}, J=8.6 \mathrm{~Hz}, 2 \mathrm{H}), 5.88-5.75$ (m, 1H), $5.12(\mathrm{dd}, J=7.7,6.8 \mathrm{~Hz}, 2 \mathrm{H}), 4.43(\mathrm{~s}, 2 \mathrm{H}), 3.80(\mathrm{~s}, 3 \mathrm{H}), 3.78-3.68(\mathrm{~m}, 1 \mathrm{H}), 3.52-3.42(\mathrm{~m}$, $2 \mathrm{H}), 2.32-2.21(\mathrm{~m}, 1 \mathrm{H}), 2.17-2.06(\mathrm{~m}, 1 \mathrm{H}), 1.90(\mathrm{~s}, 1 \mathrm{H}), 1.82-1.59(\mathrm{~m}, 2 \mathrm{H}), 1.45-1.30(\mathrm{~m}, 3 \mathrm{H})$, $0.93(\mathrm{~d}, J=6.6 \mathrm{~Hz}, 3 \mathrm{H}) .{ }^{13} \mathbf{C} \mathbf{N M R}\left(125 \mathrm{MHz}, \mathrm{CDCl}_{3}\right) \delta 159.22,134.95,130.67,129.25,117.87$, 113.82, 72.49, 68.60, 68.31, 55.27, 44.32, 42.19, 36.25, 27.00, 20.68. HRMS $(\mathrm{m} / \mathrm{z})$ : calculated for $\mathrm{C}_{17} \mathrm{H}_{26} \mathrm{O}_{3} \mathrm{Na}^{+}[\mathrm{M}+\mathrm{Na}]^{+}: 301.1774$, found 301.1775 .

a The known alcohol $\mathbf{8}$ was prepared according to the following scheme.;

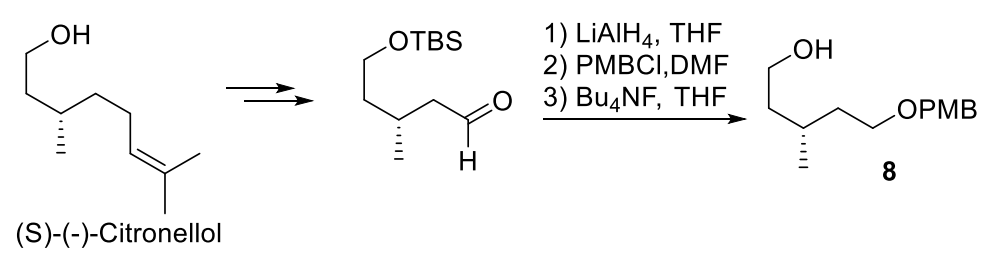

Fujiwara, K.; Naka, J.; Katagiri, T.; Sato, D.; Kawai, H.; Suzuki, T. Bull. Chem. Soc. Jpn. 2007, 80, 1173.; Lee, E. Lee,Y. R. Moon, Kwon, B. O. Shim, M. S. Yun, J. S. J. Org. Chem. 1994, 59, 1444.

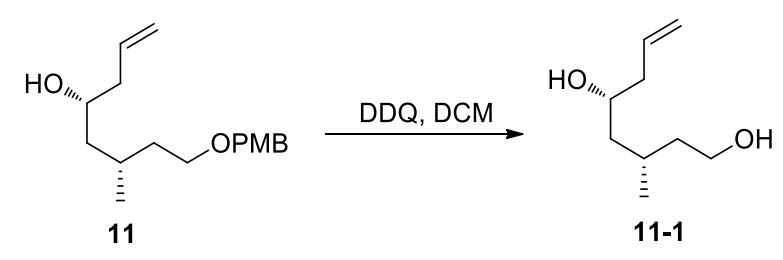

To a solution of $11(300 \mathrm{mg}, 1.1 \mathrm{mmol})$ in DCM $(10 \mathrm{~mL})$ and phosphate buffer $(1 \mathrm{~mL}, \mathrm{pH} 7.0,100$ $\mathrm{mM}$ ) was added DDQ (500 $\mathrm{mg}, 2.2 \mathrm{mmol})$ at room temperature. The reaction mixture was stirred at 
room temperature for $2 \mathrm{~h}$., and then washed sequentially with saturated aqueous solution of $\mathrm{Na}_{2} \mathrm{~S}_{2} \mathrm{O}_{3}$ $(20 \mathrm{~mL}), \mathrm{NaHCO}_{3}(20 \mathrm{~mL})$ and brine $(20 \mathrm{~mL})$. The organic phase was dried over anhydrous $\mathrm{Na}_{2} \mathrm{SO}_{4}$ and concentrated in vacuo. The residue was purified by silica gel flash chromatography to produce 11$1(162 \mathrm{mg}, 95 \%)$ as a colorless oil. $\mathrm{R}_{f}=0.4$ (silica gel, 33\% ethyl acetate in hexane); $[\alpha]_{\mathbf{D}}{ }^{\mathbf{2 0}}=-22.0(c$ 1.0, $\left.\mathrm{CHCl}_{3}\right)$; ${ }^{1} \mathbf{H}$ NMR $\left(500 \mathrm{MHz}, \mathrm{CDCl}_{3}\right) \delta 5.88-5.77(\mathrm{~m}, 1 \mathrm{H}), 5.15-5.07(\mathrm{~m}, 2 \mathrm{H}), 3.80-3.73(\mathrm{~m}$, $1 \mathrm{H}), 3.73-3.67(\mathrm{~m}, 1 \mathrm{H}), 3.67-3.58(\mathrm{~m}, 1 \mathrm{H}), 2.97(\mathrm{~s}, 2 \mathrm{H}), 2.31-2.21(\mathrm{~m}, 1 \mathrm{H}), 2.21-2.11(\mathrm{~m}, 1 \mathrm{H})$, $1.90-1.75(\mathrm{~m}, 1 \mathrm{H}), 1.75-1.64(\mathrm{~m}, 1 \mathrm{H}), 1.44-1.33(\mathrm{~m}, 2 \mathrm{H}), 1.33-1.20(\mathrm{~m}, 1 \mathrm{H}), 0.94(\mathrm{~d}, J=6.7 \mathrm{~Hz}$, $3 \mathrm{H}) .{ }^{13} \mathrm{C}$ NMR $\left(125 \mathrm{MHz}, \mathrm{CDCl}_{3}\right) \delta 134.94,117.73,68.17,60.52,44.21,42.20,38.46,25.82,20.70$. HRMS $(m / z)$ : calculated for $\mathrm{C}_{9} \mathrm{H}_{18} \mathrm{O}_{2} \mathrm{Na}^{+}[\mathrm{M}+\mathrm{Na}]^{+}: 181.1199$, found 181.1192.

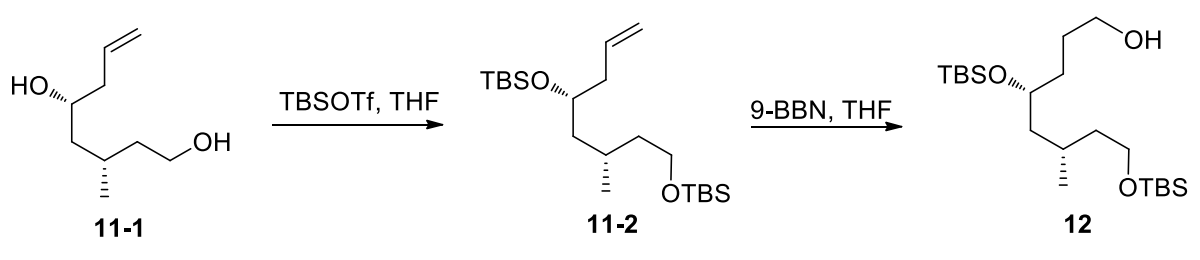

To a solution of diol 11-1 $(272 \mathrm{mg}, 1.74 \mathrm{mmol})$ in DCM $(15 \mathrm{~mL})$ was added TBSOTf $(1.13 \mathrm{~mL}, 5.25$ $\mathrm{mmol})$ and $\mathrm{Et}_{3} \mathrm{~N}(0.95 \mathrm{~mL}, 7.00 \mathrm{mmol})$ at $-78{ }^{\circ} \mathrm{C}$. The reaction mixture was allowed to slowly warm to $-30{ }^{\circ} \mathrm{C}$ and stirred at $-30{ }^{\circ} \mathrm{C}$ for $2 \mathrm{~h}$., and then was quenched with saturated aqueous solution of $\mathrm{NaHCO}_{3}(20 \mathrm{~mL})$ at $-78{ }^{\circ} \mathrm{C}$ and allowed to warm to room temperature. The mixture was dissolved in ethyl acetate $(50 \mathrm{~mL})$ and the layers were separated. The aqueous phase was extracted with ethyl acetate $(3 \times 30 \mathrm{~mL})$. The combined organic layers were washed with brine $(30 \mathrm{~mL})$, dried over anhydrous $\mathrm{Na} 2 \mathrm{SO} 4$ and concentrated in vacuo. The residue was purified by silica gel flash chromatography to produce $\mathbf{1 1 - 2}(670 \mathrm{mg}, 99 \%)$ as a colorless oil. $\mathrm{R}_{f}=0.20$ (silica gel, hexane);

To a solution of $\mathbf{1 1 - 2}(670 \mathrm{mg}, 1.76 \mathrm{mmol})$ in THF $(10 \mathrm{~mL})$ was added $9-B B N(12 \mathrm{~mL}, 0.5 \mathrm{M})$ at $0{ }^{\circ} \mathrm{C}$. The mixture was warmed to room temperature and stirred for $2 \mathrm{~h}$., and then slowly quenched by the addition of saturated aqueous solution of $\mathrm{NaHCO}_{3}(10 \mathrm{~mL})$ and $30 \%$ hydrogen peroxide $(10 \mathrm{~mL})$ at $0{ }^{\circ} \mathrm{C}$. The mixture was allowed to warm to room temperature and stirred for $2 \mathrm{~h}$. Layers were separated and the aqueous phase was extracted with ethyl ether $(2 \times 30 \mathrm{~mL})$. The organic phase was washed with brine $(30 \mathrm{~mL})$, dried over anhydrous $\mathrm{Na}_{2} \mathrm{SO}_{4}$, concentrated in vacuo and purified by silica gel flash chromatography to give $\mathbf{1 2}$ as colorless oil (630 mg, $90 \%$ ). $\mathrm{R}_{f}=0.4$ (silica gel, 10\% ethyl acetate in hexane); $[\alpha]_{\mathbf{D}}{ }^{20}=1.8\left(c 1.0, \mathrm{CHCl}_{3}\right) ;{ }^{1} \mathbf{H} \mathbf{~ N M R}\left(500 \mathrm{MHz}, \mathrm{CDCl}_{3}\right) \delta 3.88-3.79(\mathrm{~m}, 1 \mathrm{H})$, $3.69-3.55(\mathrm{~m}, 4 \mathrm{H}), 2.24(\mathrm{~s}, 1 \mathrm{H}), 1.67-1.52(\mathrm{~m}, 7 \mathrm{H}), 1.37-1.23(\mathrm{~m}, 2 \mathrm{H}), 0.91-0.83(\mathrm{~m}, 21 \mathrm{H}), 0.07$ (s, 6H), 0.05 (s, 6H). ${ }^{13} \mathrm{C}$ NMR $\left(125 \mathrm{MHz}, \mathrm{CDCl}_{3}\right) \delta$ 70.16, 63.24, 61.11, 44.12, 40.48, 33.14, 27.87, $26.29,25.97,25.90,19.94,18.33,18.10,-4.43,-4.46,-5.26,-5.29 . \mathbf{H R M S}(\mathrm{m} / \mathrm{z})$ : calculated for $\mathrm{C}_{21} \mathrm{H}_{48} \mathrm{O}_{3} \mathrm{Si}_{2} \mathrm{Na}^{+}[\mathrm{M}+\mathrm{Na}]^{+}:$427.3034, found 427.3036. 


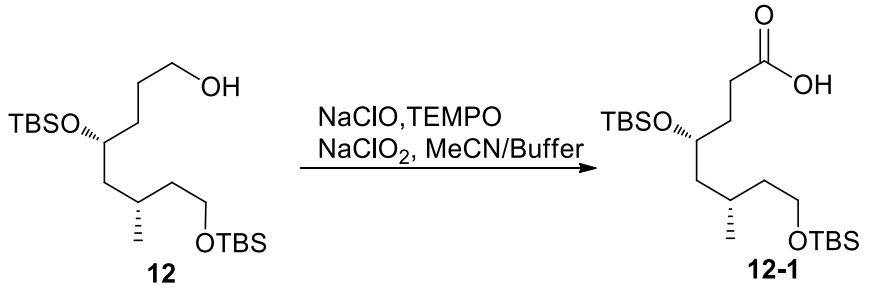

To a solution of compound $12(630 \mathrm{mg}, 1.56 \mathrm{mmol})$ in $\mathrm{CH}_{3} \mathrm{CN}(20 \mathrm{~mL})$ and phosphate buffer $(20 \mathrm{~mL}$, pH 7.0, $100 \mathrm{mM}$ ) were subsequently added $\mathrm{NaClO}_{2}(755 \mathrm{mg}, 8.39 \mathrm{mmol}), \mathrm{NaClO}(1.55 \mathrm{~mL}, 10 \%$ chlorine) and TEMPO (15 mg, $0.10 \mathrm{mmol})$ at room temperature. After being stirred for $2 \mathrm{~h}$, the $\mathrm{pH}$ value of the reaction mixture was adjusted to 3 with $1 \mathrm{M} \mathrm{HCl}$. Volatiles were removed in vacuo, the aqueous residue was extracted with ethyl ether $(2 \times 30 \mathrm{~mL})$. The combined organic layers were washed with brine $(30 \mathrm{~mL})$, dried over anhydrous $\mathrm{Na}_{2} \mathrm{SO}_{4}$, concentrated in vacuo. The residue was purified by silica gel flash chromatography to give $\mathbf{1 2 - 1}$ as a colorless oil $(610 \mathrm{mg}, 94 \%)$. $\mathbf{R}_{f}=0.4$ (silica gel, $10 \%$ ethyl acetate in hexane); $[\alpha]_{\mathbf{D}}{ }^{20}=10.1\left(c 1.0, \mathrm{CHCl}_{3}\right) ;{ }^{\mathbf{1}} \mathbf{H} \mathbf{N M R}\left(500 \mathrm{MHz}, \mathrm{CDCl}_{3}\right) \delta$ $3.87-3.78(\mathrm{~m}, 1 \mathrm{H}), 3.71-3.58(\mathrm{~m}, 2 \mathrm{H}), 2.44(\mathrm{t}, J=7.6 \mathrm{~Hz}, 2 \mathrm{H}), 1.93-1.80(\mathrm{~m}, 1 \mathrm{H}), 1.70-1.59(\mathrm{~m}$, $2 \mathrm{H}), 1.58-1.50(\mathrm{~m}, 1 \mathrm{H}), 1.46-1.39(\mathrm{~m}, 1 \mathrm{H}), 1.39-1.26(\mathrm{~m}, 2 \mathrm{H}), 0.94-0.89(\mathrm{~m}, 12 \mathrm{H}), 0.89(\mathrm{~s}, 9 \mathrm{H})$, $0.06(\mathrm{~s}, 6 \mathrm{H}), 0.05$ (s, 6H). ${ }^{13} \mathrm{C}$ NMR $\left(125 \mathrm{MHz}, \mathrm{CDCl}_{3}\right) \delta$ 180.00, 69.26, 61.10, 44.65, 40.47, 31.15, 29.52, 26.33, 25.95, 25.86, 19.90, 18.30, 18.02, -4.36, -4.56, -5.30, -5.32. HRMS $(\mathrm{m} / \mathrm{z})$ : calculated for $\mathrm{C}_{21} \mathrm{H}_{46} \mathrm{O}_{4} \mathrm{Si}_{2} \mathrm{Na}^{+}[\mathrm{M}+\mathrm{Na}]^{+}: 441.2827$, found 441.2825.

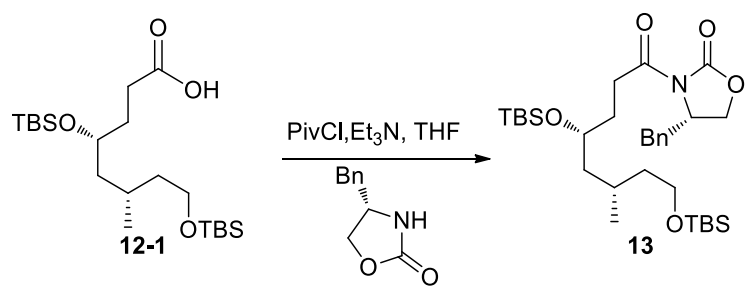

To a stirred solution of acid 12-1 (610 mg, $1.46 \mathrm{mmol})$ in dry THF (10 mL) was sequentially added $\mathrm{Et}_{3} \mathrm{~N}(0.61 \mathrm{~mL}, 4.38 \mathrm{mmol})$ and trimethylacetyl chloride $(180 \mathrm{uL}, 1.61 \mathrm{mmol})$ at $0{ }^{\circ} \mathrm{C}$. After being stirred for 20 minutes, the reaction mixture was cooled to $-78^{\circ} \mathrm{C}$.

In a separate flask, $n$-butyllithium (1.1 mL, $1.65 \mathrm{mmol}, 1.5 \mathrm{M}$ in heptane) was added to a solution of (4S)-4-benzyl-1,3-oxazolidin-2-one $(550 \mathrm{mg}, 3.11 \mathrm{mmol})$ in $\mathrm{THF}(5 \mathrm{~mL})$ at $-78{ }^{\circ} \mathrm{C}$. After being stirred for $30 \mathrm{~min}$ later, the resulting solution was transferred to the afore-mentioned reaction mixture at $78{ }^{\circ} \mathrm{C}$. This reaction mixture was stirred for $2 \mathrm{~h}$ at $-78{ }^{\circ} \mathrm{C}$ and quenched with saturated aqueous solution of $\mathrm{NaHCO}_{3}(10 \mathrm{~mL})$. Volatiles were removed in vacuo, the aqueous phase was extracted with ethyl ether $(2 \times 30 \mathrm{~mL})$. The combined organic phases were washed with brine $(30 \mathrm{~mL})$, dried over anhydrous $\mathrm{Na}_{2} \mathrm{SO}_{4}$, concentrated in vacuo. The residue was purified by silica gel flash chromatography to give $\mathbf{1 3}$ as a colorless oil (675 mg, 80\%). $\mathrm{R}_{f}=0.9$ (silica gel, $17 \%$ ethyl acetate in 
hexane); $[\alpha]_{\mathbf{D}}{ }^{20}=35.4\left(c 1.0, \mathrm{CHCl}_{3}\right) ;{ }^{1} \mathbf{H} \mathbf{N M R}\left(500 \mathrm{MHz}, \mathrm{CDCl}_{3}\right) \delta 7.37-7.30(\mathrm{~m}, 2 \mathrm{H}), 7.30-7.26$ (m, 1H), $7.24-7.18(\mathrm{~m}, 2 \mathrm{H}), 4.74-4.59(\mathrm{~m}, 1 \mathrm{H}), 4.25-4.11(\mathrm{~m}, 2 \mathrm{H}), 3.90-3.77(\mathrm{~m}, 1 \mathrm{H}), 3.71-$ $3.57(\mathrm{~m}, 2 \mathrm{H}), 3.30(\mathrm{dd}, J=13.4,3.2 \mathrm{~Hz}, 1 \mathrm{H}), 3.15-2.89(\mathrm{~m}, 2 \mathrm{H}), 2.82-2.70(\mathrm{~m}, 1 \mathrm{H}), 1.98-1.85(\mathrm{~m}$, $1 \mathrm{H}), 1.76-1.62(\mathrm{~m}, 2 \mathrm{H}), 1.62-1.54(\mathrm{~m}, 1 \mathrm{H}), 1.51-1.42(\mathrm{~m}, 1 \mathrm{H}), 1.39-1.28(\mathrm{~m}, 2 \mathrm{H}), 0.92(\mathrm{~d}, J=$ $6.6 \mathrm{~Hz}, 3 \mathrm{H}), 0.89$ (s, 18H), 0.07 (s, 3H), 0.06 (s, 3H), 0.05 (s, 6H). ${ }^{13} \mathbf{C}$ NMR $\left(125 \mathrm{MHz}, \mathrm{CDCl}_{3}\right) \delta$ 173.48, 153.36, 135.36, 129.42, 128.94, 127.32, 69.36, 66.12, 61.27, 55.15, 45.20, 40.50, 37.92, 31.59, 30.92, 26.44, 25.99, 25.91, 20.01, 18.33, 18.05, -4.32, -4.52, -5.25, -5.28. HRMS $(\mathrm{m} / \mathrm{z})$ : calculated for $\mathrm{C}_{31} \mathrm{H}_{55} \mathrm{NO}_{5} \mathrm{Si}_{2} \mathrm{Na}^{+}[\mathrm{M}+\mathrm{Na}]^{+}: 600.3511$, found 600.3512 .

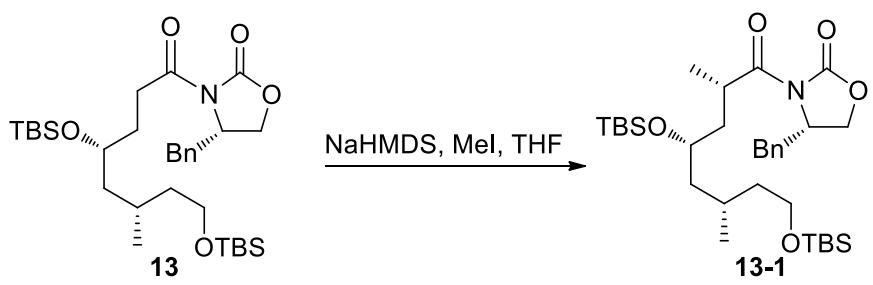

To a solution of 13 (395 mg, $0.68 \mathrm{mmol})$ in THF (10 mL) was added NaHMDS (0.85 mL, $1.70 \mathrm{mmol}$, $2.0 \mathrm{M})$ at $-78{ }^{\circ} \mathrm{C}$. After being stirred for 15 minutes, MeI (131 uL, $\left.2.05 \mathrm{mmol}\right)$ was added dropwise at $-78{ }^{\circ} \mathrm{C}$. The reaction mixture was stirred overnight at $-78{ }^{\circ} \mathrm{C}$ and then quenched with saturated aqueous $\mathrm{NH}_{4} \mathrm{Cl}(30 \mathrm{~mL})$. Volatiles were removed in vacuo, the aqueous layer was extracted with ethyl ether $(2 \times 30 \mathrm{~mL})$. The combined organic layers were washed with brine $(30 \mathrm{~mL})$, dried over anhydrous $\mathrm{Na}_{2} \mathrm{SO}_{4}$ and concentrated in vacuo. The residue was purified by silica gel flash chromatography to give $\mathbf{1 3 - 1}$ (420 mg, 99\%) as a colorless oil. $\mathbf{R}_{f}=0.80$ (silica gel, $17 \%$ ethyl acetate in hexane); $[\alpha]_{\mathbf{D}}{ }^{20}=49.1\left(c 1.0, \mathrm{CHCl}_{3}\right)$;

${ }^{1} \mathbf{H}$ NMR $\left(500 \mathrm{MHz}, \mathrm{CDCl}_{3}\right) \delta 7.33(\mathrm{t}, J=7.2 \mathrm{~Hz}, 2 \mathrm{H}), 7.29-7.24(\mathrm{~m}, 1 \mathrm{H}), 7.24-7.17(\mathrm{~m}, 2 \mathrm{H}), 4.74$ $-4.63(\mathrm{~m}, 1 \mathrm{H}), 4.21-4.09(\mathrm{~m}, 2 \mathrm{H}), 3.88-3.80(\mathrm{~m}, 1 \mathrm{H}), 3.80-3.72(\mathrm{~m}, 1 \mathrm{H}), 3.71-3.59(\mathrm{~m}, 2 \mathrm{H})$, $3.24(\mathrm{dd}, J=13.4,3.2 \mathrm{~Hz}, 1 \mathrm{H}), 2.77(\mathrm{dd}, J=13.4,9.6 \mathrm{~Hz}, 1 \mathrm{H}), 2.14(\mathrm{ddd}, J=13.6,9.6,3.7 \mathrm{~Hz}, 1 \mathrm{H})$, $1.73-1.64(\mathrm{~m}, 1 \mathrm{H}), 1.60-1.51(\mathrm{~m}, 1 \mathrm{H}), 1.51-1.43(\mathrm{~m}, 1 \mathrm{H}), 1.40-1.33(\mathrm{~m}, 2 \mathrm{H}), 1.25(\mathrm{~d}, J=7.0 \mathrm{~Hz}$, $3 \mathrm{H}), 0.93(\mathrm{~d}, J=6.6 \mathrm{~Hz}, 3 \mathrm{H}), 0.90(\mathrm{~s}, 9 \mathrm{H}), 0.86(\mathrm{~s}, 9 \mathrm{H}), 0.06(\mathrm{~s}, 6 \mathrm{H}), 0.02(\mathrm{~s}, 3 \mathrm{H}),-0.03(\mathrm{~s}, 3 \mathrm{H}) .{ }^{13} \mathrm{C}$ NMR $\left(125 \mathrm{MHz}, \mathrm{CDCl}_{3}\right) \delta 176.82,152.72,135.32,129.48,128.90,127.31,68.73,65.88,61.18$, 55.18, 45.46, 40.78, 39.80, 37.86, 34.14, 26.42, 25.99, 25.84, 19.85, 19.04, 18.33, 17.98, -4.18, -4.79, -5.26, -5.28. HRMS $(\mathrm{m} / \mathrm{z})$ : calculated for $\mathrm{C}_{32} \mathrm{H}_{57} \mathrm{NO}_{5} \mathrm{Si}_{2} \mathrm{Na}^{+}[\mathrm{M}+\mathrm{Na}]^{+}: 614.3667$, found 614.3669. 


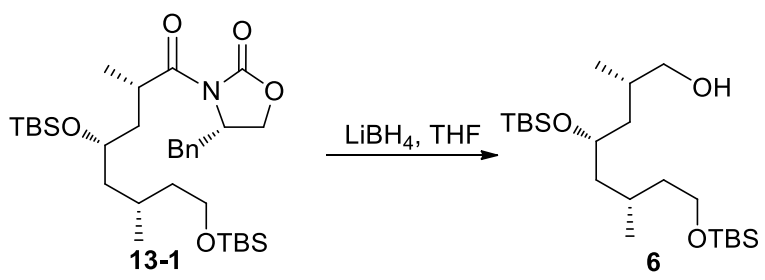

To a solution of 13-1 (420 mg, $0.71 \mathrm{mmol})$ in THF $(10 \mathrm{~mL})$ was added lithium borohydride $(1.2 \mathrm{~mL}$, $2.4 \mathrm{mmol}, 2 \mathrm{M}$ ) at $0{ }^{\circ} \mathrm{C}$. After being stirred for $4 \mathrm{~h}$, the reaction mixture was quenched by the addition of $\mathrm{MeOH}(0.2 \mathrm{~mL})$ at $0{ }^{\circ} \mathrm{C}$. The reaction mixture was allowed to warm to room temperature and stirred for additional $3 \mathrm{~h}$. and then added a saturated aqueous solution of $\mathrm{NaHCO}_{3}(10 \mathrm{~mL})$. After the solution was stirred until clear phases were obtained $(1.5 \mathrm{~h})$, the aqueous layer was extracted with ethyl ether $(2 \times 30 \mathrm{~mL})$. The combined organic phases were washed with brine $(30 \mathrm{~mL})$, dried over anhydrous $\mathrm{Na}_{2} \mathrm{SO}_{4}$, concentrated in vacuo. The residue was purified by silica gel flash chromatography to give 6 as a colorless oil $(260 \mathrm{mg}, 88 \%): \mathrm{R}_{f}=0.4$ (silica gel, $10 \%$ ethyl acetate in hexane); $[\alpha]_{\mathbf{D}}{ }^{20}=4.8\left(c 1.0, \mathrm{CHCl}_{3}\right) ;{ }^{1} \mathbf{H}$ NMR $\left(500 \mathrm{MHz}, \mathrm{CDCl}_{3}\right) \delta 3.99-3.91(\mathrm{~m}, 1 \mathrm{H}), 3.75-3.68$ (m, 1H), $3.68-3.55(\mathrm{~m}, 2 \mathrm{H}), 3.46(\mathrm{~s}, 1 \mathrm{H}), 3.37-3.25(\mathrm{~m}, 1 \mathrm{H}), 1.96-1.83(\mathrm{~m}, 1 \mathrm{H}), 1.65-1.54(\mathrm{~m}$, $4 \mathrm{H}), 1.48-1.37(\mathrm{~m}, 1 \mathrm{H}), 1.35-1.29(\mathrm{~m}, 2 \mathrm{H}), 0.90(\mathrm{~s}, 9 \mathrm{H}), 0.90-0.87(\mathrm{~m}, 12 \mathrm{H}), 0.86(\mathrm{~d}, J=6.8 \mathrm{~Hz}$, 3H), 0.10 (s, 3H) , 0.09 (s, 3H), 0.04 (s, 6H). $\left.{ }^{13} \mathbf{C ~ N M R ~ ( 1 2 5 ~ M H z , ~} \mathrm{CDCl}_{3}\right) \delta$ 69.78, 68.78, 60.89, $43.35,41.97,40.56,31.55,26.19,25.96,25.84,19.63,18.78,18.25,18.07,-4.56,-4.60,-5.28,-5.31$. HRMS $(\mathrm{m} / \mathrm{z})$ : calculated for $\mathrm{C}_{22} \mathrm{H}_{50} \mathrm{O}_{3} \mathrm{Si}_{2} \mathrm{Na}^{+}[\mathrm{M}+\mathrm{Na}]^{+}: 441.3191$, found 441.3193 .

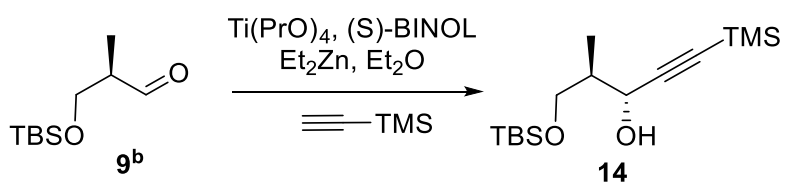

To a solution of $\mathrm{Et}_{2} \mathrm{Zn}(18.8 \mathrm{~mL}, 1.0 \mathrm{M}, 18.8 \mathrm{mmol})$ in toluene was carefully added TMS acetylene $(2.6 \mathrm{~mL}, 18.8 \mathrm{mmol})$. The mixture was heated to reflux for $1 \mathrm{~h}$, cooled to room temperature, followed by addition of (S)-BINOL $(0.52 \mathrm{~g}, 1.88 \mathrm{mmol})$ in $\mathrm{Et}_{2} \mathrm{O}(20 \mathrm{~mL})$ and $\mathrm{Ti}(\mathrm{OiPr})_{4}(1.39 \mathrm{~mL}, 4.70 \mathrm{mmol})$. After being stirred for $1 \mathrm{~h}$ later, aldehyde $9(0.95 \mathrm{~g}, 4.70 \mathrm{mmol})$ in $\mathrm{Et}_{2} \mathrm{O}(10 \mathrm{~mL})$ was added to the reaction solution. The reaction mixture was stirred overnight and quenched with tartaric acid $(50 \mathrm{~mL}$, 1.0 $\mathrm{M}$ in water). After the solution was stirred until clear phases were obtained, the aqueous phase was extracted with $\mathrm{Et}_{2} \mathrm{O}(3 \times 30 \mathrm{~mL})$. The combined organic phases were washed with brine $(30 \mathrm{~mL})$, dried over anhydrous $\mathrm{Na}_{2} \mathrm{SO}_{4}$ and concentrated in vacuo. The residue was purified by silica gel flash chromatography to give $\mathbf{1 4}$ as a colorless oil $(1.14 \mathrm{~g}, 80 \%): \mathrm{R}_{f}=0.6$ (silica gel, $10 \%$ ethyl acetate in hexane); $[\alpha]_{\mathbf{D}}{ }^{20}=-6.2\left(c 1.0, \mathrm{CHCl}_{3}\right) ;{ }^{1} \mathbf{H}$ NMR $\left(500 \mathrm{MHz}, \mathrm{CDCl}_{3}\right) \delta 4.39(\mathrm{t}, J=5.8 \mathrm{~Hz}, 1 \mathrm{H}), 3.94(\mathrm{dd}$, $J=10.0,4.0 \mathrm{~Hz}, 1 \mathrm{H}), 3.57$ (dd, $J=10.0,6.6 \mathrm{~Hz}, 1 \mathrm{H}), 3.46(\mathrm{~d}, J=5.4 \mathrm{~Hz}, 1 \mathrm{H}), 1.93$ (ddd, $J=13.3,6.7$, $4.1 \mathrm{~Hz}, 1 \mathrm{H}), 1.60(\mathrm{~s}, 1 \mathrm{H}), 1.02(\mathrm{~d}, J=7.0 \mathrm{~Hz}, 3 \mathrm{H}), 0.90$ (s, 9H), $0.18(\mathrm{~s}, 9 \mathrm{H}), 0.08(\mathrm{~s}, 3 \mathrm{H}), 0.08$ (s, 
3H). ${ }^{13} \mathbf{C}$ NMR $\left(125 \mathrm{MHz}, \mathrm{CDCl}_{3}\right) \delta 105.82,89.87,67.13,66.76,40.62,25.86,18.21,12.91,-0.08,-$ 5.56, -5.61. HRMS $(\mathrm{m} / \mathrm{z})$ : calculated for $\mathrm{C}_{15} \mathrm{H}_{32} \mathrm{O}_{2} \mathrm{Si}_{2} \mathrm{Na}^{+}[\mathrm{M}+\mathrm{Na}]^{+}: 323.1833$, found 323.1839.

${ }^{\mathbf{b}}$ The known aldehyde $\mathbf{9}$ was prepared according to the following scheme:

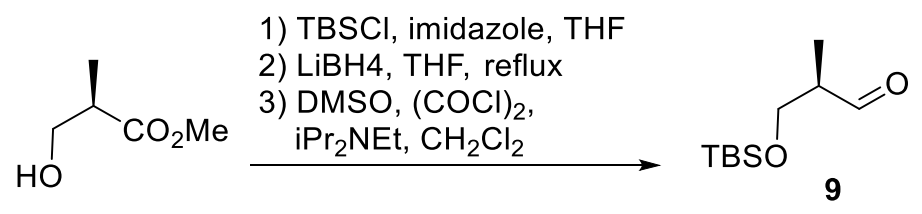

Kirkham, J. E. D.; Lee, V.; Baldwin, J. E. Chem. Commun. 2006, 27, 2863.

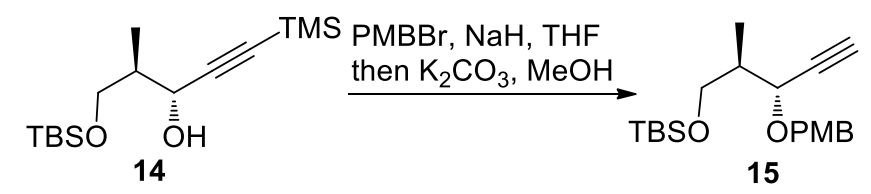

To a solution of $14(100 \mathrm{mg}, 0.33 \mathrm{mmol})$ in THF $(5 \mathrm{~mL})$ was added NaH $(27 \mathrm{mg}, 0.67 \mathrm{mmol}, 60 \%$ dispersion in mineral oil) at $0{ }^{\circ} \mathrm{C}$. The resulting solution was stirred for 30 minutes, before 4 methoxybenzyl bromide $(59.6 \mathrm{uL}, 0.40 \mathrm{mmol})$ was slowly added at $0{ }^{\circ} \mathrm{C}$. The resulting reaction mixture was stirred overnight at room temperature, and then concentrated in vacuo. The residue was dissolved in $\mathrm{MeOH}(5 \mathrm{~mL})$, and $\mathrm{K}_{2} \mathrm{CO}_{3}(138 \mathrm{mg}, 0.99 \mathrm{mmol})$ was added. The reaction mixture was stirred for $1 \mathrm{~h}$ at room temperature and quenched with saturated aqueous solution of $\mathrm{NH}_{4} \mathrm{Cl}(15 \mathrm{~mL})$. Volatiles were removed in vacuo, and the aqueous residue was extracted with ethyl acetate $(3 \times 25$ $\mathrm{mL})$. The combined organic phases were washed with brine $(30 \mathrm{~mL})$, dried over $\mathrm{Na}_{2} \mathrm{SO}_{4}$ and concentrated in vacuo. The residue was purified by silica gel flash chromatography to give compound $15(85 \mathrm{mg}, 73 \%)$ as a colorless oil. $\mathrm{R}_{f}=0.7$ (silica gel, $10 \%$ ethyl acetate in hexane); $[\alpha]_{\mathbf{D}}{ }^{20}=41.4(c$ $\left.0.5, \mathrm{CHCl}_{3}\right) ;{ }^{1} \mathbf{H}$ NMR $\left(500 \mathrm{MHz}, \mathrm{CDCl}_{3}\right) \delta 7.28(\mathrm{~d}, J=8.6 \mathrm{~Hz}, 2 \mathrm{H}), 6.87(\mathrm{~d}, J=8.7 \mathrm{~Hz}, 2 \mathrm{H}), 4.74(\mathrm{~d}$, $J=11.4 \mathrm{~Hz}, 1 \mathrm{H}), 4.43(\mathrm{~d}, J=11.4 \mathrm{~Hz}, 1 \mathrm{H}), 4.19(\mathrm{dd}, J=6.0,2.1 \mathrm{~Hz}, 1 \mathrm{H}), 3.80(\mathrm{~s}, 3 \mathrm{H}), 3.62-3.45$ (m, 2H), $2.45(\mathrm{~d}, J=2.1 \mathrm{~Hz}, 1 \mathrm{H}), 2.02(\mathrm{dt}, J=12.5,6.3 \mathrm{~Hz}, 1 \mathrm{H}), 1.00(\mathrm{~d}, J=6.8 \mathrm{~Hz}, 3 \mathrm{H}), 0.85$ (s, 9H), 0.01 (s, 6H). ${ }^{13} \mathbf{C}$ NMR (125 MHz, $\left.\mathrm{CDCl}_{3}\right) \delta 159.27,130.15,129.57,113.80,81.50,74.73,70.47$, 69.79, 64.38, 55.28, 40.46, 25.89, 18.24, 12.21, -5.42, -5.48. HRMS $(\mathrm{m} / \mathrm{z})$ : calculated for $\mathrm{C}_{20} \mathrm{H}_{32} \mathrm{NaO}_{3} \mathrm{SNa}^{+}[\mathrm{M}+\mathrm{Na}]^{+}: 371.2013$, found 371.2005.

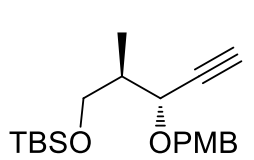

15

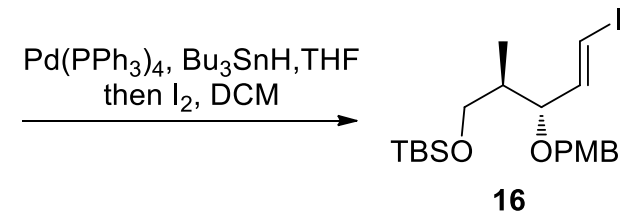

16

To a stirred solution of $15(85 \mathrm{mg}, 0.24 \mathrm{mmol})$ and $\mathrm{Pd}\left(\mathrm{PPh}_{3}\right)_{4}(14 \mathrm{mg}, 0.012 \mathrm{mmol})$ in THF $(5 \mathrm{~mL})$ was added $n-\mathrm{Bu}_{3} \mathrm{SnH}(79 \mathrm{uL}, 0.29 \mathrm{mmol})$. After being stirred for 20 minutes, THF was removed under reduced pressure. The residue was purified by silica gel flash chromatography to provide the 
corresponding vinyl tributyltin as a colorless oil. To a solution of the resulting vinyl tributyltin in DCM $(5 \mathrm{~mL})$ was added $\mathrm{I}_{2}(1 \mathrm{M}$ in DCM) until the color of the solution persisted. The reaction was quenched with saturated aqueous solution of $\mathrm{Na}_{2} \mathrm{SO}_{3}(30 \mathrm{~mL})$. Layers were separated, the aqueous layer was extracted with DCM $(2 \times 25 \mathrm{~mL})$. The combined organic layers were dried over $\mathrm{MgSO}_{4}$, and concentrated in vacuo. The residue was purified by silica gel flash chromatography to afford $\mathbf{1 6}$ (90 $\mathrm{mg}, 77 \%$ ) as a colorless oil. $\mathrm{R}_{f}=0.80$ (silica gel, 5\% ethyl acetate in hexane); $[\alpha]_{\mathrm{D}}{ }^{20}=9.7$ (c 1.0, $\left.\mathrm{CHCl}_{3}\right) ;{ }^{1} \mathbf{H}$ NMR $\left(400 \mathrm{MHz}, \mathrm{CDCl}_{3}\right) \delta 7.24(\mathrm{~d}, \mathrm{~J}=8.6 \mathrm{~Hz}, 2 \mathrm{H}), 6.88(\mathrm{~d}, \mathrm{~J}=8.6 \mathrm{~Hz}, 2 \mathrm{H}), 6.49(\mathrm{dd}, \mathrm{J}=$ 14.5, 8.2 Hz, 1H), $6.27(\mathrm{~d}, \mathrm{~J}=14.5 \mathrm{~Hz}, 1 \mathrm{H}), 4.51(\mathrm{~d}, \mathrm{~J}=11.3 \mathrm{~Hz}, 1 \mathrm{H}), 4.28(\mathrm{~d}, \mathrm{~J}=11.4 \mathrm{~Hz}, 1 \mathrm{H}), 3.82$ - $3.77(\mathrm{~m}, 4 \mathrm{H}), 3.64-3.50(\mathrm{~m}, 2 \mathrm{H}), 1.87(\mathrm{dt}, \mathrm{J}=12.3,5.6 \mathrm{~Hz}, 1 \mathrm{H}), 0.90-0.87(\mathrm{~m}, 12 \mathrm{H}), 0.03(\mathrm{~s}$, $6 \mathrm{H}) .{ }^{13} \mathrm{C}$ NMR $\left(100 \mathrm{MHz}, \mathrm{CDCl}_{3}\right) \delta 159.12,145.35,130.41,129.26,113.77,82.26,78.41,70.40$, 64.24, 55.27, 39.86, 25.91, 18.25, 12.63, -5.41, -5.45. HRMS $(\mathrm{m} / \mathrm{z})$ : calculated for $\mathrm{C}_{20} \mathrm{H}_{33} \mathrm{IO}_{3} \mathrm{SiNa}^{+}[\mathrm{M}$ $+\mathrm{Na}]^{+}: 499.1136$, found 499.1137 .

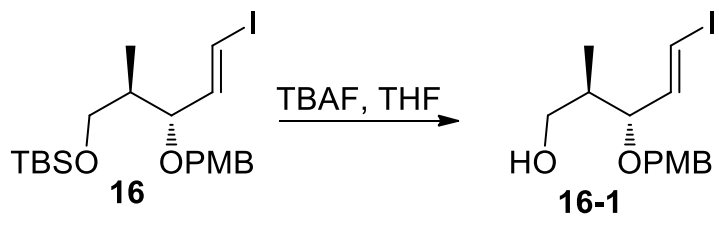

To a solution of $16(335 \mathrm{mg}, 0.70 \mathrm{mmol})$ in THF $(10 \mathrm{~mL})$ was added TBAF $(1.5 \mathrm{~mL}, 1.50 \mathrm{mmol}, 1.0$ $\mathrm{M}$ in THF) at $0{ }^{\circ} \mathrm{C}$. The reaction mixture was stirred at room temperature for $3 \mathrm{~h}$ before it was quenched by addition of saturated aqueous solution of $\mathrm{NH}_{4} \mathrm{Cl}(20 \mathrm{~mL})$, and then extracted with ethyl acetate $(3 \times 30 \mathrm{~mL})$. The combined organic layers were washed with water $(30 \mathrm{~mL})$ and brine $(30 \mathrm{~mL})$, dried over $\mathrm{Na}_{2} \mathrm{SO}_{4}$ and concentrated in vacuo. The residue was purified by silica gel flash chromatography to produce 16-1 (250 mg, 98\%) as a colorless oil. $\mathrm{R}_{f}=0.20$ (silica gel, 33\% ethyl acetate in hexane); $[\alpha]_{\mathbf{D}}{ }^{20}=45.0\left(c 1.0, \mathrm{CHCl}_{3}\right) ;{ }^{1} \mathbf{H} \mathbf{~ N M R}\left(400 \mathrm{MHz}, \mathrm{CDCl}_{3}\right) \delta 7.23(\mathrm{~d}, J=8.6 \mathrm{~Hz}$, 2H), $6.89(\mathrm{~d}, J=8.7 \mathrm{~Hz}, 2 \mathrm{H}), 6.48(\mathrm{dd}, J=14.6,8.3 \mathrm{~Hz}, 1 \mathrm{H}), 6.34(\mathrm{~d}, J=14.6 \mathrm{~Hz}, 1 \mathrm{H}), 4.56(\mathrm{~d}, J=$ $11.4 \mathrm{~Hz}, 1 \mathrm{H}), 4.27(\mathrm{~d}, J=11.4 \mathrm{~Hz}, 1 \mathrm{H}), 3.81(\mathrm{~s}, 3 \mathrm{H}), 3.72-3.57(\mathrm{~m}, 2 \mathrm{H}), 3.58-3.47(\mathrm{~m}, 1 \mathrm{H}), 1.87$ $(\mathrm{ddd}, J=14.9,7.1,3.7 \mathrm{~Hz}, 1 \mathrm{H}), 0.83(\mathrm{~d}, J=7.0 \mathrm{~Hz}, 3 \mathrm{H}) .{ }^{13} \mathbf{C}$ NMR $\left(100 \mathrm{MHz}, \mathrm{CDCl}_{3}\right) \delta 159.36$, $145.33,129.52,129.48,113.97,86.02,79.54,70.39,66.54,55.25,39.44,13.46$. HRMS $(\mathrm{m} / \mathrm{z})$ : calculated for $\mathrm{C}_{14} \mathrm{H}_{19} \mathrm{IO}_{3} \mathrm{Na}^{+}[\mathrm{M}+\mathrm{Na}]^{+}: 385.0271$, found 385.0276 .

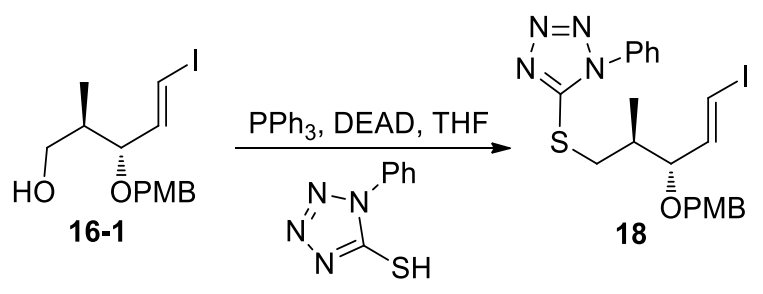


To a solution of alcohol 16-1 $(250 \mathrm{mg}, 0.69 \mathrm{mmol})$ in THF $(20 \mathrm{~mL})$ was sequentially added 1-phenyl1H-tetrazole-5-thiol (200 mg, $1.12 \mathrm{mmol}$ ), $\mathrm{Ph}_{3} \mathrm{P}$ (300 mg, $1.12 \mathrm{mmol}$ ), and DEAD (170 uL, 1.12 $\mathrm{mmol}$ ) at $0{ }^{\circ} \mathrm{C}$. After being stirred at room temperature for $2 \mathrm{~h}$, the reaction mixture was quenched by addition of saturated aqueous solution of $\mathrm{NaHCO}_{3}(20 \mathrm{~mL})$ and extracted with ethyl acetate $(3 \mathrm{x}$ $30 \mathrm{~mL})$. The combined organic layers were washed with water $(30 \mathrm{~mL})$ and brine $(30 \mathrm{~mL})$, dried over $\mathrm{Na}_{2} \mathrm{SO}_{4}$ and concentrated in vacuo. The residue was purified by silica gel flash chromatography to produce 18 (328 $\mathrm{mg}, 91 \%)$ as a colorless oil. $\mathrm{R}_{f}=0.40$ (silica gel, $33 \%$ ethyl acetate in hexane); $[\alpha]_{\mathbf{D}}{ }^{\mathbf{2 0}}$ $=10.0\left(c\right.$ 1.0, $\left.\mathrm{CHCl}_{3}\right) ;{ }^{1} \mathbf{H}$ NMR $\left(400 \mathrm{MHz}, \mathrm{CDCl}_{3}\right) \delta 7.58-7.50(\mathrm{~m}, 5 \mathrm{H}), 7.22(\mathrm{~d}, J=8.6 \mathrm{~Hz}, 2 \mathrm{H})$, $6.85(\mathrm{~d}, J=8.6 \mathrm{~Hz}, 2 \mathrm{H}), 6.49(\mathrm{dd}, J=14.6,7.9 \mathrm{~Hz}, 1 \mathrm{H}), 6.39$ (d, $J=14.6 \mathrm{~Hz}, 1 \mathrm{H}), 4.55$ (d, $J=11.4$ $\mathrm{Hz}, 1 \mathrm{H}), 4.27$ (d, $J=11.4 \mathrm{~Hz}, 1 \mathrm{H}), 3.80(\mathrm{~s}, 3 \mathrm{H}), 3.71-3.56(\mathrm{~m}, 2 \mathrm{H}), 3.47-3.36(\mathrm{~m}, 1 \mathrm{H}), 2.22-2.17$ $(\mathrm{m}, 1 \mathrm{H}), 1.03(\mathrm{~d}, J=6.9 \mathrm{~Hz}, 3 \mathrm{H}) .{ }^{13} \mathbf{C} \mathbf{~ N M R}\left(100 \mathrm{MHz}, \mathrm{CDCl}_{3}\right) \delta 159.24,154.59,144.47,133.68$, $130.03,129.74,129.63,129.54,123.81,113.79,113.69,83.63,79.91,70.34,55.22,37.27,36.47$, 15.41. HRMS $(m / z)$ : calculated for $\mathrm{C}_{21} \mathrm{H}_{23} \mathrm{IN}_{4} \mathrm{O}_{2} \mathrm{SNa}^{+}[\mathrm{M}+\mathrm{Na}]^{+}: 545.0479$, found 545.0477.

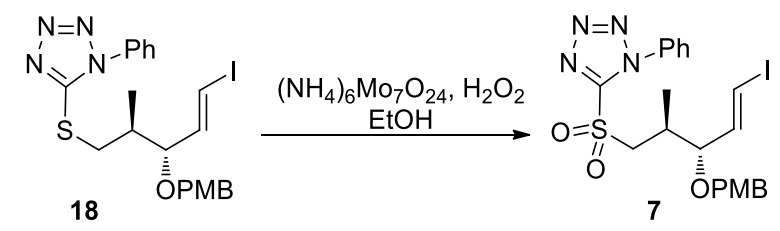

To a solution of $18(51 \mathrm{mg}, 0.10 \mathrm{mmol})$ in $\mathrm{EtOH}(10 \mathrm{~mL})$ was added a portion $(7 \mathrm{~mL})$ of a stock solution of $\left(\mathrm{NH}_{4}\right)_{6} \mathrm{Mo}_{7} \mathrm{O}_{24} \cdot 4 \mathrm{H}_{2} \mathrm{O}(50 \mathrm{mg}, 0.04 \mathrm{mmol})$ and $30 \% \mathrm{H}_{2} \mathrm{O}_{2}(2 \mathrm{~mL})$. After being stirred at room temperature for $24 \mathrm{~h}$, the reaction mixture was concentrated in vacuo and extracted with ethyl acetate $(3 \times 30 \mathrm{~mL})$. The combined organic layers were washed with water $(30 \mathrm{~mL})$ and brine $(30 \mathrm{~mL})$, dried over $\mathrm{Na}_{2} \mathrm{SO}_{4}$ and concentrated in vacuo. The residue was purified by silica gel flash chromatography to produce $7(45.3 \mathrm{mg}, 84 \%)$ as a colorless oil. $\mathrm{R}_{f}=0.39$ (silica gel, $33 \%$ ethyl acetate in hexane); $[\alpha]_{\mathbf{D}}{ }^{20}=20.4\left(c 1.0, \mathrm{CHCl}_{3}\right) ;{ }^{1} \mathbf{H} \mathbf{~ N M R}\left(500 \mathrm{MHz}, \mathrm{CDCl}_{3}\right) \delta 7.67-7.51(\mathrm{~m}, 5 \mathrm{H}), 7.21(\mathrm{~d}, J$ $=8.6 \mathrm{~Hz}, 2 \mathrm{H}), 6.89(\mathrm{~d}, J=8.6 \mathrm{~Hz}, 2 \mathrm{H}), 6.50-6.36(\mathrm{~m}, 2 \mathrm{H}), 4.54(\mathrm{~d}, J=11.4 \mathrm{~Hz}, 1 \mathrm{H}), 4.26(\mathrm{~d}, J=$ $11.4 \mathrm{~Hz}, 1 \mathrm{H}), 4.07(\mathrm{dd}, J=14.6,3.6 \mathrm{~Hz}, 1 \mathrm{H}), 3.82(\mathrm{~s}, 3 \mathrm{H}), 3.73-3.63(\mathrm{~m}, 1 \mathrm{H}), 3.53(\mathrm{dd}, J=14.6,8.8$ $\mathrm{Hz}, 1 \mathrm{H}), 1.16(\mathrm{~d}, J=6.9 \mathrm{~Hz}, 3 \mathrm{H}) .{ }^{13} \mathbf{C} \mathbf{~ N M R}\left(125 \mathrm{MHz}, \mathrm{CDCl}_{3}\right) \delta 159.39,153.97,143.50,133.00$, $131.44,129.62,129.52,129.27,125.22,113.93,83.12,80.93,70.52,58.15,55.27,32.73,16.14$. HRMS $(m / z)$ : calculated for $\mathrm{C}_{21} \mathrm{H}_{23} \mathrm{IN}_{4} \mathrm{O}_{4} \mathrm{SNa}^{+}[\mathrm{M}+\mathrm{Na}]^{+}: 577.0377$, found 577.0378. 


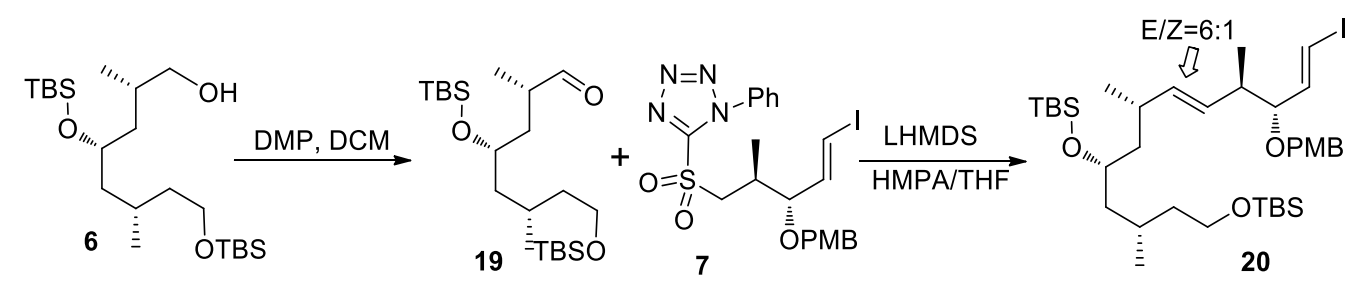

To a solution of $6(150 \mathrm{mg}, 0.36 \mathrm{mmol})$ in DCM $(5 \mathrm{~mL}), \mathrm{NaHCO}_{3}(50 \mathrm{mg}, 0.60 \mathrm{mmol})$ were added at $0{ }^{\circ} \mathrm{C}$ followed by addition of Dess-Martin periodinane $(250 \mathrm{mg}, 0.59 \mathrm{mmol})$. After being stirred at room temperature for $1 \mathrm{~h}$, the reaction mixture was concentrated in vacuo. The residue was purified by silica gel flash chromatography to produce 19 (140 mg, 94\%) as a colorless oil, which was used directly in the next step without further purification.

To a cooled solution of sulfone 7 (300 $\mathrm{mg}, 0.54 \mathrm{mmol})$ in THF ( $3 \mathrm{~mL}$,) was added LHMDS (0.56 ml, $1 \mathrm{M})$ at $-78{ }^{\circ} \mathrm{C}$. After being stirred at $-78{ }^{\circ} \mathrm{C}$ for 30 minutes, aldehyde 19 (140 mg, $\left.0.34 \mathrm{mmol}\right)$ was added over 30 minutes, and the reaction was allowed to warmed to room temperature and stirred overnight. The reaction mixture was quenched with saturated aqueous solution of $\mathrm{NH}_{4} \mathrm{Cl}(15 \mathrm{~mL})$ and extracted with ethyl acetate $(3 \times 25 \mathrm{~mL})$. The combined organic phases were washed with brine (30 $\mathrm{mL}$ ), dried over $\mathrm{Na}_{2} \mathrm{SO}_{4}$ and concentrated in vacuo. The residue was purified by silica gel flash chromatography to give compound $\mathbf{2 0}(190 \mathrm{mg}, 76 \%, \mathrm{E} / \mathrm{Z}=6: 1)$ as a colorless oil. $\mathrm{R}_{f}=0.70$ (silica gel, $5 \%$ ethyl acetate in hexane); $[\alpha]_{\mathbf{D}}{ }^{20}=27.6\left(c 1.0, \mathrm{CHCl}_{3}\right) ;{ }^{1} \mathbf{H} \mathbf{~ N M R}\left(500 \mathrm{MHz}, \mathrm{CDCl}_{3}\right) \delta 7.24(\mathrm{~d}, J=$ $8.5 \mathrm{~Hz}, 2 \mathrm{H}), 6.88(\mathrm{~d}, \mathrm{~J}=8.6 \mathrm{~Hz}, 2 \mathrm{H}), 6.47(\mathrm{dd}, J=14.5,7.9 \mathrm{~Hz}, 1 \mathrm{H}), 6.24(\mathrm{~d}, J=14.5 \mathrm{~Hz}, 1 \mathrm{H}), 5.42-$ $5.25(\mathrm{~m}, 2 \mathrm{H}), 4.52(\mathrm{~d}, J=11.6 \mathrm{~Hz}, 1 \mathrm{H}), 4.29(\mathrm{~d}, J=11.6 \mathrm{~Hz}, 1 \mathrm{H}), 3.82(\mathrm{~s}, 3 \mathrm{H}), 3.74-3.69(\mathrm{~m}, 1 \mathrm{H})$, $3.67-3.62(\mathrm{~m}, 2 \mathrm{H}), 3.59-3.53(\mathrm{~m}, 1 \mathrm{H}), 2.41-2.25(\mathrm{~m}, 2 \mathrm{H}), 1.67-1.61(\mathrm{~m}, 1 \mathrm{H}), 1.59-1.54(\mathrm{~m}$, 1H), $1.46-1.39(\mathrm{~m}, 2 \mathrm{H}), 1.37-1.31(\mathrm{~m}, 2 \mathrm{H}), 1.30-1.27(\mathrm{~m}, 1 \mathrm{H}), 0.98(\mathrm{~m}, 6 \mathrm{H}), 0.92-0.89(\mathrm{~m}$, 21H), $0.06(\mathrm{~s}, 12 \mathrm{H}) .{ }^{13} \mathbf{C} \mathbf{~ N M R}\left(125 \mathrm{MHz}, \mathrm{CDCl}_{3}\right) \delta 159.15,145.28,137.01,130.43,129.80,129.17$, $113.77,85.01,78.22,70.20,69.05,61.24,55.28,45.75,44.83,40.77,40.56,32.99,26.35,26.02$, $21.88,20.23,18.35,18.10,15.94,-3.84,-4.04,-5.24,-5.25$. HRMS $(\mathrm{m} / \mathrm{z})$ : calculated for $\mathrm{C}_{36} \mathrm{H}_{65} \mathrm{IO}_{4} \mathrm{Si}_{2} \mathrm{Na}^{+}[\mathrm{M}+\mathrm{Na}]^{+}:$767.3358, found 767.3353.

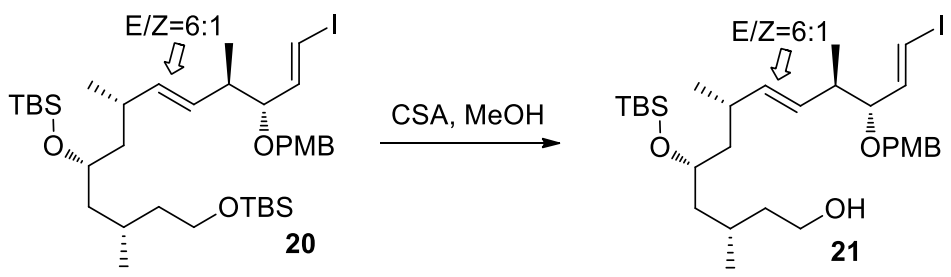

To a solution of 20 (100 mg, $0.13 \mathrm{mmol})$ in $\mathrm{MeOH}(5 \mathrm{~mL})$, was added camphorsulfonic acid $(10 \mathrm{mg}$, $0.04 \mathrm{mmol}$ ) at $0{ }^{\circ} \mathrm{C}$. The reaction mixture was stirred at $0{ }^{\circ} \mathrm{C}$ for $1 \mathrm{~h}$ at which point 20 had been consumed as judged by TLC analysis. The reaction was quenched by addition of $\mathrm{Et}_{3} \mathrm{~N}$ ( $5 \mathrm{uL}, 0.04$ mmol) and then concentrated in vacuo. The residue was purified by silica gel flash chromatography to 
give compound 21 ( $83 \mathrm{mg}, 98 \%, \mathrm{E} / \mathrm{Z}=6: 1)$ as a colorless oil. $\mathrm{R}_{f}=0.40$ (silica gel, 10\% ethyl acetate in hexane); $[\alpha]_{\mathbf{D}}{ }^{20}=32.3\left(c 1.0, \mathrm{CHCl}_{3}\right) ;{ }^{1} \mathbf{H}$ NMR $\left(500 \mathrm{MHz}, \mathrm{CDCl}_{3}\right) \delta 7.24(\mathrm{~d}, J=8.4 \mathrm{~Hz}, 2 \mathrm{H}), 6.88(\mathrm{~d}$, $J=8.4 \mathrm{~Hz}, 2 \mathrm{H}), 6.52-6.39(\mathrm{~m}, 1 \mathrm{H}), 6.24(\mathrm{~d}, J=14.5 \mathrm{~Hz}, 1 \mathrm{H}), 5.40-5.24(\mathrm{~m}, 2 \mathrm{H}), 4.52(\mathrm{~d}, J=11.6$ $\mathrm{Hz}, 1 \mathrm{H}), 4.29$ (d, $J=11.6 \mathrm{~Hz}, 1 \mathrm{H}), 3.81(\mathrm{~s}, 3 \mathrm{H}), 3.76-3.72(\mathrm{~m}, 1 \mathrm{H}), 3.71-3.65(\mathrm{~m}, 2 \mathrm{H}), 3.59-3.47$ (m, 1H), $2.39-2.22(\mathrm{~m}, 2 \mathrm{H}), 1.71-1.60(\mathrm{~m}, 3 \mathrm{H}), 1.43-1.33(\mathrm{~m}, 4 \mathrm{H}), 0.98(\mathrm{~m}, 6 \mathrm{H}), 0.89(\mathrm{~m}, 12 \mathrm{H})$, 0.06 (s, 6H). ${ }^{13} \mathrm{C}$ NMR $\left(125 \mathrm{MHz}, \mathrm{CDCl}_{3}\right) \delta 159.09,145.25,136.90,130.34,129.82,129.18,113.72$, 84.90, 78.32, 70.13, 68.95, 60.92, 55.25, 45.55, 44.68, 40.75, 40.35, 33.02, 25.98, 21.84, 20.17, 18.07, 16.03, -3.89, -4.06. HRMS $(\mathrm{m} / \mathrm{z})$ : calculated for $\mathrm{C}_{30} \mathrm{H}_{51} \mathrm{IO}_{4} \mathrm{SiNa}^{+}\left[\mathrm{M}+\mathrm{Na}^{+}: 653.2494\right.$, found 653.2490 .
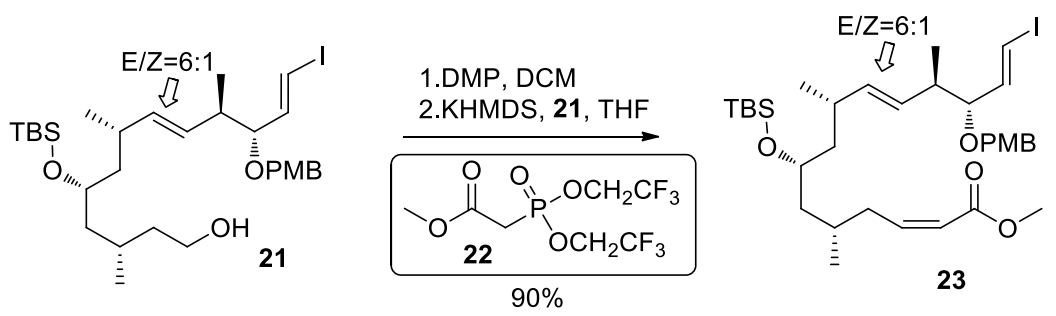

$\mathrm{NaHCO}_{3}(69 \mathrm{mg}, 0.82 \mathrm{mmol})$ was added to a solution of $21(150 \mathrm{mg}, 0.24 \mathrm{mmol})$ in DCM (5 mL) at $0{ }^{\circ} \mathrm{C}$ followed by addition of Dess-Martin periodinane $(150 \mathrm{mg}, 0.35 \mathrm{mmol})$. The reaction was stirred for $1 \mathrm{~h}$ at room temperature. The reaction mixture was concentrated in vacuo. Followed by filtered through a pad of silica gel, the residue was concentrated in vacuo to afford aldehyde (140 mg, 94\%) as a colorless oil, which was used directly in the next step without further purification.

To a solution of 18-crown-6 (100 mg, $0.36 \mathrm{mmol})$ and $\left(\mathrm{CF}_{3} \mathrm{CH}_{2}\right) \mathrm{P}(\mathrm{O}) \mathrm{CH}_{2} \mathrm{CO}_{2} \mathrm{Me}(114 \mathrm{mg}, 0.36 \mathrm{mmol})$ in $\operatorname{THF}(7 \mathrm{~mL}$ ) was added potassium bis(trimethylsilyl)amide (KHMDS) (714 uL, 0.36 mmol, $0.5 \mathrm{M}$ in toluene) at $-78{ }^{\circ} \mathrm{C}$. After being stirred for 15 minutes, aldehyde (140 mg, $\left.0.22 \mathrm{mmol}\right)$ in THF $(2 \mathrm{~mL})$ was added dropwise. The reaction was stirred overnight at $-78{ }^{\circ} \mathrm{C}$ and quenched with saturated aqueous solution of $\mathrm{NH}_{4} \mathrm{Cl}(15 \mathrm{~mL})$ and extracted with ethyl acetate $(3 \times 25 \mathrm{~mL})$. The combined organic phases were washed with brine $(30 \mathrm{~mL})$, dried over $\mathrm{Na}_{2} \mathrm{SO}_{4}$ and concentrated in vacuo. The residue was purified by silica gel flash chromatography to provide compound 23 (147 mg, 96\%, $\mathrm{E} / \mathrm{Z}=6: 1$ ) as a colorless oil. $\mathrm{R}_{f}=0.65$ (silica gel, $10 \%$ ethyl acetate in hexane); $[\alpha]_{\mathbf{D}}{ }^{20}=26.3$ (c 1.0, $\left.\mathrm{CHCl}_{3}\right) ;{ }^{1} \mathbf{H}$ NMR $\left(500 \mathrm{MHz}, \mathrm{CDCl}_{3}\right) \delta 7.23(\mathrm{~d}, J=8.5 \mathrm{~Hz}, 2 \mathrm{H}), 6.88(\mathrm{~d}, J=8.5 \mathrm{~Hz}, 2 \mathrm{H}), 6.46(\mathrm{dd}, J=$ $14.5,7.9 \mathrm{~Hz}, 1 \mathrm{H}), 6.26-6.18(\mathrm{~m}, 2 \mathrm{H}), 5.84(\mathrm{~d}, J=11.6 \mathrm{~Hz}, 1 \mathrm{H}), 5.41-5.22(\mathrm{~m}, 2 \mathrm{H}), 4.52(\mathrm{~d}, J=$ $11.6 \mathrm{~Hz}, 1 \mathrm{H}), 4.29$ (d, $J=11.6 \mathrm{~Hz}, 1 \mathrm{H}), 3.81$ (s, 3H), $3.76-3.69$ (m, 4H), $3.60-3.52$ (m, 1H), $2.65-$ $2.57(\mathrm{~m}, 2 \mathrm{H}), 2.38-2.31(\mathrm{~m}, 1 \mathrm{H}), 2.31-2.22(\mathrm{~m}, 1 \mathrm{H}), 1.74-1.65(\mathrm{~m}, 1 \mathrm{H}), 1.50-1.29(\mathrm{~m}, 4 \mathrm{H}), 1.02$ $-0.94(\mathrm{~m}, 6 \mathrm{H}), 0.91-0.87(\mathrm{~m}, 12 \mathrm{H}), 0.06(\mathrm{~s}, 3 \mathrm{H}), 0.05(\mathrm{~s}, 3 \mathrm{H}) .{ }^{13} \mathbf{C} \mathbf{N M R}\left(125 \mathrm{MHz}, \mathrm{CDCl}_{3}\right) \delta$ $166.85,159.16,149.32,145.32$, 136.96, 130.43, 129.82, 129.18, 120.21, 113.77, 84.99, 78.24, 70.21, 


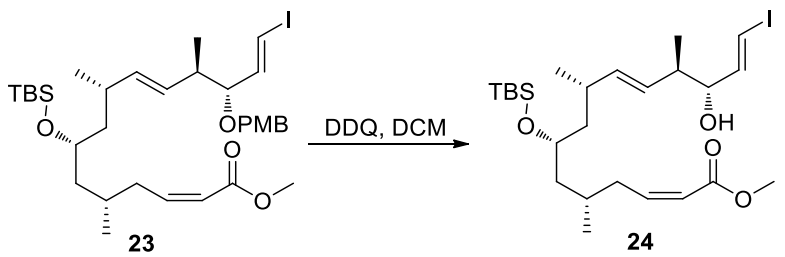

To a solution of $23(110 \mathrm{mg}, 0.17 \mathrm{mmol})$ in DCM $(7 \mathrm{~mL})$ was added phosphate buffer $(\mathrm{pH} 7.2,100$ $\mathrm{mM}, 1 \mathrm{~mL})$ and DDQ (120 mg, $0.53 \mathrm{mmol})$ at room temperature. The reaction mixture was stirred for $3 \mathrm{~h}$ at room temperature and then extracted with DCM $(3 \times 25 \mathrm{~mL})$. The combined organic phases were washed sequentially with saturated aqueous solution of $\mathrm{Na}_{2} \mathrm{~S}_{2} \mathrm{O}_{3}(20 \mathrm{~mL}), \mathrm{NaHCO}_{3}(20 \mathrm{~mL})$, brine $(20 \mathrm{~mL})$ and dried over anhydrous $\mathrm{Na}_{2} \mathrm{SO}_{4}$ and concentrated in vacuo. The residue was purified by silica gel flash chromatography to produce $24(74 \mathrm{mg}, 82 \%)$ as a colorless oil. $\mathrm{R}_{f}=0.40$ (silica gel, $5 \%$ ethyl acetate in hexane); $[\alpha]_{\mathbf{D}}{ }^{20}=13.0\left(c 1.0, \mathrm{CHCl}_{3}\right) ;{ }^{1} \mathbf{H} \mathbf{N M R}\left(500 \mathrm{MHz}, \mathrm{CDCl}_{3}\right) \delta 6.56(\mathrm{dd}, J=$ 14.4, 6.6 Hz, 1H), 6.36 (d, $J=14.5 \mathrm{~Hz}, 1 \mathrm{H}), 6.28-6.19(\mathrm{~m}, 1 \mathrm{H}), 5.84(\mathrm{~d}, J=11.6 \mathrm{~Hz}, 1 \mathrm{H}), 5.46-$ $5.21(\mathrm{~m}, 2 \mathrm{H}), 3.83-3.73(\mathrm{~m}, 2 \mathrm{H}), 3.71(\mathrm{~s}, 3 \mathrm{H}), 2.61(\mathrm{t}, J=6.5 \mathrm{~Hz}, 2 \mathrm{H}), 2.37-2.30(\mathrm{~m}, 1 \mathrm{H}), 2.25-$ $2.14(\mathrm{~m}, 1 \mathrm{H}), 1.71-1.58(\mathrm{~m}, 2 \mathrm{H}), 1.46-1.34(\mathrm{~m}, 4 \mathrm{H}), 1.01-0.96(\mathrm{~m}, 6 \mathrm{H}), 0.91-0.87(\mathrm{~m}, 12 \mathrm{H})$, $0.06(\mathrm{~s}, 3 \mathrm{H}), 0.05(\mathrm{~s}, 3 \mathrm{H}) .{ }^{13} \mathbf{C}$ NMR $\left(125 \mathrm{MHz}, \mathrm{CDCl}_{3}\right) \delta 166.88,149.31,146.70,139.54,129.34$, $120.24,77.93$, 69.02, 50.99, 44.99, 44.82, 43.19, 36.12, 33.28, 29.86, 29.71, 26.00, 21.85, 20.05, 18.14, 16.33, -3.92, -4.02. HRMS $(m / z)$ : calculated for $\mathrm{C}_{25} \mathrm{H}_{45} \mathrm{IO}_{4} \mathrm{Na}^{+}[\mathrm{M}+\mathrm{Na}]^{+}: 587.2024$, found 587.2023.

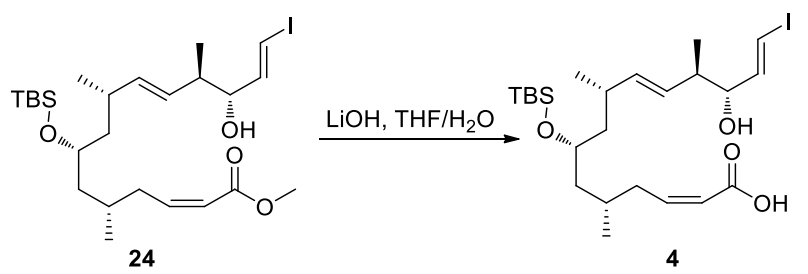

To a solution of 24 (74 mg, $0.13 \mathrm{mmol})$ in THF $(5 \mathrm{~mL}), \mathrm{MeOH}(1 \mathrm{~mL})$ and $\mathrm{H}_{2} \mathrm{O}(3 \mathrm{~mL})$ was added $\mathrm{LiOH}(20 \mathrm{mg}, 0.49 \mathrm{mmol})$ at $0{ }^{\circ} \mathrm{C}$. The reaction mixture was allowed to warm to room temperature, stirred at for $5 \mathrm{~h}$, and extracted with DCM (3 x $25 \mathrm{~mL})$. The combined organic phase were dried over anhydrous $\mathrm{Na}_{2} \mathrm{SO}_{4}$ and concentrated in vacuo. The residue was purified by silica gel flash chromatography to produce $4(62 \mathrm{mg}, 86 \%)$ as a colorless oil. $\mathrm{R}_{f}=0.50$ (silica gel, $25 \%$ ethyl acetate in hexane); $[\alpha]_{\mathbf{D}}{ }^{20}=20.6\left(c 0.35, \mathrm{CHCl}_{3}\right) ;{ }^{1} \mathbf{H} \mathbf{~ N M R}\left(400 \mathrm{MHz}, \mathrm{CDCl}_{3}\right) \delta 6.55(\mathrm{dd}, J=14.4,6.6 \mathrm{~Hz}$, $1 \mathrm{H}), 6.40-6.26(\mathrm{~m}, 2 \mathrm{H}), 5.86(\mathrm{~d}, J=11.6 \mathrm{~Hz}, 1 \mathrm{H}), 5.50-5.17(\mathrm{~m}, 2 \mathrm{H}), 3.86-3.71(\mathrm{~m}, 2 \mathrm{H}), 2.70-$ $2.53(\mathrm{~m}, 2 \mathrm{H}), 2.38-2.25(\mathrm{~m}, 1 \mathrm{H}), 2.25-2.13(\mathrm{~m}, 1 \mathrm{H}), 1.78-1.65(\mathrm{~m}, 1 \mathrm{H}), 1.49-1.32(\mathrm{~m}, 4 \mathrm{H}), 1.02$ $-0.94(\mathrm{~m}, 6 \mathrm{H}), 0.94-0.87(\mathrm{~m}, 12 \mathrm{H}), 0.06(\mathrm{~s}, 3 \mathrm{H}), 0.05(\mathrm{~s}, 3 \mathrm{H}) .13 \mathrm{C} \mathrm{NMR}\left(100 \mathrm{MHz}, \mathrm{CDCl}_{3}\right) \delta$ 
$170.13,151.53,146.49,139.67,129.29,119.85,78.00,69.01,44.93,44.80,43.19,36.12,33.30,29.93$, 29.71, 25.99, 21.93, 20.12, 18.14, 16.46, -3.92, -4.05. HRMS $(\mathrm{m} / \mathrm{z})$ : calculated for $\mathrm{C}_{24} \mathrm{H}_{43} \mathrm{IO}_{4} \mathrm{Na}^{+}[\mathrm{M}+$ $\mathrm{Na}]^{+}: 573.1868$, found 573.1868 .

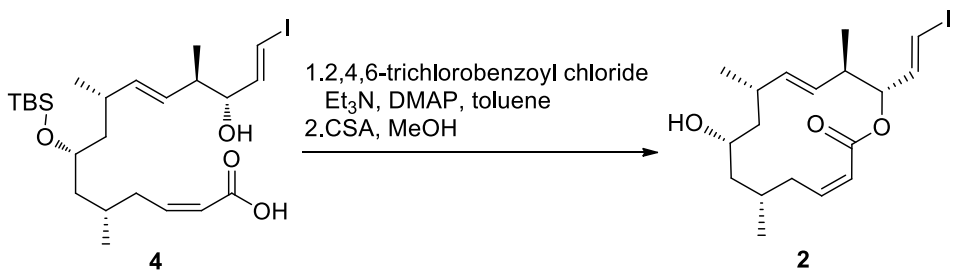

To a solution of $4(15 \mathrm{mg}, 0.03 \mathrm{mmol})$ and triethylamine $(18 \mu \mathrm{L}, 0.12 \mathrm{mmol})$ in dry toluene $(20 \mathrm{~mL})$ was added 2,4,6-trichlorobenzoyl chloride $(95 \mu \mathrm{L}, 0.09 \mathrm{mmol})$ at $0{ }^{\circ} \mathrm{C}$. After being allowed to warm to room temperature and stirred for $1 \mathrm{~h}$, DMAP $(18 \mathrm{mg}, 0.15 \mathrm{mmol})$ in toluene $(5 \mathrm{~mL})$ was added to the reaction mixture. The mixture was stirred overnight at room temperature and quenched with saturated aqueous solution of $\mathrm{NH}_{4} \mathrm{Cl}(15 \mathrm{~mL})$ and extracted with ethyl acetate $(3 \times 25 \mathrm{~mL})$. The combined organic phases were washed with brine $(30 \mathrm{~mL})$, dried over $\mathrm{Na}_{2} \mathrm{SO}_{4}$ and concentrated in vacuo. The residue was used directly in the next step without further purification.

To a solution of the residue in $\mathrm{MeOH}(5 \mathrm{~mL})$ was added camphorsulfonic acid ( $2 \mathrm{mg}, 0.01 \mathrm{mmol})$. The reaction mixture was stirred for $1 \mathrm{~h}$ at which point $\mathbf{2 0}$ had been consumed as judged by TLC analysis, and then quenched by addition of $\mathrm{Et}_{3} \mathrm{~N}(1.2 \mathrm{uL}, 0.01 \mathrm{mmol})$. The solution was concentrated in vacuo. The residue was purified by silica gel flash chromatography to give compound 2 (7.6 $\mathrm{mg}$, $67 \%$, two steps) as a colorless oil. $\mathbf{R}_{f}=0.40$ (silica gel, $10 \%$ ethyl acetate in hexane); $[\alpha]_{\mathbf{D}}{ }^{20}=90.0(c$ $\left.0.2, \mathrm{CHCl}_{3}\right) ;{ }^{1} \mathbf{H}$ NMR $\left(400 \mathrm{MHz}, \mathrm{CDCl}_{3}\right) \delta 6.56-6.43(\mathrm{~m}, 2 \mathrm{H}), 6.34-6.23(\mathrm{~m}, 1 \mathrm{H}), 5.87(\mathrm{dd}, J=$ 11.6, $2.5 \mathrm{~Hz}, 1 \mathrm{H}), 5.18-5.10(\mathrm{~m}, 2 \mathrm{H}), 5.03(\mathrm{dd}, J=15.0,9.2 \mathrm{~Hz}, 1 \mathrm{H}), 3.81-3.70(\mathrm{~m}, 1 \mathrm{H}), 3.37(\mathrm{t}, J$ $=10.7 \mathrm{~Hz}, 1 \mathrm{H}), 2.37-2.26(\mathrm{~m}, 1 \mathrm{H}), 2.25-2.09(\mathrm{~m}, 2 \mathrm{H}), 1.96(\mathrm{dd}, J=14.8,2.8 \mathrm{~Hz}, 1 \mathrm{H}), 1.68-1.56$ $(\mathrm{m}, 2 \mathrm{H}), 1.39-1.26(\mathrm{~m}, 3 \mathrm{H}), 1.05(\mathrm{~d}, J=7.1 \mathrm{~Hz}, 3 \mathrm{H}), 0.98-0.93(\mathrm{~m}, 6 \mathrm{H}) .{ }^{13} \mathbf{C} \mathbf{~ N M R}(100 \mathrm{MHz}$, $\left.\mathrm{CDCl}_{3}\right) \delta 165.06,146.49,143.12,137.74,131.55,121.63,81.03,65.94,45.99,42.97,42.67,34.48$, 31.22, 29.70, 27.08, 22.34, 20.03, 17.52. HRMS $(\mathrm{m} / \mathrm{z})$ : calculated for $\mathrm{C}_{18} \mathrm{H}_{27} \mathrm{IO}_{3} \mathrm{Na}^{+}\left[\mathrm{M}+\mathrm{Na}^{+}\right.$: 441.0897, found 441.0893 .

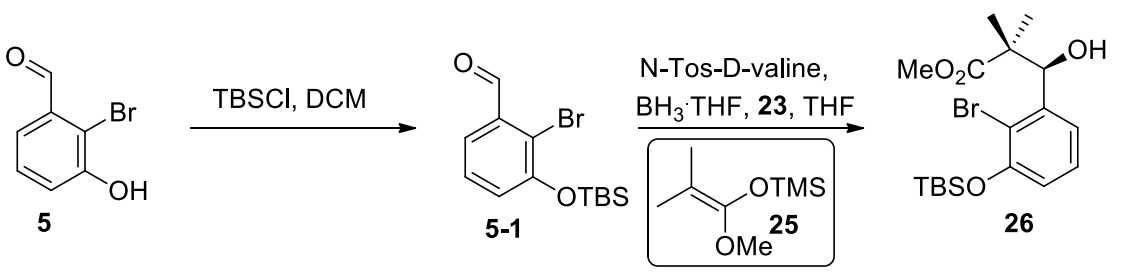

To a solution of compound 5 (500 mg, $2.25 \mathrm{mmol}$ ) and imidazole (500 mg, $7.43 \mathrm{mmol}$ ) in DCM (20 $\mathrm{mL}$ ) was added $\mathrm{TBSCl}(600 \mathrm{mg}, 4.03 \mathrm{mmol})$ at $0{ }^{\circ} \mathrm{C}$. After being stirred at room temperature for $1 \mathrm{~h}$, 
the reaction was quenched by addition of saturated aqueous solution of $\mathrm{NH}_{4} \mathrm{Cl}(20 \mathrm{~mL})$ and extracted with DCM $(3 \times 30 \mathrm{~mL})$. The combined organic layers were washed with water $(30 \mathrm{~mL})$ and brine $(30$ $\mathrm{mL}$ ), dried over $\mathrm{Na}_{2} \mathrm{SO}_{4}$ and concentrated in vacuo. The residue was purified by silica gel chromatography to produce $\mathbf{5 - 1}(775 \mathrm{mg}, 99 \%)$ as a colorless oil. $\mathrm{R}_{f}=0.85$ (silica gel, $10 \%$ ethyl acetate in hexane);

$\mathrm{BH}_{3}$. THF complex (2.5 mL, 1.0 M solution in THF) was added to a solution of N-Ts- $D$-Val (676 mg, $2.46 \mathrm{mmol})$ in DCM $(7 \mathrm{~mL})$ at $0{ }^{\circ} \mathrm{C}$ under Ar. The mixture was stirred for $0.5 \mathrm{~h}$ and allowed to warm to room temperature for addition $1 \mathrm{~h}$. The resulting mixture was re-cooled to $-78{ }^{\circ} \mathrm{C}$. To this solution, 5-1 $(775 \mathrm{mg}, 2.46 \mathrm{mmol})$ in DCM $(3 \mathrm{~mL})$ and silyl ketene acetal $(0.73 \mathrm{~mL}, 3.20 \mathrm{mmol})$ were slowly added. After being stirred at $-78{ }^{\circ} \mathrm{C}$ for $12 \mathrm{~h}$, the reaction mixture was quenched by addition of saturated aqueous solution of $\mathrm{NH}_{4} \mathrm{Cl}(20 \mathrm{~mL})$ and extracted with DCM $(3 \times 30 \mathrm{~mL})$. The combined organic layers were washed with water $(30 \mathrm{~mL})$ and brine $(30 \mathrm{~mL})$, dried over $\mathrm{Na}_{2} \mathrm{SO}_{4}$ and concentrated in vacuo. The residue was purified by silica gel flash chromatography to produce $\mathbf{2 6}$ (1.0 $\mathrm{g}, 98 \%$ ) as a colorless oil. $\mathrm{R}_{f}=0.45$ (silica gel, $20 \%$ ethyl acetate in hexane); $[\alpha]_{\mathbf{D}}{ }^{20}=20.8$ (c 1.0, $\left.\mathrm{CHCl}_{3}\right) ;{ }^{1} \mathbf{H}$ NMR $\left(500 \mathrm{MHz}, \mathrm{CDCl}_{3}\right) \delta 7.17(\mathrm{t}, J=7.9 \mathrm{~Hz}, 1 \mathrm{H}), 7.08(\mathrm{dd}, J=7.8,1.4 \mathrm{~Hz}, 1 \mathrm{H}), 6.83$ (dd, $J=7.9,1.5 \mathrm{~Hz}, 1 \mathrm{H}), 5.56(\mathrm{~d}, J=4.6 \mathrm{~Hz}, 1 \mathrm{H}), 3.76(\mathrm{~s}, 3 \mathrm{H}), 3.41(\mathrm{~d}, J=4.7 \mathrm{~Hz}, 1 \mathrm{H}), 1.22(\mathrm{~s}, 3 \mathrm{H})$, 1.20 (s, 3H), 1.04 (s, 9H), 0.24 (s, 3H), 0.23 (s, 3H). ${ }^{13} \mathbf{C}$ NMR (125 MHz, $\left.\mathrm{CDCl}_{3}\right) \delta 178.41,152.29$, $141.39,127.22,121.82,119.18,118.09,52.22,48.57,25.80,23.54,19.01,18.41,-4.14,-4.26$. HRMS $(\mathrm{m} / z)$ : calculated for $\mathrm{C}_{18} \mathrm{H}_{29} \mathrm{BrO}_{4} \mathrm{SiNa}^{+}[\mathrm{M}+\mathrm{Na}]^{+}$: 439.0911, found 439.0910.

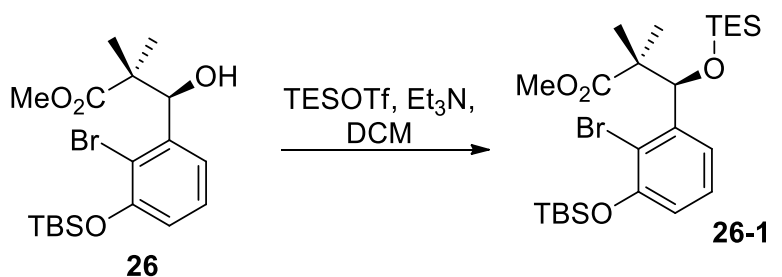

To a solution of $26(680 \mathrm{mg}, 1.63 \mathrm{mmol})$ in DCM $(15 \mathrm{~mL})$, was added $\mathrm{Et}_{3} \mathrm{~N}(0.70 \mathrm{~mL}, 5.03 \mathrm{mmol})$ and TESOTf $(0.60 \mathrm{~mL}, 2.66 \mathrm{mmol})$ at $-50{ }^{\circ} \mathrm{C}$. The reaction mixture was allowed to slowly warm to $30{ }^{\circ} \mathrm{C}$ and stirred at $-30{ }^{\circ} \mathrm{C}$ for $2 \mathrm{~h}$ before it was quenched with saturated aqueous solution of $\mathrm{NaHCO}_{3}$ $(20 \mathrm{~mL})$ at $-50^{\circ} \mathrm{C}$. After the solution was warmed to room temperature and stirred until clear phases were obtained $(1.5 \mathrm{~h})$, the aqueous phase was extracted with DCM $(3 \times 30 \mathrm{~mL})$. The combined organic layers were washed with brine $(30 \mathrm{~mL})$, dried over anhydrous $\mathrm{Na}_{2} \mathrm{SO}_{4}$ and concentrated in vacuo. The residue was purified by silica gel flash chromatography to produce $\mathbf{2 6 - 1}$ ( $848 \mathrm{mg}, 98 \%$ ) as a colorless oil. $\mathbf{R}_{f}=0.90$ (silica gel, $20 \%$ ethyl acetate in hexane); $[\alpha]_{\mathbf{D}}{ }^{20}=-10.8 \quad\left(c 1.0, \mathrm{CHCl}_{3}\right) ;{ }^{1} \mathbf{H} \mathbf{~ N M R}(500$ $\left.\mathrm{MHz}, \mathrm{CDCl}_{3}\right) \delta 7.17-7.08(\mathrm{~m}, 2 \mathrm{H}), 6.82(\mathrm{dd}, J=5.6,3.9 \mathrm{~Hz}, 1 \mathrm{H}), 5.70(\mathrm{~s}, 1 \mathrm{H}), 3.71(\mathrm{~s}, 3 \mathrm{H}), 1.19$ (s, $3 \mathrm{H}), 1.08(\mathrm{~s}, 3 \mathrm{H}), 1.05(\mathrm{~s}, 9 \mathrm{H}), 0.81(\mathrm{t}, J=7.9 \mathrm{~Hz}, 9 \mathrm{H}), 0.46-0.38(\mathrm{~m}, 6 \mathrm{H}), 0.23(\mathrm{~s}, 3 \mathrm{H}), 0.23$ (s, $3 \mathrm{H}) .{ }^{13} \mathrm{C}$ NMR $\left(125 \mathrm{MHz}, \mathrm{CDCl}_{3}\right) \delta 177.17,151.96,142.19,126.59,123.62,119.23,117.88,51.78$, 
50.06, 25.87, 22.90, 18.46, 18.19, 6.62, 4.63, -4.19, -4.28. HRMS $(\mathrm{m} / \mathrm{z})$ : calculated for $\mathrm{C}_{24} \mathrm{H}_{43} \mathrm{BrO}_{4} \mathrm{Si}_{2} \mathrm{Na}^{+}[\mathrm{M}+\mathrm{Na}]^{+}:$553.1775, found 553.1774.

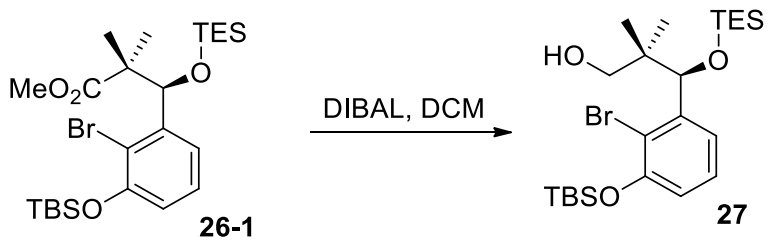

To a solution of ester 26-1 (548 mg, $1.03 \mathrm{mmol})$ in DCM (15 mL) was added DIBAL-H (2 mL, $1.5 \mathrm{M}$ in toluene) at $-78^{\circ} \mathrm{C}$. The reaction mixture was allowed to warm to $-40{ }^{\circ} \mathrm{C}$ and stirred for $1 \mathrm{~h}$ before it was re-cooled to $-78^{\circ} \mathrm{C}$ and quenched by addition of $\mathrm{MeOH}(1 \mathrm{~mL})$. Aqueous Rochelle's salt $(20 \mathrm{~mL})$ was added, and the solution was stirred for $2 \mathrm{~h}$ at room temperature. The aqueous phase was extracted with DCM $(3 \times 20 \mathrm{~mL})$. The combined organic layers were washed with brine $(30 \mathrm{~mL})$, dried over anhydrous $\mathrm{Na}_{2} \mathrm{SO}_{4}$ and concentrated in vacuo. The residue was purified by silica gel flash chromatography to produce 27 (485 mg, 95\%) as a colorless oil. $\mathrm{R}_{f}=0.20$ (silica gel, 3\% ethyl acetate in hexane); $[\alpha]_{\mathbf{D}}{ }^{20}=2.6\left(c 1.0, \mathrm{CHCl}_{3}\right) ;{ }^{1} \mathbf{H}$ NMR $\left(500 \mathrm{MHz}, \mathrm{CDCl}_{3}\right) \delta 7.23-7.13(\mathrm{~m}, 2 \mathrm{H}), 6.83(\mathrm{dd}, J$ $=7.6,1.9 \mathrm{~Hz}, 1 \mathrm{H}), 5.23(\mathrm{~s}, 1 \mathrm{H}), 3.75(\mathrm{dd}, J=11.0,3.5 \mathrm{~Hz}, 1 \mathrm{H}), 3.51(\mathrm{dd}, J=6.9,3.7 \mathrm{~Hz}, 1 \mathrm{H}), 3.27$ $(\mathrm{dd}, J=11.0,6.9 \mathrm{~Hz}, 1 \mathrm{H}), 1.15(\mathrm{~s}, 3 \mathrm{H}), 1.05(\mathrm{~s}, 9 \mathrm{H}), 0.84(\mathrm{t}, J=7.9 \mathrm{~Hz}, 9 \mathrm{H}), 0.76(\mathrm{~s}, 3 \mathrm{H}), 0.55-0.41$ $(\mathrm{m}, 6 \mathrm{H}), 0.24$ (s, 3H) , 0.24 (s, 3H). ${ }^{13} \mathbf{C}$ NMR $\left(125 \mathrm{MHz}, \mathrm{CDCl}_{3}\right) \delta 152.09,142.70,127.04,122.80$, $119.19,117.78,80.76,70.48,40.46,25.87,23.39,20.49,18.46,6.62,4.53,-4.17,-4.29$. HRMS $(\mathrm{m} / \mathrm{z})$ : calculated for $\mathrm{C}_{23} \mathrm{H}_{43} \mathrm{BrO}_{3} \mathrm{Si}_{2} \mathrm{Na}^{+}[\mathrm{M}+\mathrm{Na}]^{+}: 525.1826$, found 525.1827 .

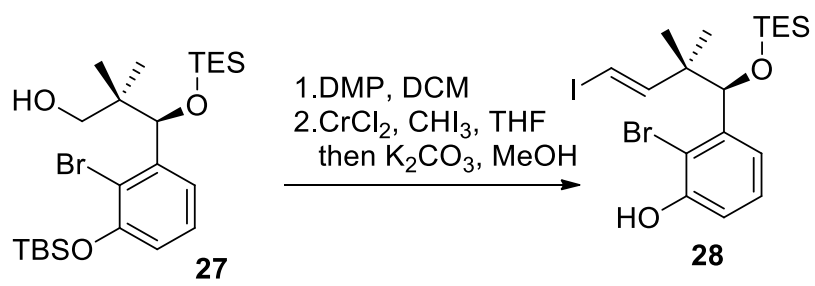

To a solution of $27(210 \mathrm{mg}, 0.56 \mathrm{mmol})$ in DCM (10 mL) was added $\mathrm{NaHCO}_{3}(200 \mathrm{mg}, 2.38 \mathrm{mmol})$ and Dess-Martin periodinane $\left(500 \mathrm{mg}, 1.2 \mathrm{mmol}\right.$ ) at $0{ }^{\circ} \mathrm{C}$. After being stirred for $1 \mathrm{~h}$ at room temperature, the reaction mixture was concentrated in vacuo and filtered through a pad of silica gel to afford the corresponding aldehyde as a colorless oil, which was used directly in the next step without further purification.

To a solution of anhydrous $\mathrm{CrCl}_{2}(510 \mathrm{mg}, 4.15 \mathrm{mmol})$ in THF $(5 \mathrm{~mL})$ was added a solution of the aldehyde and iodoform (616 mg, $1.76 \mathrm{mmol}$ ) in THF (5 mL). After being stirred overnight, the reaction mixture was quenched by addition of saturated aqueous solution of $\mathrm{NH}_{4} \mathrm{Cl}(20 \mathrm{~mL})$ and extracted with DCM $(3 \times 30 \mathrm{~mL})$. The combined organic layers were concentrated in vacuo and the residue was dissolved in $\mathrm{MeOH}(5 \mathrm{~mL})$. To this solution, $\mathrm{K}_{2} \mathrm{CO}_{3}(200 \mathrm{mg}, 1.43 \mathrm{mmol}$ ) was added and the mixture was stirred at room temperature for $1 \mathrm{~h}$ before it was quenched by saturated aqueous 
solution of $\mathrm{NH}_{4} \mathrm{Cl}(15 \mathrm{~mL})$ and extracted with ethyl acetate $(3 \times 25 \mathrm{~mL})$. The combined organic phases were washed with brine $(30 \mathrm{~mL})$, dried over $\mathrm{Na}_{2} \mathrm{SO}_{4}$ and concentrated in vacuo. The residue was purified by silica gel flash chromatography to give compound 28 (145 mg, 68\%, two steps) as a colorless oil. $\mathrm{R}_{f}=0.20$ (silica gel, $3 \%$ ethyl acetate in hexane); $[\alpha]_{\mathbf{D}}{ }^{20}=52.3\left(c 1.0, \mathrm{CHCl}_{3}\right) ;{ }^{1} \mathbf{H}$ NMR $\left(500 \mathrm{MHz}, \mathrm{CDCl}_{3}\right) \delta 7.18(\mathrm{t}, J=7.9 \mathrm{~Hz}, 1 \mathrm{H}), 7.03-6.88(\mathrm{~m}, 2 \mathrm{H}), 6.71(\mathrm{~d}, J=14.7 \mathrm{~Hz}, 1 \mathrm{H}), 5.86(\mathrm{~d}, J$ $=14.7 \mathrm{~Hz}, 1 \mathrm{H}), 5.63(\mathrm{~s}, 1 \mathrm{H}), 4.87(\mathrm{~s}, 1 \mathrm{H}), 1.06(\mathrm{~s}, 3 \mathrm{H}), 1.00(\mathrm{~s}, 3 \mathrm{H}), 0.84(\mathrm{t}, J=7.9 \mathrm{~Hz}, 9 \mathrm{H}), 0.54-$ $0.38(\mathrm{~m}, 6 \mathrm{H}) .{ }^{13} \mathrm{C}$ NMR $\left(125 \mathrm{MHz}, \mathrm{CDCl}_{3}\right) \delta 152.31,151.40,141.84,127.54,122.37,114.74,112.34$, 78.80, 74.92, 47.53, 23.57, 21.95, 6.71, 4.71. HRMS (m/z): calculated for $\mathrm{C}_{18} \mathrm{H}_{28} \mathrm{BrIO}_{2} \mathrm{SiNa}^{+}[\mathrm{M}+$ $\mathrm{Na}]^{+}: 532.9979$, found 532.9974 .
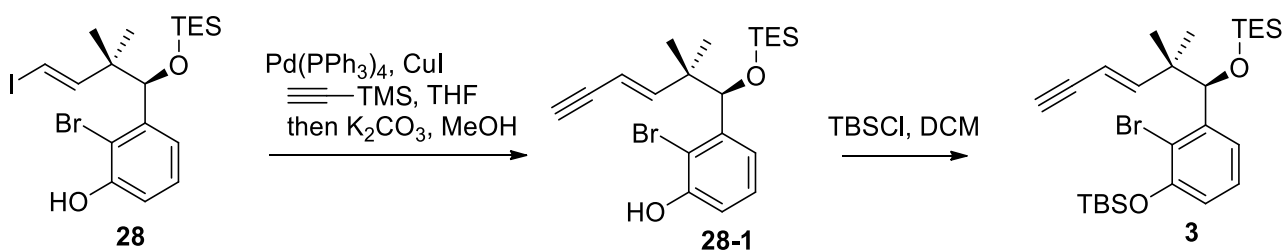

To a solution of $28(50 \mathrm{mg}, 0.10 \mathrm{mmol})$ and $\mathrm{Et}_{3} \mathrm{~N}(14 \mathrm{uL}, 0.10 \mathrm{mmol})$ in dry THF $(2 \mathrm{~mL})$ under argon was added trimethylsilylacetylene (42 $\mathrm{uL}, 0.30 \mathrm{mmol}), \mathrm{Pd}\left(\mathrm{PPh}_{3}\right)_{4}(11.5 \mathrm{mg}, 0.01 \mathrm{mmol})$ and $\mathrm{CuI}(3.8$ $\mathrm{mg}, 0.02 \mathrm{mmol}$ ) at room temperature. After being stirred for $2.5 \mathrm{~h}$ at room temperature, the reaction mixture was concentrated in vacuo and dissolved in $\mathrm{MeOH}(5 \mathrm{~mL})$. To this solution, $\mathrm{K}_{2} \mathrm{CO}_{3}(40 \mathrm{mg}$, $0.29 \mathrm{mmol}$ ) was added and the mixture was stirred for $1 \mathrm{~h}$ at room temperature before it was quenched with saturated aqueous solution of $\mathrm{NH}_{4} \mathrm{Cl}(15 \mathrm{~mL})$ and extracted with ethyl acetate $(3 \times 25 \mathrm{~mL})$. The combined organic phases were washed with brine $(30 \mathrm{~mL})$, dried over $\mathrm{Na}_{2} \mathrm{SO}_{4}$ and concentrated in vacuo. The residue was purified by silica gel flash chromatography to give compound $\mathbf{2 8 - 1}$ (36 $\mathrm{mg}$, $90 \%$ ) as a colorless oil. $\mathrm{R}_{f}=0.20$ (silica gel, $3 \%$ ethyl acetate in hexane).

To a solution of compound 28-1 (12 mg, $0.03 \mathrm{mmol}$ ) and imidazole (10 mg, $0.15 \mathrm{mmol})$ in DCM (3 $\mathrm{mL}$ ) was added TBSCl $(25 \mathrm{mg}, 0.17 \mathrm{mmol})$ at $0{ }^{\circ} \mathrm{C}$. After a catalytic amount of DMAP (one crystal) was added, the reaction mixture was stirred at room temperature for $2 \mathrm{~h}$ and then quenched by addition of saturated aqueous solution of $\mathrm{NH}_{4} \mathrm{Cl}(2 \mathrm{~mL})$ and $\mathrm{DCM}(10 \mathrm{~mL})$. Layers were separated and the aqueous phase was extracted with DCM $(3 \times 15 \mathrm{~mL})$. The combined organic layers were washed with water $(20 \mathrm{~mL})$ and brine $(20 \mathrm{~mL})$, dried over anhydrous $\mathrm{Na}_{2} \mathrm{SO}_{4}$ and concentrated in vacuo. The residue was purified by silica gel flash chromatography to produce $\mathbf{3}(15 \mathrm{mg}, 98 \%)$ as a colorless oil. $\mathrm{R}_{f}=0.80$ (silica gel, 3\% ethyl acetate in hexane); $[\alpha]_{\mathbf{D}}{ }^{20}=55.8\left(c 0.5, \mathrm{CHCl}_{3}\right) ;{ }^{1} \mathbf{H} \mathbf{~ N M R}(400 \mathrm{MHz}$, $\left.\mathrm{CDCl}_{3}\right) \delta 7.11(\mathrm{t}, J=7.8 \mathrm{~Hz}, 1 \mathrm{H}), 7.03(\mathrm{dd}, J=7.8,1.6 \mathrm{~Hz}, 1 \mathrm{H}), 6.79(\mathrm{dd}, J=7.8,1.7 \mathrm{~Hz}, 1 \mathrm{H}), 6.51$ $(\mathrm{d}, J=16.5 \mathrm{~Hz}, 1 \mathrm{H}), 5.27$ (dd, $J=16.5,2.2 \mathrm{~Hz}, 1 \mathrm{H}), 5.06$ (s, 1H), $2.80(\mathrm{~d}, J=2.0 \mathrm{~Hz}, 1 \mathrm{H}), 1.09$ (s, $3 \mathrm{H}), 1.04$ (s, 9H), 0.98 (s, 3H), $0.82(\mathrm{~d}, J=7.9 \mathrm{~Hz}, 9 \mathrm{H}), 0.54-0.38(\mathrm{~m}, 6 \mathrm{H}), 0.23(\mathrm{~s}, 3 \mathrm{H}), 0.21$ (s, 3H). ${ }^{13} \mathrm{C}$ NMR $\left(100 \mathrm{MHz}, \mathrm{CDCl}_{3}\right) \delta 152.64,151.81,143.17,126.61,123.13,119.04,106.57,83.12$, $78.90,75.98,44.00,29.71,25.90,24.33,22.01,18.47,6.72,4.68,-4.16,-4.27$. HRMS $(\mathrm{m} / \mathrm{z})$ : calculated for $\mathrm{C}_{26} \mathrm{H}_{43} \mathrm{BrO}_{2} \mathrm{Si}_{2} \mathrm{Na}^{+}[\mathrm{M}+\mathrm{Na}]^{+}$: 545.1877, found 545.1882. 


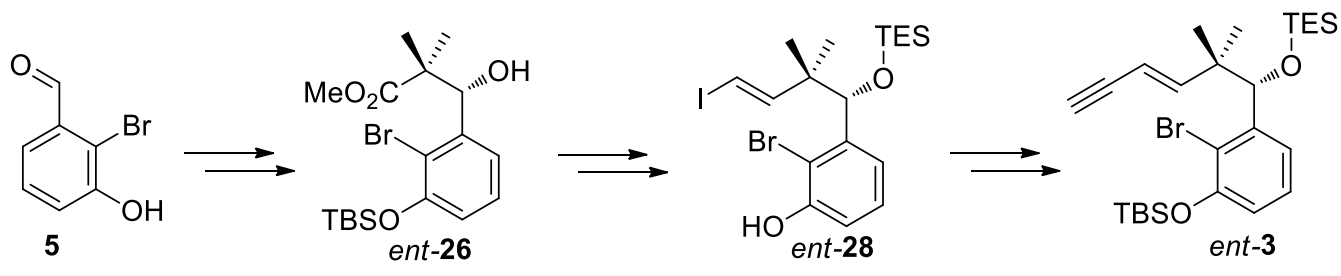

ent-3 was synthesized according to the procedures described for $\mathbf{3}$. The NMR analytical data of ent-3 were identical to the data of $\mathbf{3}$.
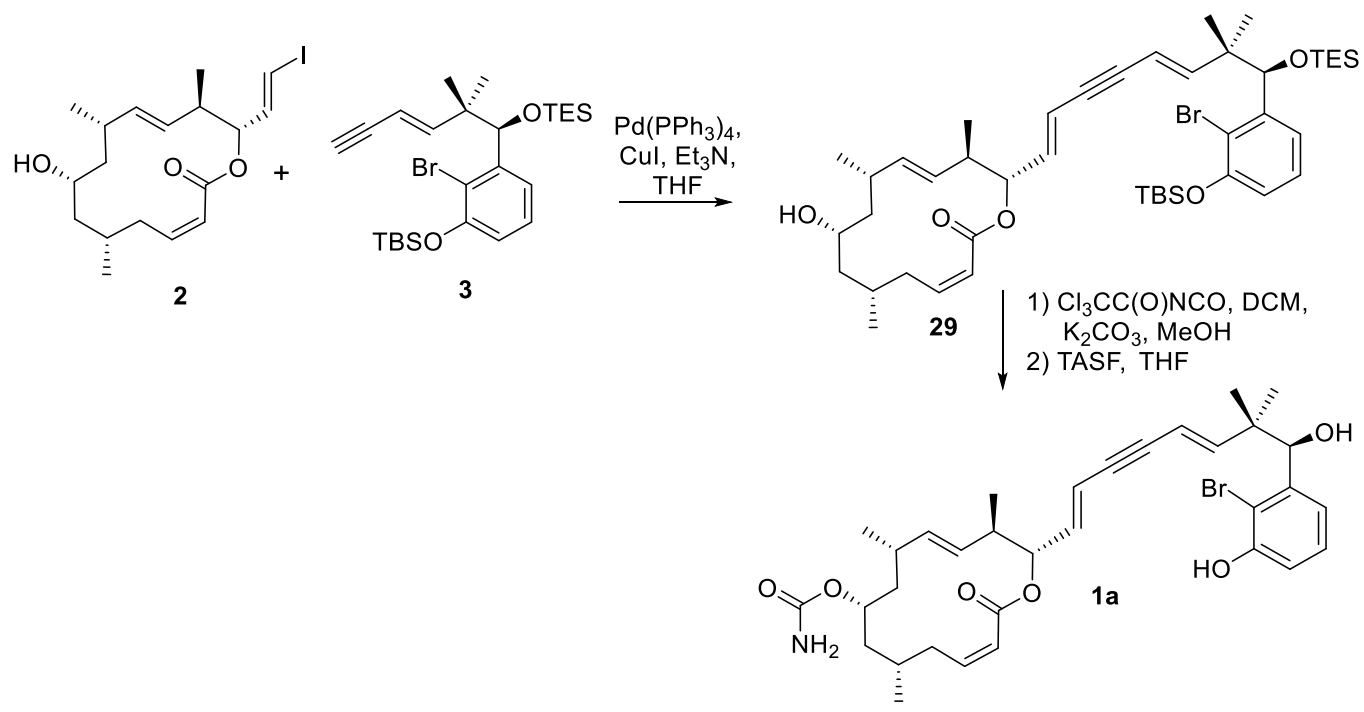

To a solution of $2(9 \mathrm{mg}, 0.02 \mathrm{mmol}), 3(20 \mathrm{uL}, 0.04 \mathrm{mmol})$, and $\mathrm{Et}_{3} \mathrm{~N}(3 \mathrm{uL}, 0.02 \mathrm{mmol})$ in dry THF $(2 \mathrm{~mL})$ under argon was added $\mathrm{Pd}\left(\mathrm{PPh}_{3}\right)_{4}(12 \mathrm{mg}, 0.01 \mathrm{mmol})$ and $\mathrm{CuI}(8 \mathrm{mg}, 0.05 \mathrm{mmol})$ at room temperature. After being stirred for $3 \mathrm{~h}$ at room temperature, the reaction was concentrated in vacuo before was quenched with saturated aqueous solution of $\mathrm{NH}_{4} \mathrm{Cl}(15 \mathrm{~mL})$ and extracted with ethyl acetate $(3 \times 25 \mathrm{~mL})$. The combined organic phases were washed with brine $(30 \mathrm{~mL})$, dried over $\mathrm{Na}_{2} \mathrm{SO}_{4}$ and concentrated in vacuo. The residue was purified by silica gel flash chromatography to give compound 29 (13 mg, 74\%) as a colorless oil. $\mathbf{R}_{f}=0.60$ (silica gel, 25\% ethyl acetate in hexane); $[\alpha]_{\mathbf{D}}{ }^{20}=31.0(c 1.0, \mathrm{MeOH}) ;{ }^{1} \mathbf{H}$ NMR $\left(500 \mathrm{MHz}, \mathrm{CDCl}_{3}\right) \delta 7.12(\mathrm{t}, J=7.8 \mathrm{~Hz}, 1 \mathrm{H}), 7.04(\mathrm{dd}, J=7.8$, $1.5 \mathrm{~Hz}, 1 \mathrm{H}), 6.79(\mathrm{dd}, J=7.9,1.5 \mathrm{~Hz}, 1 \mathrm{H}), 6.42(\mathrm{~d}, J=16.4 \mathrm{~Hz}, 1 \mathrm{H}), 6.28(\mathrm{td}, J=12.8,3.4 \mathrm{~Hz}, 1 \mathrm{H})$, $6.02(\mathrm{dd}, J=15.8,8.0 \mathrm{~Hz}, 1 \mathrm{H}), 5.90-5.80(\mathrm{~m}, 2 \mathrm{H}), 5.40(\mathrm{dd}, J=16.3,2.0 \mathrm{~Hz}, 1 \mathrm{H}), 5.24-5.11(\mathrm{~m}$, 2H), $5.09-4.98(\mathrm{~m}, 2 \mathrm{H}), 3.77(\mathrm{td}, J=14.2,4.7 \mathrm{~Hz}, 1 \mathrm{H}), 3.42(\mathrm{t}, J=10.6 \mathrm{~Hz}, 1 \mathrm{H}), 2.35-2.26(\mathrm{~m}$, $1 \mathrm{H}), 2.25-2.11(\mathrm{~m}, 2 \mathrm{H}), 2.00-1.91(\mathrm{~m}, 1 \mathrm{H}), 1.65-1.61(\mathrm{~m}, 2 \mathrm{H}), 1.40-1.30(\mathrm{~m}, 3 \mathrm{H}), 1.11(\mathrm{~s}, 3 \mathrm{H})$, $1.08-1.03(\mathrm{~m}, 12 \mathrm{H}), 1.01-0.94(\mathrm{~m}, 9 \mathrm{H}), 0.84(\mathrm{t}, J=7.9 \mathrm{~Hz}, 9 \mathrm{H}), 0.53-0.37$ (m, 6H), $0.23(\mathrm{~d}, J=$ $4.8 \mathrm{~Hz}, 6 \mathrm{H}) .{ }^{13} \mathbf{C}$ NMR $\left(125 \mathrm{MHz}, \mathrm{CDCl}_{3}\right) \delta 165.21,151.88,151.22,145.98,143.30,138.71,137.48$, $132.12,126.63,123.17,121.98,119.05,117.67,114.09,107.53,90.50,86.12,79.08,76.12,66.06$, 46.13, 44.12, 43.25, 43.10, 34.52, 31.28, 29.72, 27.17, 25.93, 24.39, 22.37, 20.06, 18.49, 17.66, 6.72, 4.77, -4.15, -4.24. HRMS (m/z): calculated for $\mathrm{C}_{44} \mathrm{H}_{69} \mathrm{BrO}_{5} \mathrm{Si}_{2} \mathrm{Na}^{+}[\mathrm{M}+\mathrm{Na}]^{+}:$835.3759, found 
835.3762.

To a solution of $29(13 \mathrm{mg}, 0.016 \mathrm{mmol})$ in DCM (4 mL) was added trichloroacetylisocyanate $(2.3 \mu \mathrm{L}$, $0.019 \mathrm{mmol}$ ) at room temperature. After being stirred for $30 \mathrm{~min}$ and concentrated in vacuo the mixture was added $\mathrm{MeOH}(4 \mathrm{~mL})$ and $\mathrm{K}_{2} \mathrm{CO}_{3}$, and stirred for $1 \mathrm{~h}$. The reaction mixture was quenched with saturated aqueous solution of $\mathrm{NH}_{4} \mathrm{Cl}(15 \mathrm{~mL})$ and extracted with ethyl acetate $(3 \times 25 \mathrm{~mL})$. The combined organic phases were washed with brine $(30 \mathrm{~mL})$, dried over $\mathrm{Na}_{2} \mathrm{SO}_{4}$ and concentrated in vacuo. The residue was purified by silica gel flash chromatography to give the corresponding carbamate (11 mg, 93\%) as a colorless oil.

To a solution of carbamate $(11 \mathrm{mg}, 0.015 \mathrm{mmol})$ in THF $(2 \mathrm{~mL})$ was added a solution of TASF $(15 \mathrm{mg}$, $0.055 \mathrm{mmol})$ in THF $(1 \mathrm{~mL})$ at $0{ }^{\circ} \mathrm{C}$. After being stirred at $0{ }^{\circ} \mathrm{C}$ for $36 \mathrm{~h}$, the reaction was quenched with saturated aqueous solution of $\mathrm{NH}_{4} \mathrm{Cl}(15 \mathrm{~mL})$ and extracted with ethyl acetate $(3 \times 25 \mathrm{~mL})$. The combined organic phases were washed with brine $(30 \mathrm{~mL})$, dried over $\mathrm{Na}_{2} \mathrm{SO}_{4}$ and concentrated in vacuo. The residue was purified by silica gel flash chromatography to give compound 1a $(7.6 \mathrm{mg}$, $82 \%)$ as a colorless oil. $\mathrm{R}_{f}=0.20$ (silica gel, $40 \%$ ethyl acetate in hexane); $[\alpha]_{\mathbf{D}}{ }^{20}=66.0(c 0.1, \mathrm{MeOH})$;

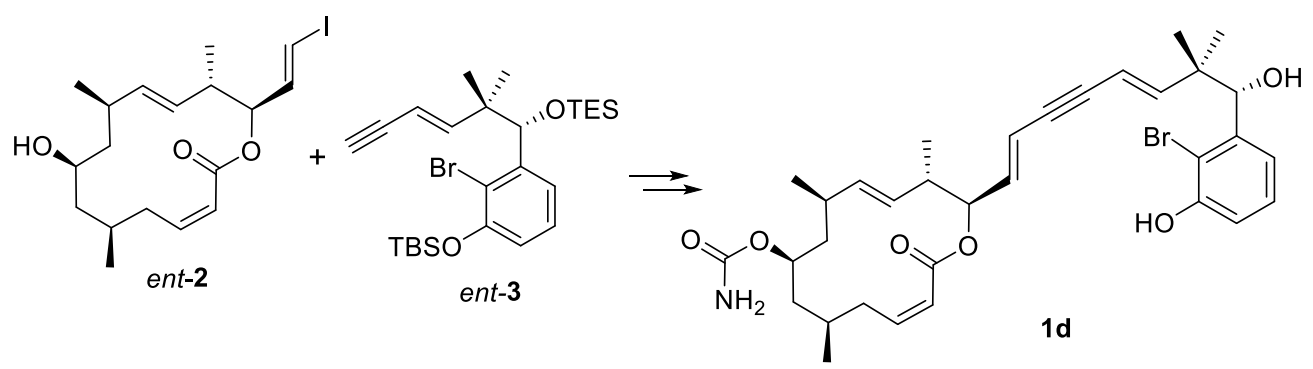

1d was synthesized according to the procedures for the synthesis of 1a.

Optical rotation for $\mathbf{1 d}:[\alpha]_{\mathbf{D}}{ }^{20}=-62.86(c 0.1, \mathrm{MeOH})$

NMR analytical data for $\mathbf{1 a}$ and $\mathbf{1 d}$ are identical:

${ }^{1} \mathbf{H}$ NMR (400 MHz, DMSO-d6) $\delta 10.08(\mathrm{~s}, 1 \mathrm{H}), 7.13(\mathrm{t}, J=7.9 \mathrm{~Hz}, 1 \mathrm{H}), 6.83(\mathrm{dd}, J=7.8,2.2 \mathrm{~Hz}$, 2H), $6.36(\mathrm{~d}, J=16.4 \mathrm{~Hz}, 1 \mathrm{H}), 6.13(\mathrm{td}, J=12.1,3.1 \mathrm{~Hz}, 1 \mathrm{H}), 6.06(\mathrm{dd}, J=15.8,7.6 \mathrm{~Hz}, 1 \mathrm{H}), 5.99-$ $5.88(\mathrm{~m}, 2 \mathrm{H}), 5.53(\mathrm{~d}, J=4.4 \mathrm{~Hz}, 1 \mathrm{H}), 5.45(\mathrm{dd}, J=16.4,2.0 \mathrm{~Hz}, 1 \mathrm{H}), 5.21(\mathrm{dd}, J=15.0,9.4 \mathrm{~Hz}, 1 \mathrm{H})$, $5.13-4.96(\mathrm{~m}, 2 \mathrm{H}), 4.88(\mathrm{~d}, J=4.4 \mathrm{~Hz}, 1 \mathrm{H}), 4.53-4.41(\mathrm{~m}, 1 \mathrm{H}), 3.47-3.36(\mathrm{~m}, 1 \mathrm{H}), 2.29-2.17(\mathrm{~m}$, $1 \mathrm{H}), 2.05-1.93(\mathrm{~m}, 1 \mathrm{H}), 1.89-1.81(\mathrm{~m}, 1 \mathrm{H}), 1.80-1.68(\mathrm{~m}, 1 \mathrm{H}), 1.44-1.32(\mathrm{~m}, 2 \mathrm{H}), 1.09-0.99$ (m, 5H), $0.99-0.91(\mathrm{~m}, 6 \mathrm{H}), 0.91-0.84(\mathrm{~m}, 6 \mathrm{H}) .{ }^{13} \mathbf{C}$ NMR (100 MHz, DMSO-d6) $\delta 164.08,156.59$, $153.18,151.55,143.13,142.38,139.55,136.29,131.92,126.79,122.19,120.00,114.25,113.28$, $111.60,106.71,90.34,86.28,76.45,75.60,68.21,44.04,42.98,41.71,40.98,33.17,31.20,26.76$, $24.00,22.34,21.92,19.81,17.34$. 
HRMS $(m / z)$ : calculated for $\mathrm{C}_{33} \mathrm{H}_{42} \mathrm{BrNO}_{6} \mathrm{Na}^{+}[\mathrm{M}+\mathrm{Na}]^{+}: 650.2088$, found 650.2087.
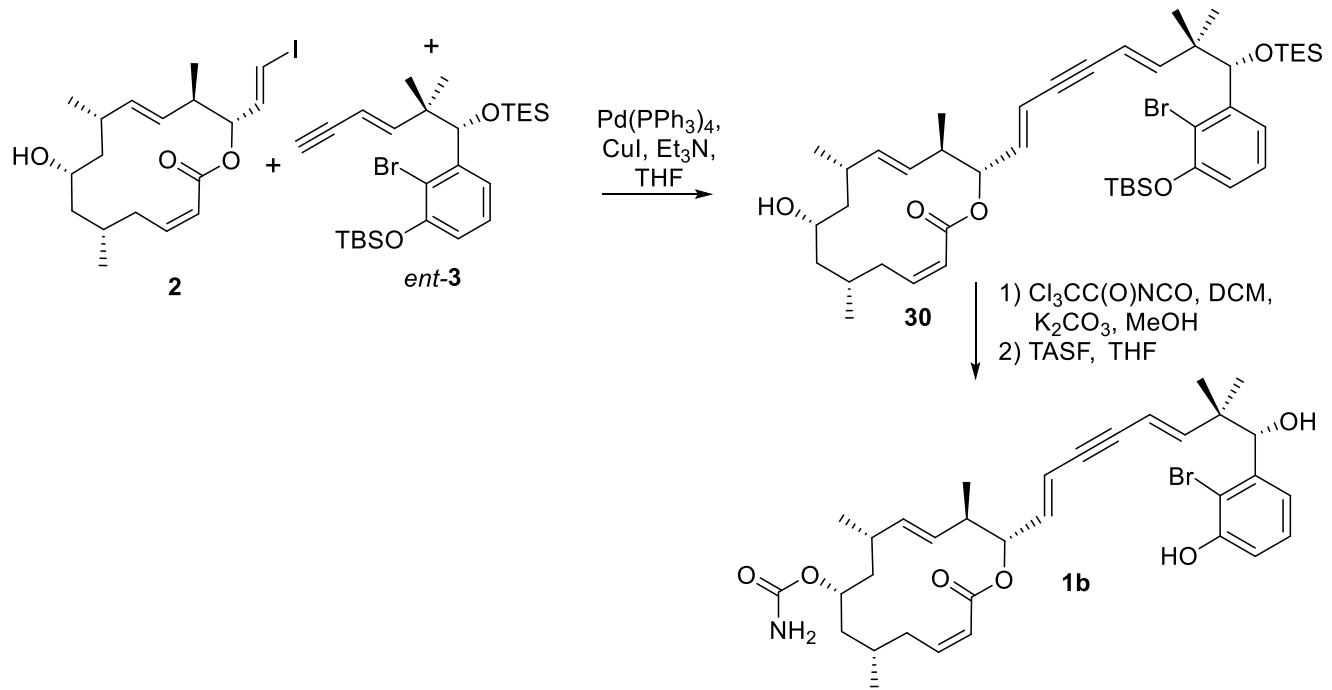

$\mathbf{3 0}$ and $\mathbf{1 b}$ were synthesized according to the procedures described for the synthesis of $\mathbf{2 9}$ and $\mathbf{1 a}$, respectively.

Analytical data for 30: $($ Yield $=68 \%) \mathrm{R}_{f}=0.60$ (silica gel, $25 \%$ ethyl acetate in hexane); $[\alpha]_{\mathbf{D}}{ }^{20}=25.0$ (c 0.7, $\mathrm{CHCl} 3)$;

${ }^{1} \mathbf{H}$ NMR $\left(500 \mathrm{MHz}, \mathrm{CDCl}_{3}\right) \delta 7.12(\mathrm{t}, J=7.9 \mathrm{~Hz}, 1 \mathrm{H}), 7.04(\mathrm{~d}, J=6.5 \mathrm{~Hz}, 1 \mathrm{H}), 6.79(\mathrm{dd}, J=7.8,1.4$ Hz, 1H), $6.42(\mathrm{~d}, J=16.4 \mathrm{~Hz}, 1 \mathrm{H}), 6.33-6.19(\mathrm{~m}, 1 \mathrm{H}), 6.02(\mathrm{dd}, J=15.8,8.0 \mathrm{~Hz}, 1 \mathrm{H}), 5.92-5.80$ (m, 2H), $5.40(\mathrm{dd}, J=16.3,2.0 \mathrm{~Hz}, 1 \mathrm{H}), 5.26-5.11(\mathrm{~m}, 2 \mathrm{H}), 5.09-4.99(\mathrm{~m}, 2 \mathrm{H}), 3.86-3.68(\mathrm{~m}, 1 \mathrm{H})$, $3.42(\mathrm{t}, J=10.9 \mathrm{~Hz}, 1 \mathrm{H}), 2.32-2.24(\mathrm{~m}, 1 \mathrm{H}), 2.25-2.09(\mathrm{~m}, 2 \mathrm{H}), 1.99-1.92(\mathrm{~m}, 1 \mathrm{H}), 1.72-1.60$ $(\mathrm{m}, 2 \mathrm{H}), 1.38-1.30(\mathrm{~m}, 3 \mathrm{H}), 1.11(\mathrm{~s}, 3 \mathrm{H}), 1.08-1.02(\mathrm{~m}, 12 \mathrm{H}), 1.02-0.93(\mathrm{~m}, 9 \mathrm{H}), 0.84(\mathrm{t}, J=7.9$ $\mathrm{Hz}, 9 \mathrm{H}), 0.54-0.39(\mathrm{~m}, 6 \mathrm{H}), 0.23(\mathrm{~d}, J=4.8 \mathrm{~Hz}, 6 \mathrm{H}) .{ }^{13} \mathbf{C} \mathbf{N M R}\left(125 \mathrm{MHz}, \mathrm{CDCl}_{3}\right) \delta 165.21,151.88$, $151.23,145.98,143.30,138.71,137.48,132.13,126.63,123.17,121.98,119.06,117.67,114.10$, $107.53,90.51,86.12,79.09,76.13,66.07,46.13,44.12,43.25,43.10,34.53,31.29,29.72,27.18$, $25.93,24.40,22.37,20.07,18.49,17.67,6.73,4.77,-4.15,-4.24$.

HRMS $(\mathrm{m} / z)$ : calculated for $\mathrm{C}_{44} \mathrm{H}_{69} \mathrm{BrO}_{5} \mathrm{Si}_{2} \mathrm{Na}^{+}\left[\mathrm{M}+\mathrm{Na}^{+}\right.$: 835.3759, found 835.3757.

1b: $($ Yield $=65 \%) . \mathrm{R}_{f}=0.20$ (silica gel, $40 \%$ ethyl acetate in hexane); $[\alpha]_{\mathbf{D}}{ }^{20}=12.0(c 0.1, \mathrm{MeOH})$;<smiles>C#C/C=C/C(C)(C)C(OC#C)c1cccc(OCC(C)(C)C)c1Br</smiles> 
1c was synthesized according to the procedures for the synthesis of 1a. Analytical data for $1 \mathbf{c}:[\alpha]_{\mathbf{D}}{ }^{20}=$ -13.0 ( $c$ $0.1, \mathrm{MeOH})$;

NMR and Mass data for $\mathbf{1 b}$ and $\mathbf{1 c}$ are identical:

${ }^{1}$ H NMR (400 MHz, DMSO-d6) $\delta 10.06(\mathrm{~s}, 1 \mathrm{H}), 7.13(\mathrm{t}, J=7.9 \mathrm{~Hz}, 1 \mathrm{H}), 6.83(\mathrm{dd}, J=7.9,2.9 \mathrm{~Hz}$, 2H), $6.36(\mathrm{~d}, J=16.4 \mathrm{~Hz}, 1 \mathrm{H}), 6.18-6.10(\mathrm{~m}, 1 \mathrm{H}), 6.06(\mathrm{dd}, J=15.8,7.6 \mathrm{~Hz}, 1 \mathrm{H}), 6.00-5.90(\mathrm{~m}$, 2H), $5.52(\mathrm{~d}, J=4.4 \mathrm{~Hz}, 1 \mathrm{H}), 5.50-5.41(\mathrm{~m}, 1 \mathrm{H}), 5.22(\mathrm{dd}, J=15.0,9.3 \mathrm{~Hz}, 1 \mathrm{H}), 5.14-5.00(\mathrm{~m}$, 2H), $4.89(\mathrm{~d}, J=4.4 \mathrm{~Hz}, 1 \mathrm{H}), 4.51-4.41(\mathrm{~m}, 1 \mathrm{H}), 3.48-3.35(\mathrm{~m}, 1 \mathrm{H}), 2.28-2.18(\mathrm{~m}, 1 \mathrm{H}), 2.05-$ $1.92(\mathrm{~m}, 1 \mathrm{H}), 1.90-1.80(\mathrm{~m}, 1 \mathrm{H}), 1.80-1.68(\mathrm{~m}, 1 \mathrm{H}), 1.45-1.32(\mathrm{~m}, 2 \mathrm{H}), 1.11-0.99(\mathrm{~m}, 5 \mathrm{H}), 0.99$ $-0.91(\mathrm{~m}, 6 \mathrm{H}), 0.91-0.84(\mathrm{~m}, 6 \mathrm{H}) .{ }^{\mathbf{1 3}} \mathbf{C}$ NMR (100 MHz, DMSO-d6) $\delta$ 164.08, 156.59, 153.18, $151.55,143.13,142.38,139.54,136.29,131.91,126.78,122.19,120.00,114.26,113.28,111.61$, $106.70,90.34,86.28,76.46,75.61,68.24,44.07,42.97,41.70,40.98,33.17,31.21,26.77,24.02$, $22.33,21.92,19.81,17.34$.

HRMS $(m / z)$ : calculated for $\mathrm{C}_{33} \mathrm{H}_{42} \mathrm{BrNO}_{6} \mathrm{Na}^{+}[\mathrm{M}+\mathrm{Na}]^{+}: 650.2088$, found 650.2100 .

\section{Biological Evaluation of Synthetic Compounds}

\section{Material and Methods}

Compounds: Four synthetic compounds were dissolved in DMSO. The final concentration of DMSO in the assay was below $0.01 \%$.

Cell culture: Breast carcinoma cell line MCF7, neuroblastoma cell line SH-SY5Y, cervical adenocarcinoma cell line HeLa, colon carcinoma cell lines HT-29 and RKO, immortalized human hepatocyte cell line MIHA, lung adenocarcinoma cell line H1299, prostate carcinoma cell line PC-3 and $\mathrm{T}$ lymphocyte cell line Jurkat were obtained from American Type Culture Collection (Manassas, VA). These cell lines were cultured in DMEM containing supplements $(10 \% \mathrm{FBS}$, penicillin/streptomycin and L-glutamine).

The effect of the synthetic compounds on the proliferation of cancer cell lines: Cells were seeded into 96-well plates overnight and cultured with incremental concentrations of the compounds in the medium containing 1\% FBS for another $72 \mathrm{~h}$. Cell proliferation was measured using 3-(4, 5dimethylthiazol-2-yl)-5-(3-carboxymethoxyohenyl)-2-(4-sulfophenyl-2H-tetrazolium) (MTS) assay. (Promega Co., Madison, WI). According to the manufacturer's instruction, $20 \mu \mathrm{L}$ of CellTiter96 Aqueous solution was added into each well containing $100 \mu \mathrm{L}$ medium and incubated at $37^{\circ} \mathrm{C}$ for 4 hours. The absorbance at $490 \mathrm{~nm}$ was measured using an ELISA plate reader (Bio-Rad microplate reader 680, Bio-Rad Laboratories, California, USA). The $\mathrm{IC}_{50}$ values were calculated by Prism 5 (GraphPad Prism software Inc, USA). 


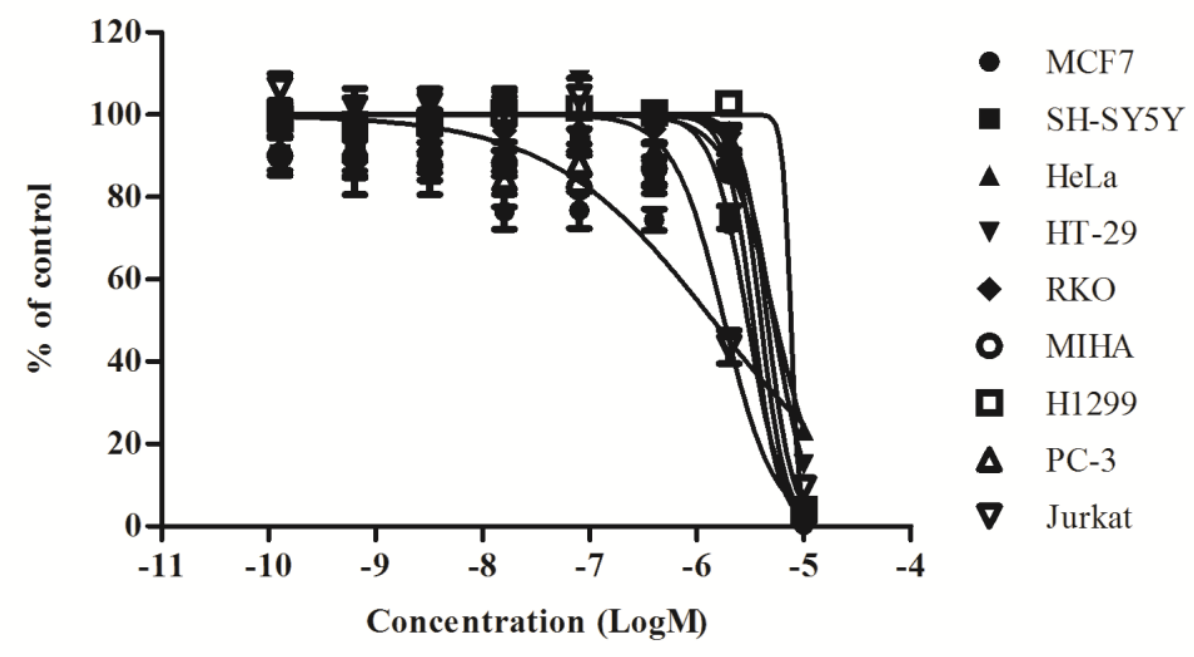

Figure 1. Effect of 1a on the proliferation of cancer cell lines. Effect of 1a on proliferation of cancer cell lines was assessed by MTS assay. Cells were incubated for 72 hours in the presence of various concentrations of 1a. Cell proliferation was measured by MTS assay. Representative data of three experiments were shown, and each concentration was repeated six times in each experiment.

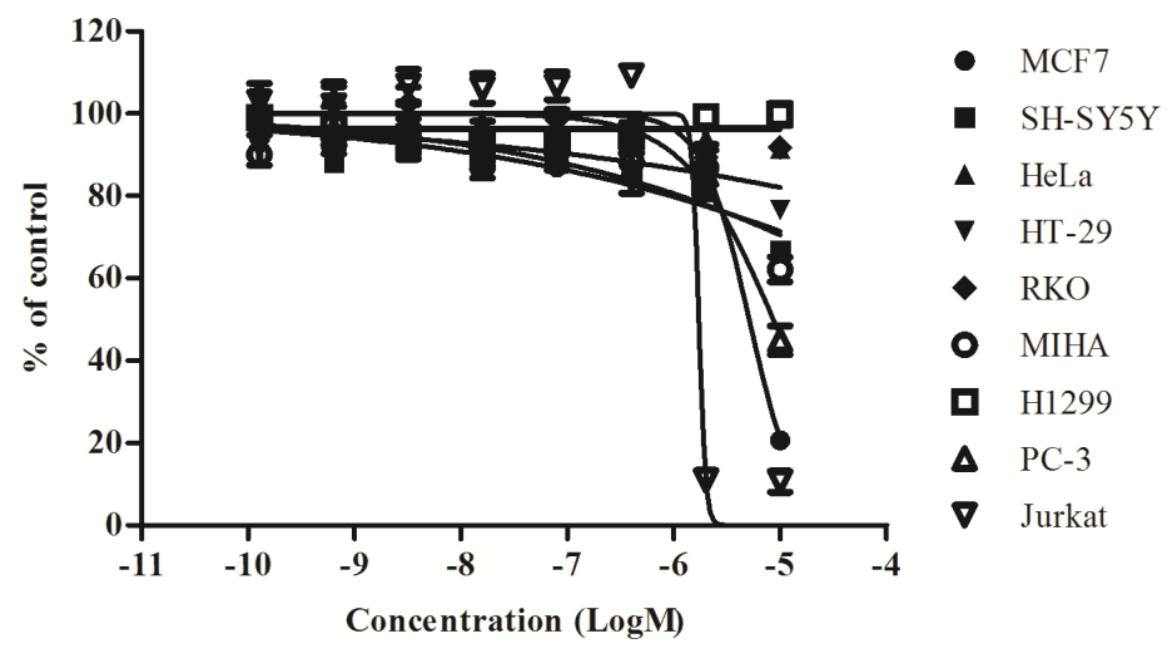

Figure 2. Effect of $\mathbf{1 b}$ on the proliferation of cancer cell lines. Effect of $\mathbf{1 b}$ on proliferation of cancer cell lines was assessed by MTS assay. Cells were incubated for 72 hours in the presence of various concentrations of $\mathbf{1 b}$. Cell proliferation was measured by MTS assay. Representative data of three experiments were shown, and each concentration was repeated six times in each experiment. 


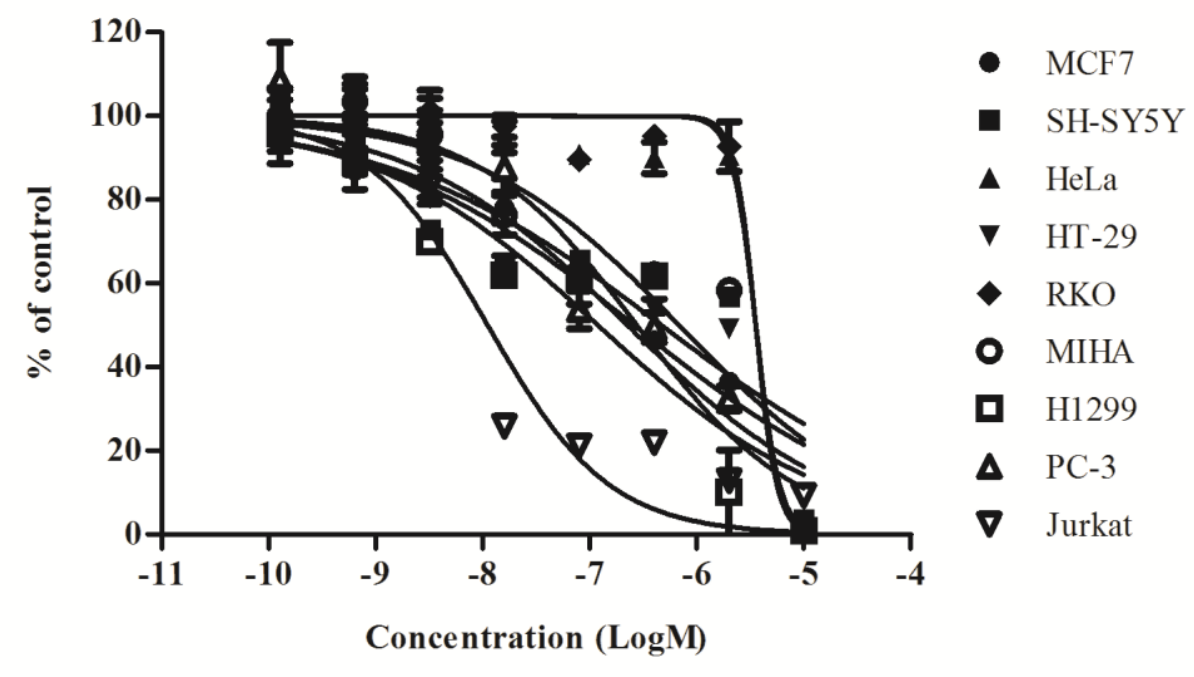

Figure 3. Effect of 1c on the proliferation of cancer cell lines. Effect of $1 \mathrm{c}$ on proliferation of cancer cell lines was assessed by MTS assay. Cells were incubated for 72 hours in the presence of various concentrations of 1c. Cell proliferation was measured by MTS assay. Representative data of three experiments were shown, and each concentration was repeated six times in each experiment.

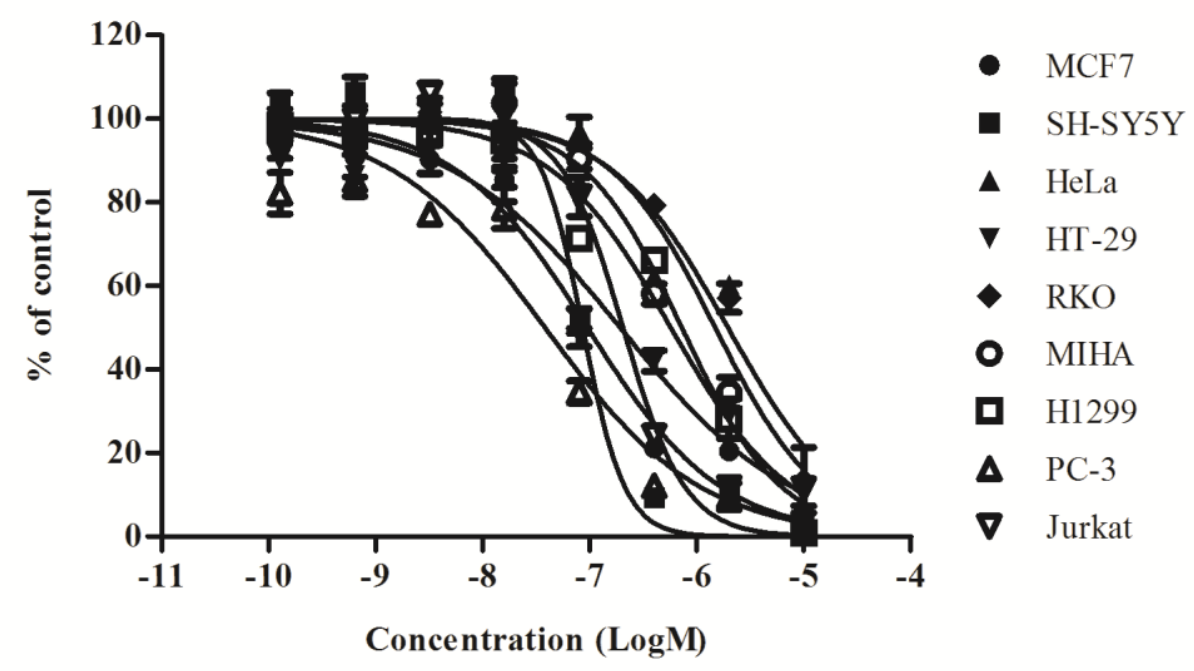

Figure 4. Effect of 1d on the proliferation of cancer cell lines. Effect of $\mathbf{1 d}$ on proliferation of cancer cell lines was assessed by MTS assay. Cells were incubated for 72 hours in the presence of various concentrations of 1d. Cell proliferation was measured by MTS assay. Representative data of three experiments were shown, and each concentration was repeated six times in each experiment. 
${ }^{1}$ H NMR Spectra of Natural and Synthetic Callyspongiolide

Callyspongiolide (Natural Product, $600 \mathrm{MHz}$, DMSO-d6)

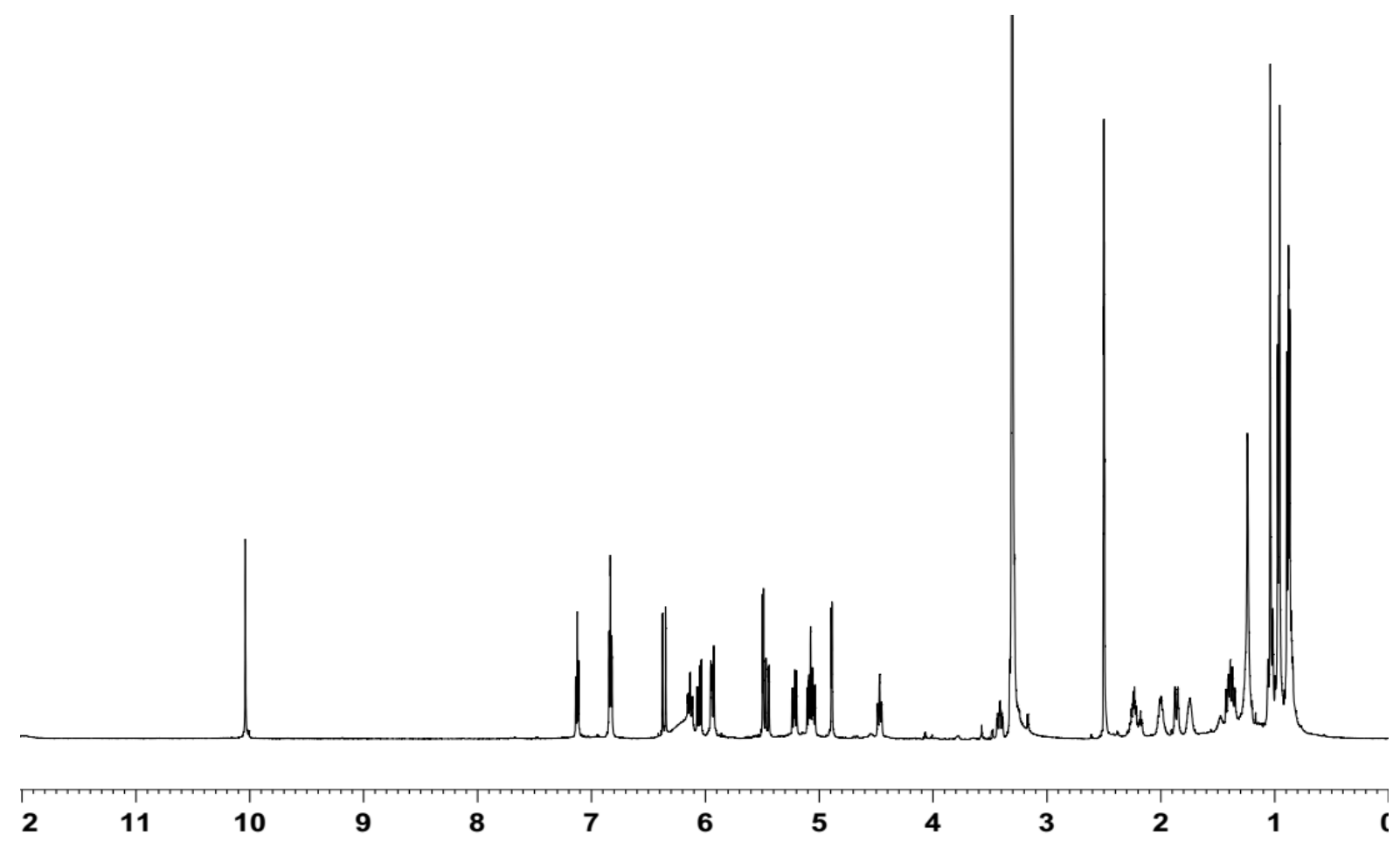

Callyspongiolide 1a (Synthetic Sample 1a, $400 \mathrm{MHz}$, DMSO-d6)

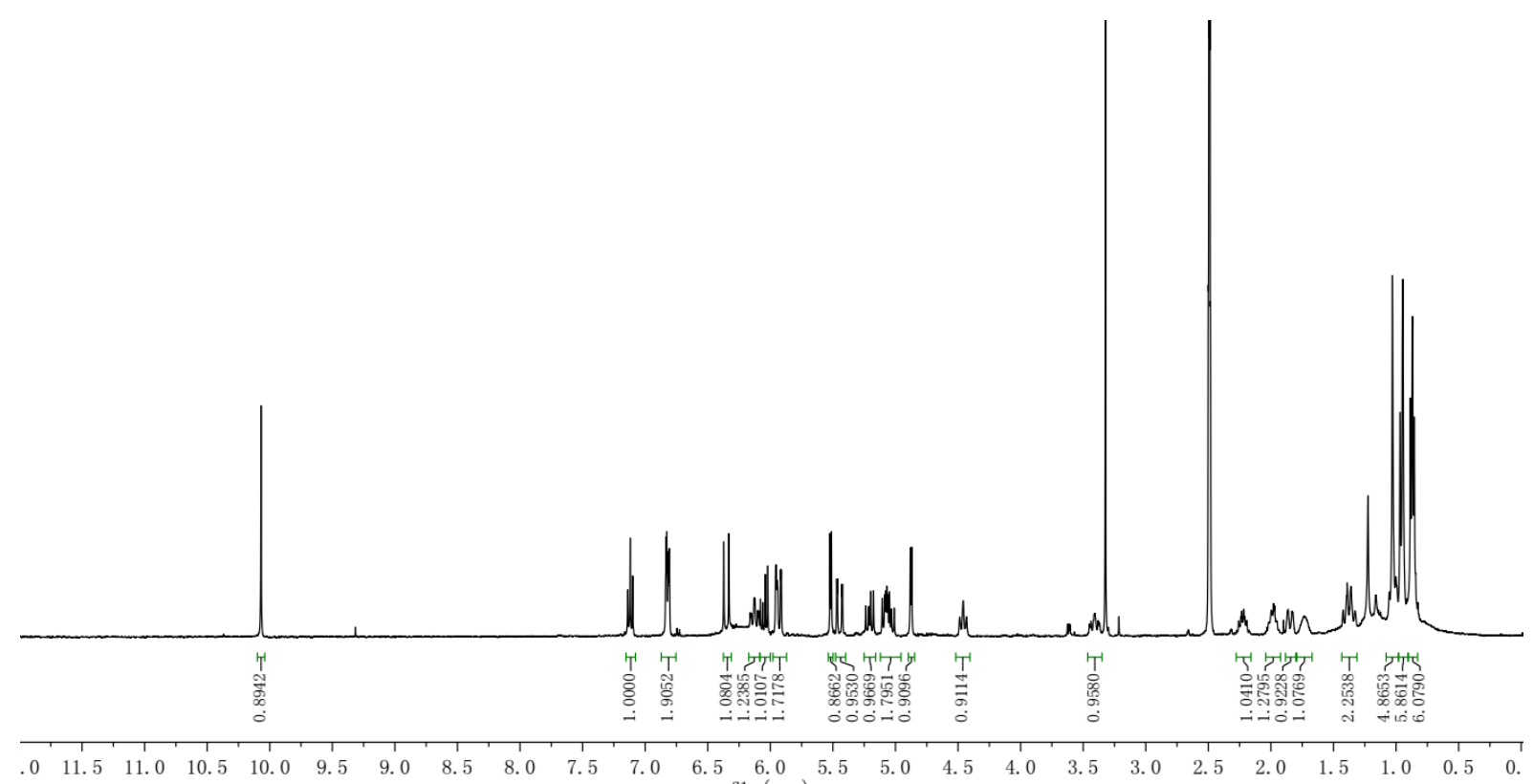


Callyspongiolide (Natural Product, $600 \mathrm{MHz}$, DMSO-d6)

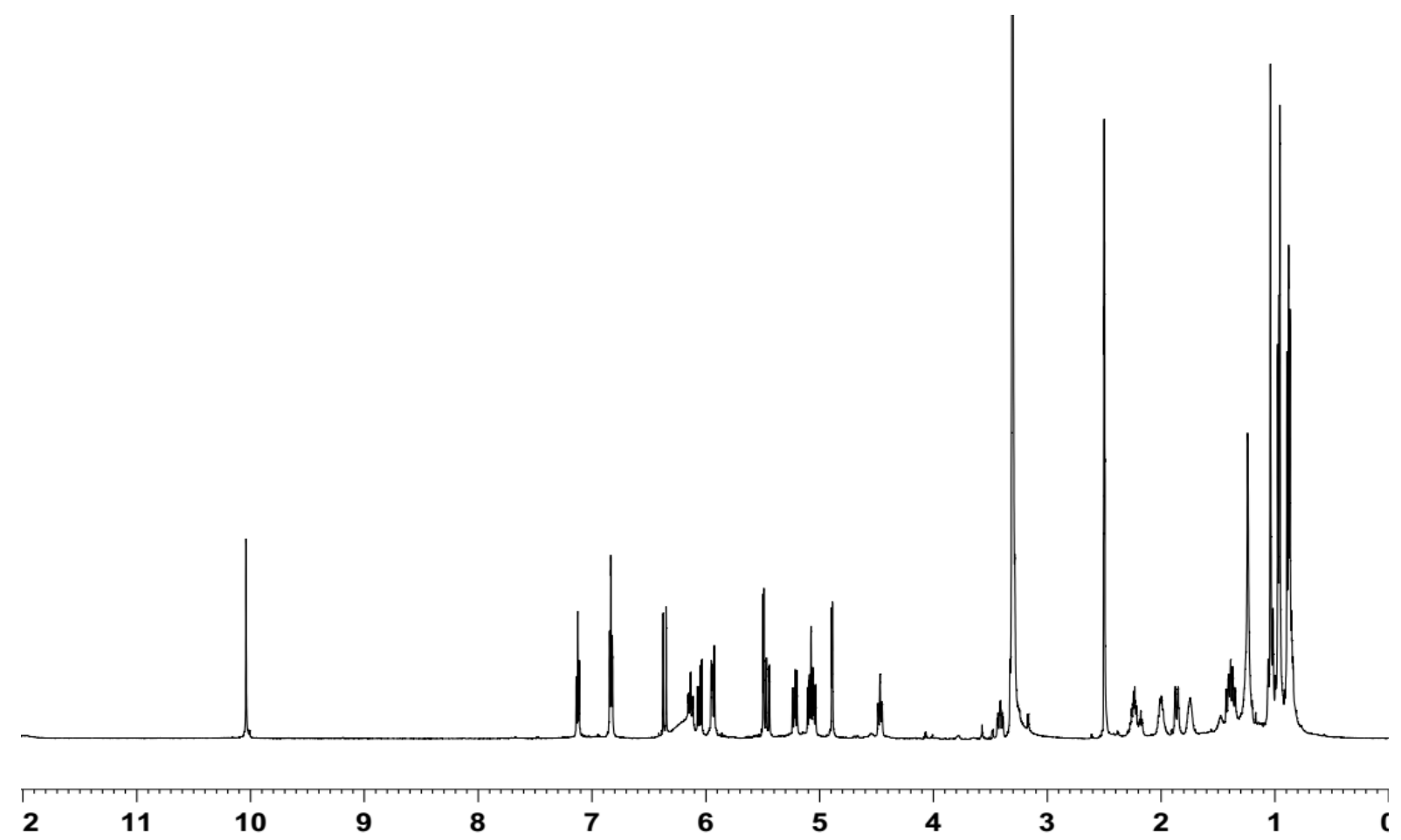

Callyspongiolide 1b (Synthetic Sample 1b, 400 MHz, DMSO-d6)

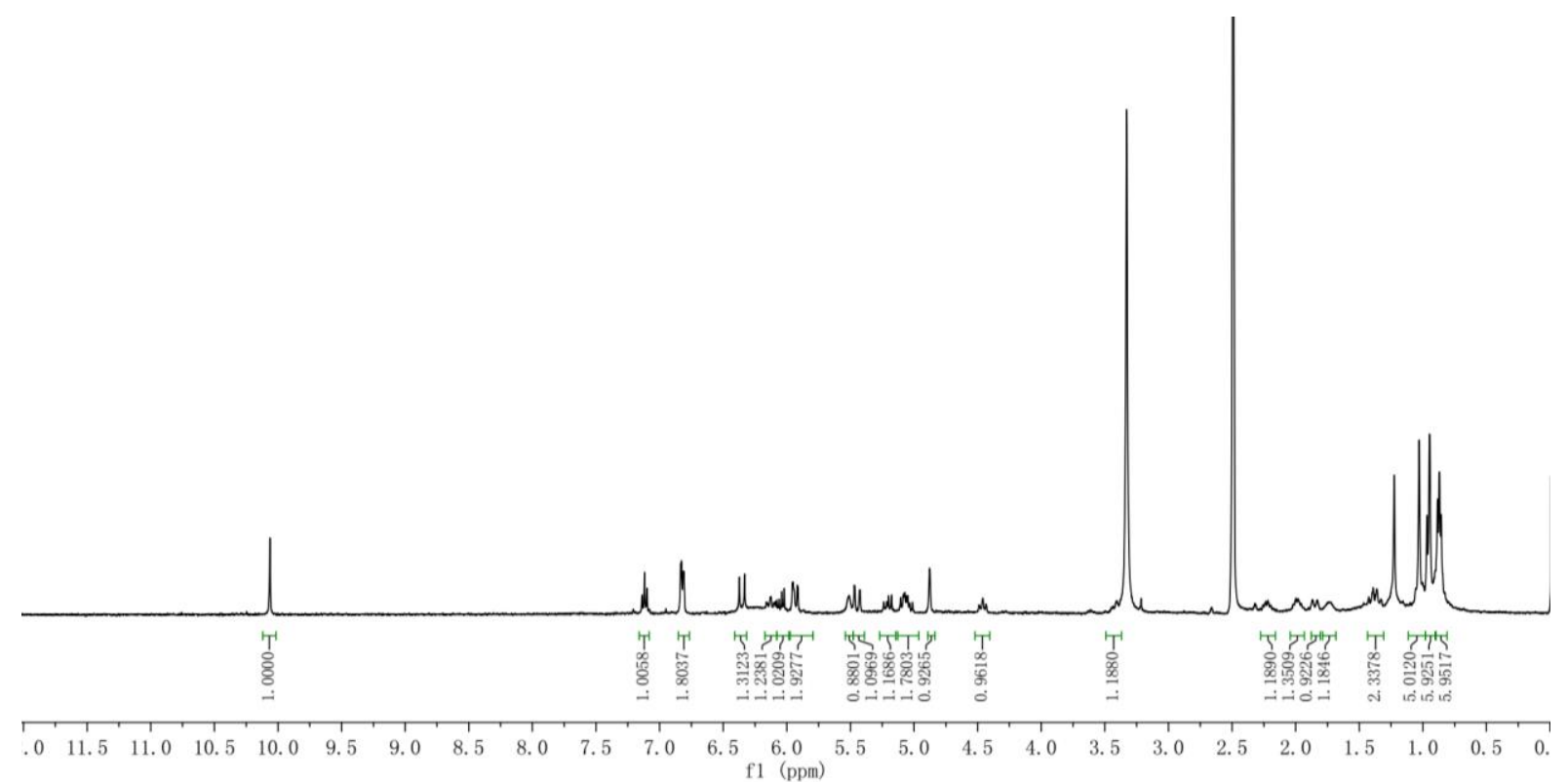


Callyspongiolide (Natural Product, $600 \mathrm{MHz}$, DMSO-d6)

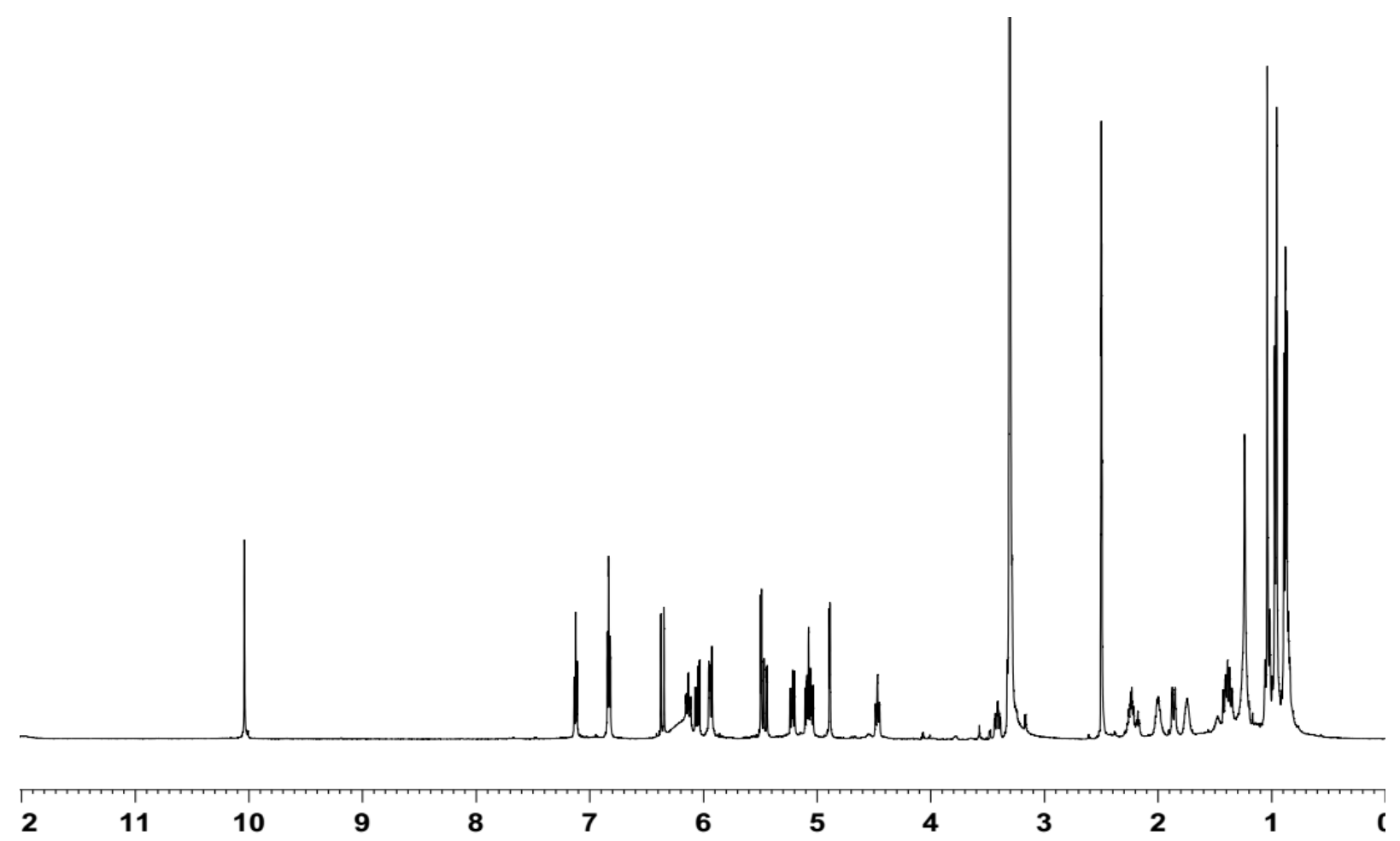

Callyspongiolide 1c (Synthetic Sample 1c, 400 MHz, DMSO-d6)

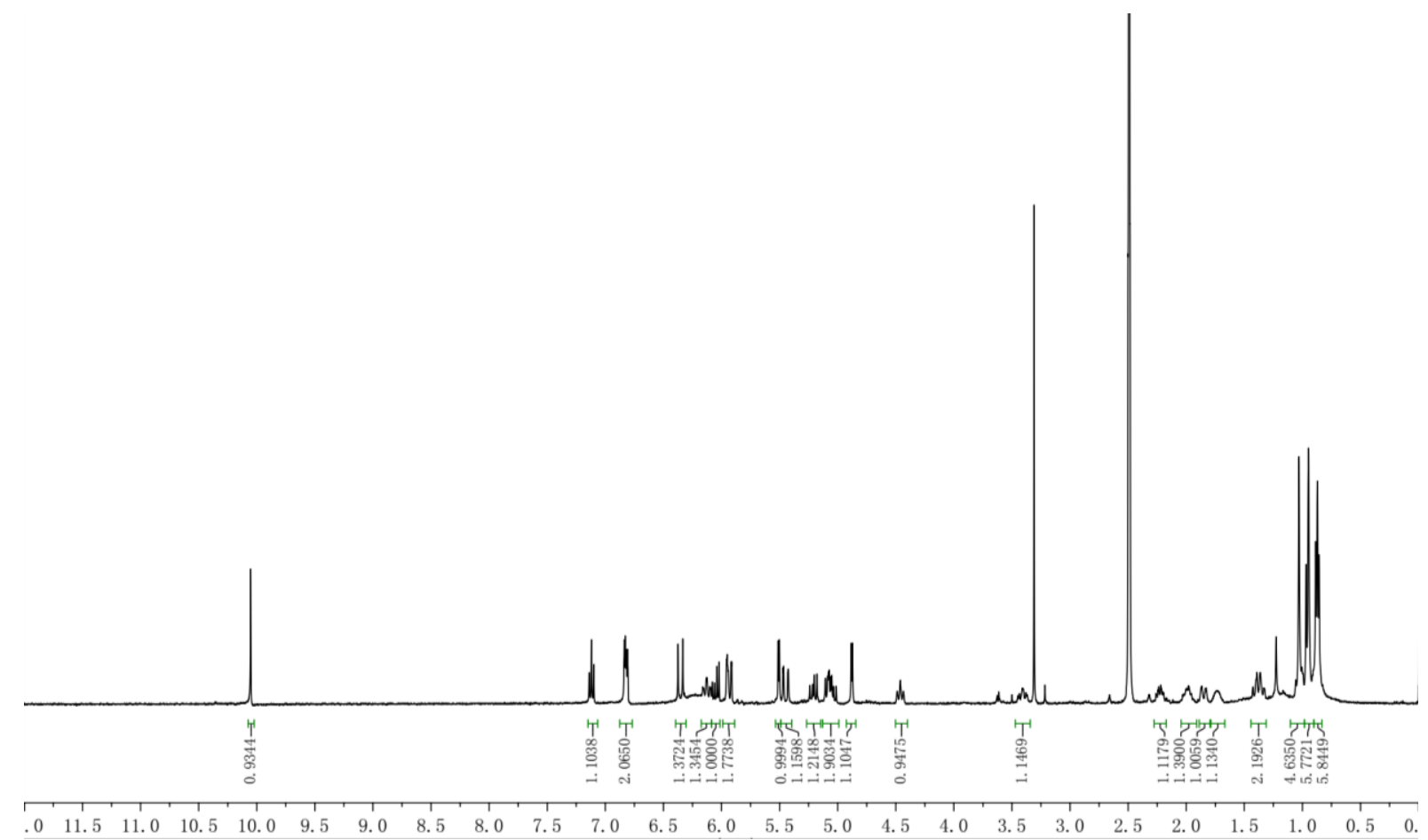


Callyspongiolide (Natural Product, $600 \mathrm{MHz}$, DMSO-d6)

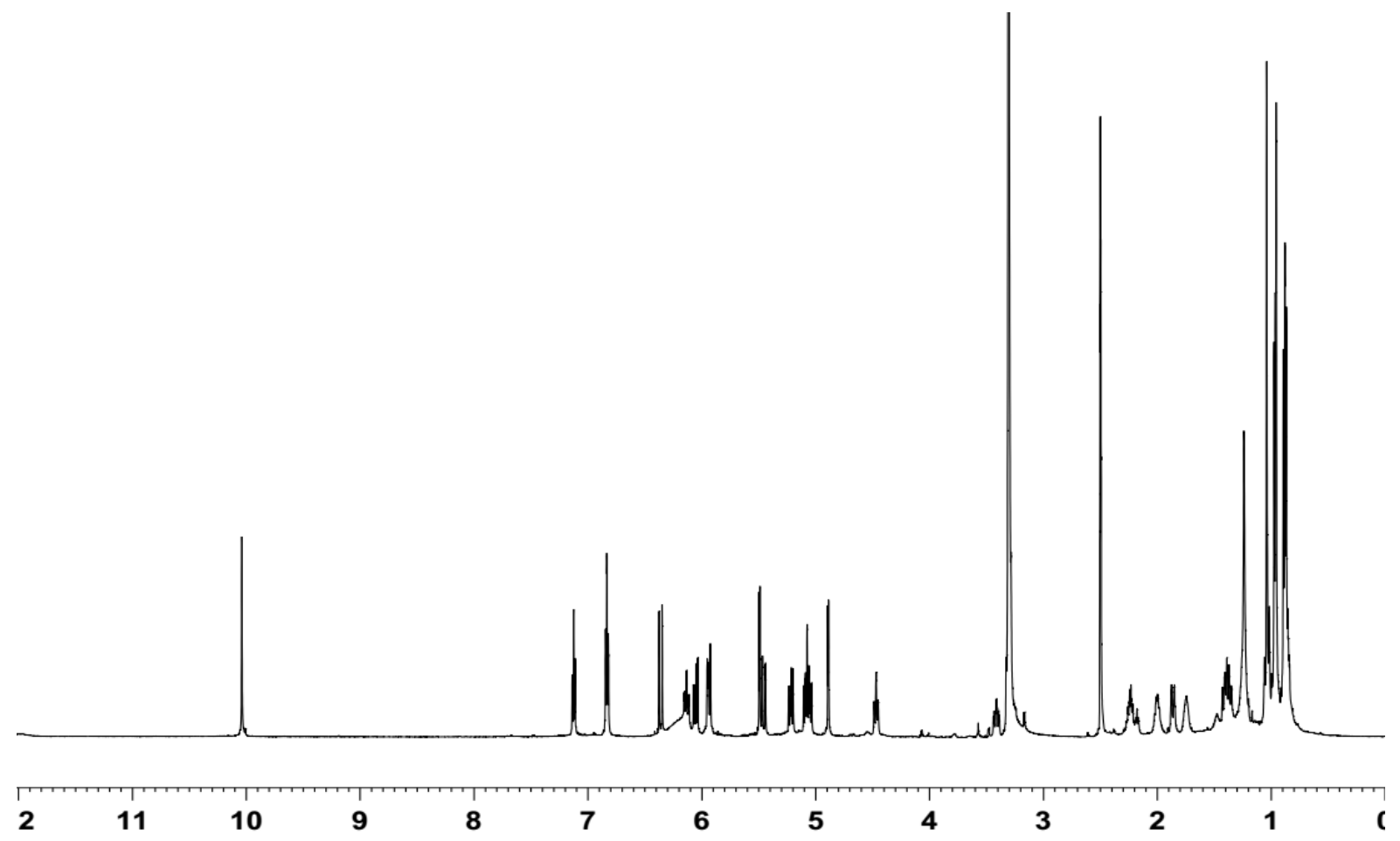

Callyspongiolide 1d (Synthetic Sample 1d, 400 MHz, DMSO-d6)

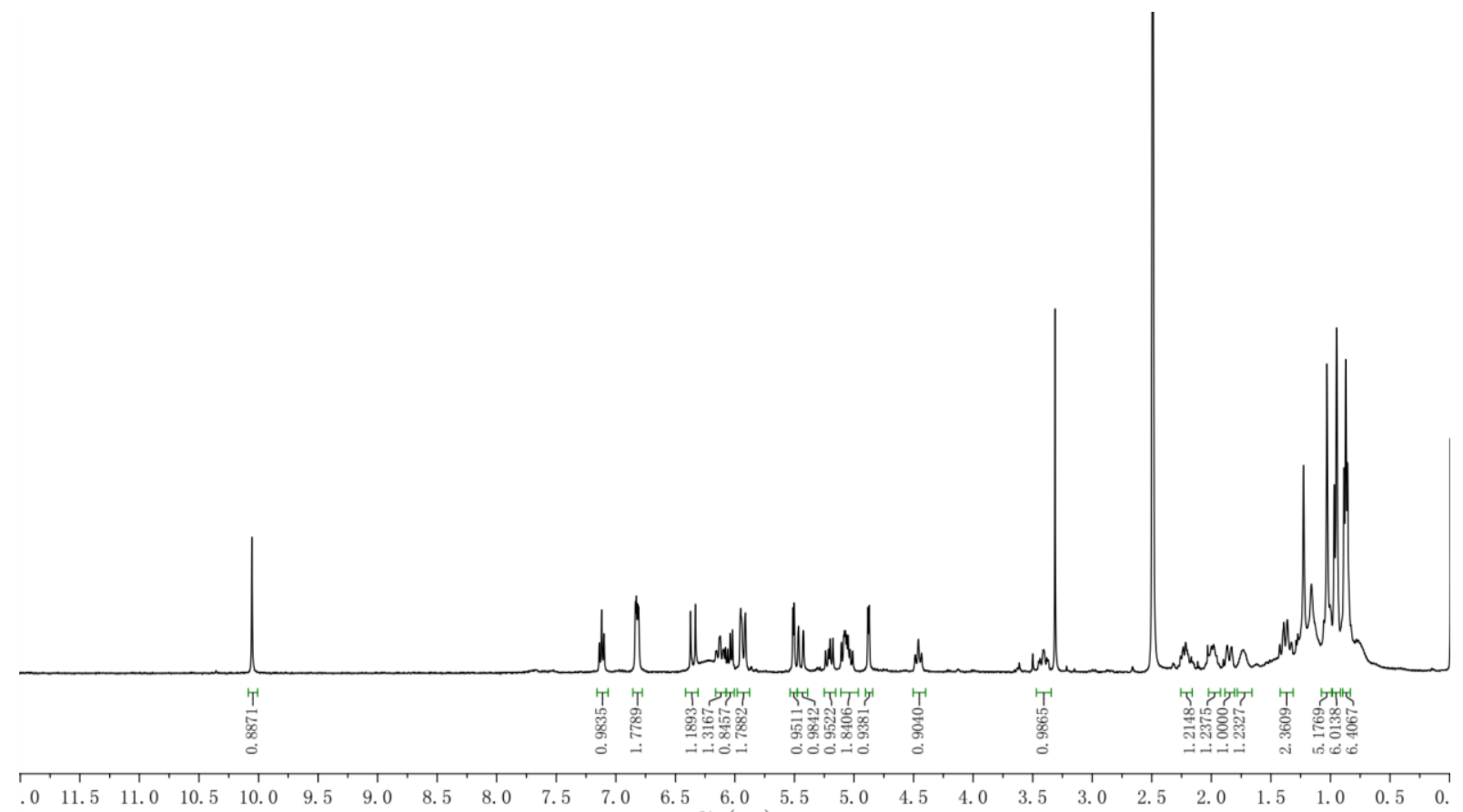


${ }^{13}$ C NMR Spectra of Natural and Synthetic Callyspongiolides

Callyspongiolide (Natural Product, $150 \mathrm{MHz}, \mathrm{DMSO}-d 6$ )

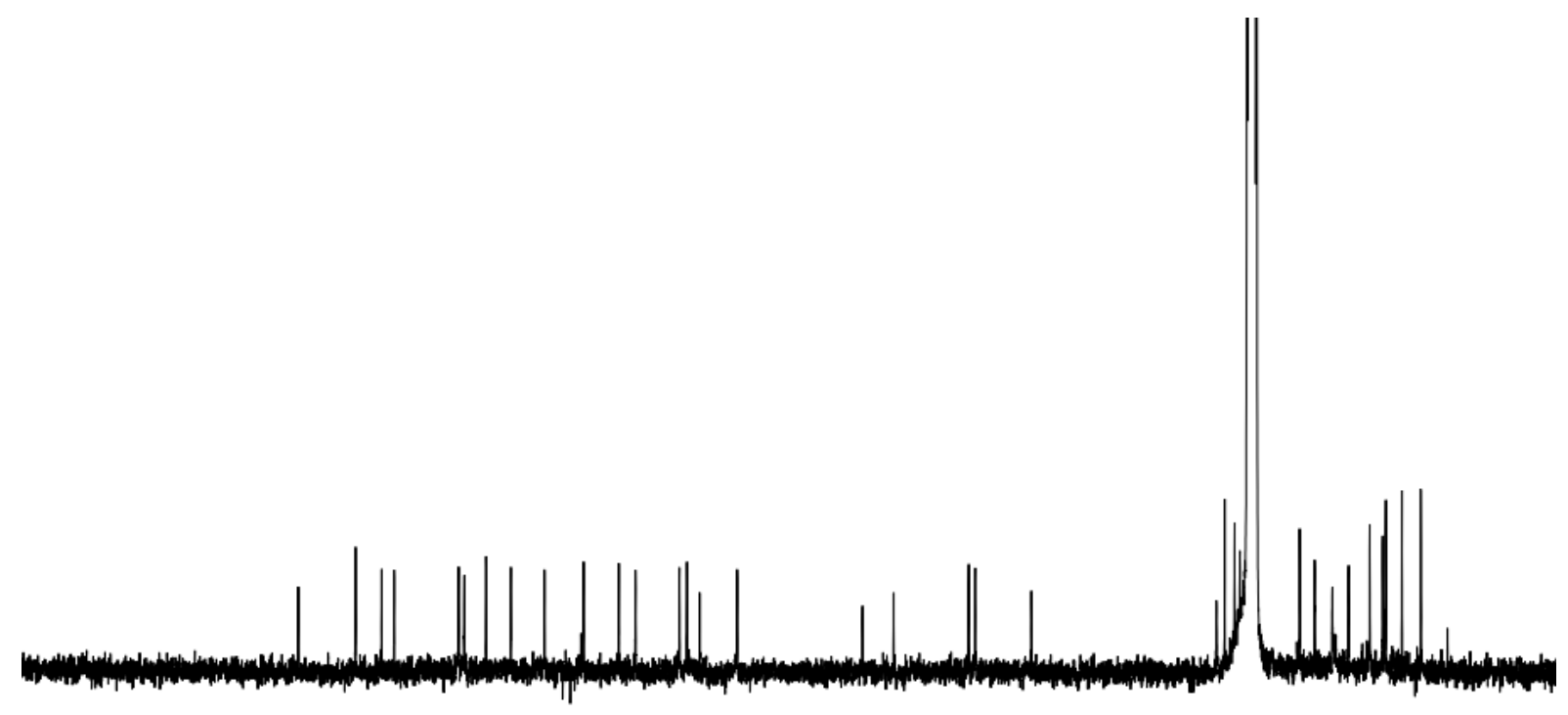

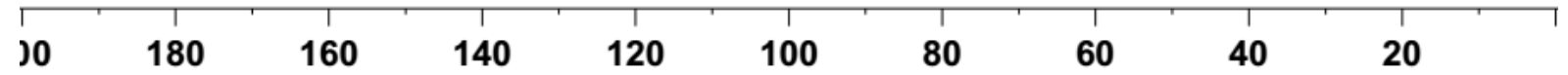

Callyspongiolide 1a (Synthetic Sample 1a, 100 MHz, DMSO-d6)

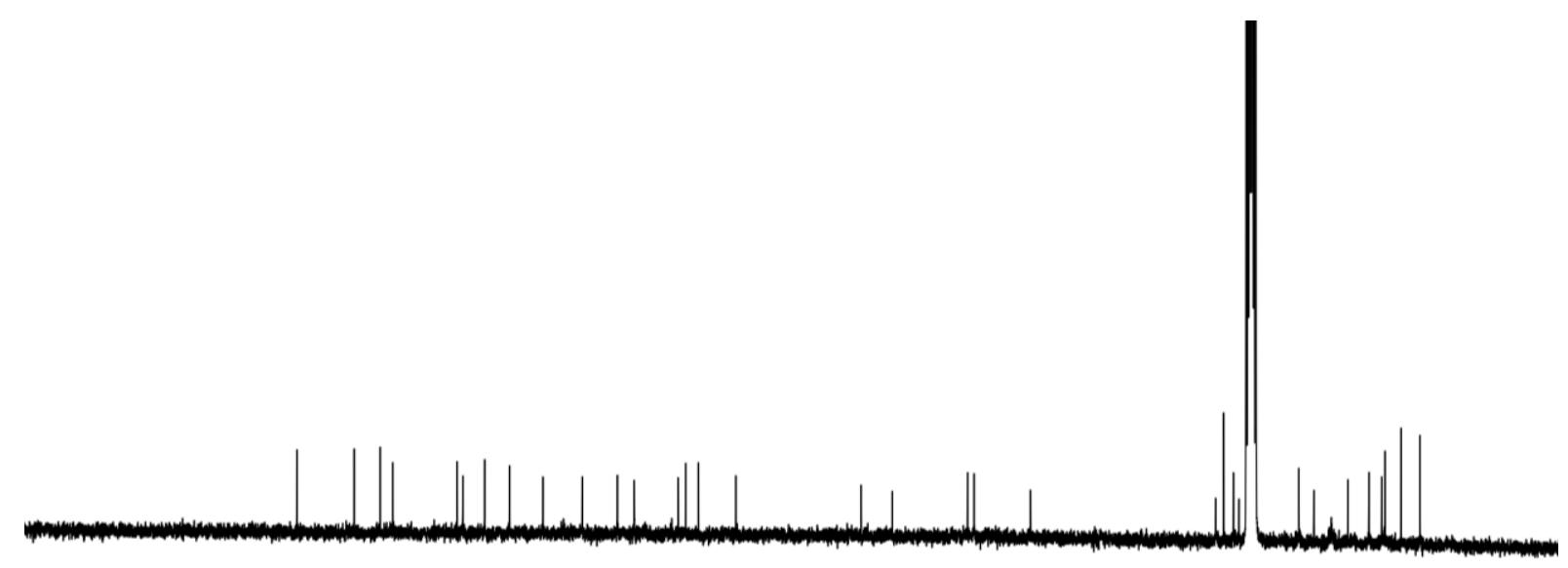

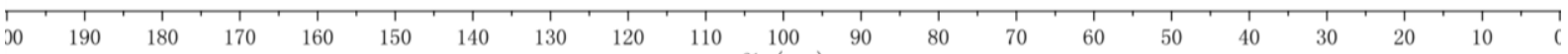


Callyspongiolide (Natural Product, $150 \mathrm{MHz}, \mathrm{DMSO}-d 6$ )

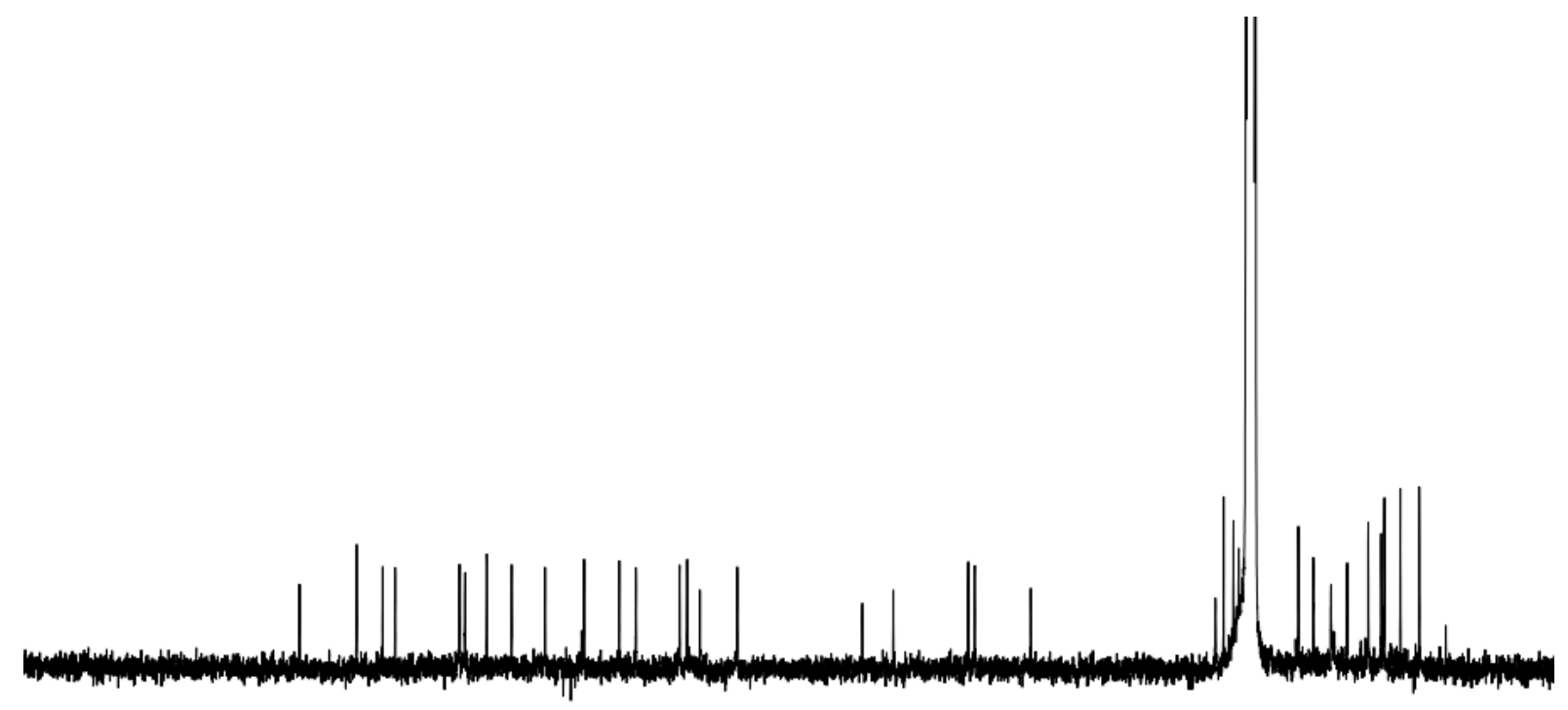

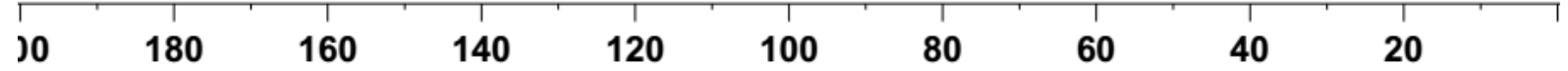

Callyspongiolide 1b (Synthetic Sample 1b, 100 MHz, DMSO- $d 6$ )

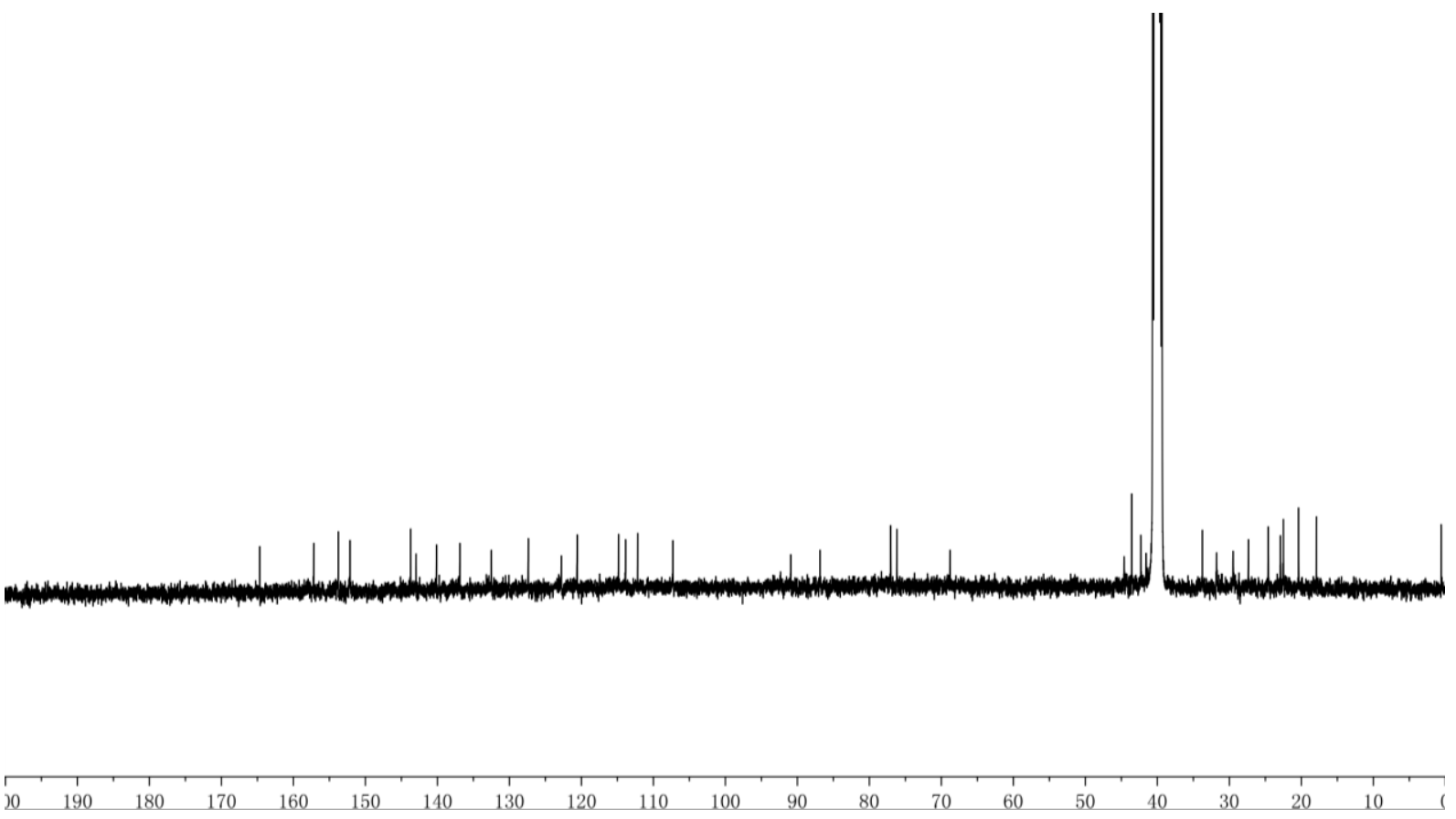


Callyspongiolide (Natural Product, $150 \mathrm{MHz}, \mathrm{DMSO}-d 6$ )

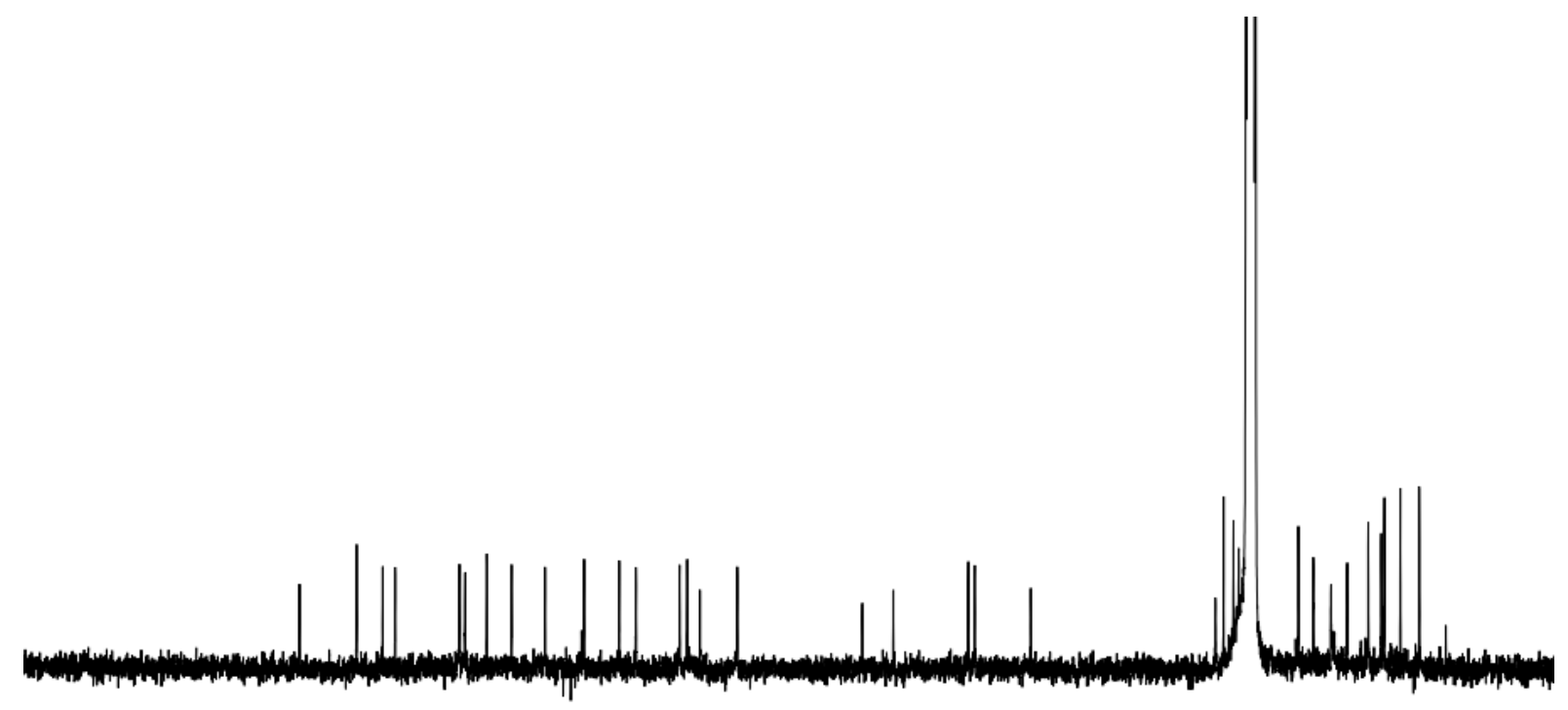

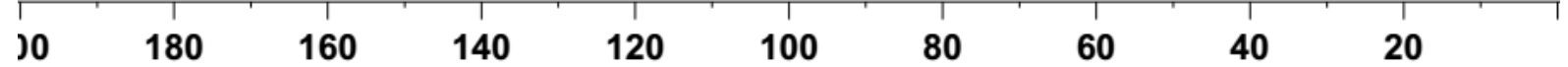

Callyspongiolide 1c (Synthetic Sample 1c, 100 MHz, DMSO-d6)

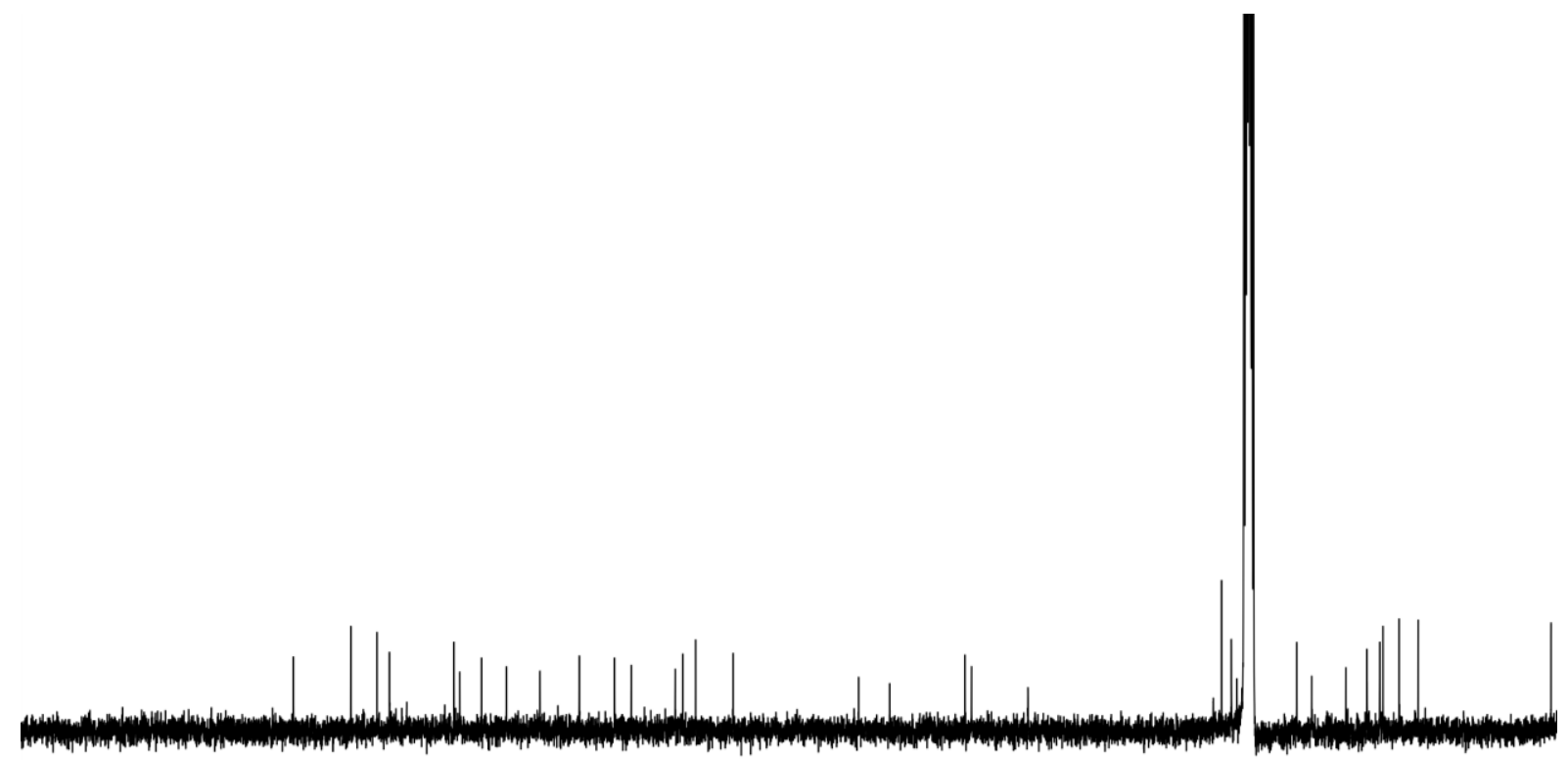

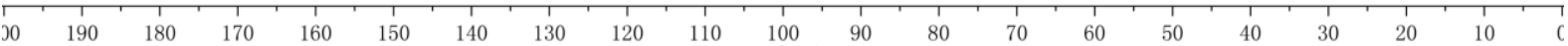


Callyspongiolide (Natural Product, $150 \mathrm{MHz}, \mathrm{DMSO}-d 6$ )

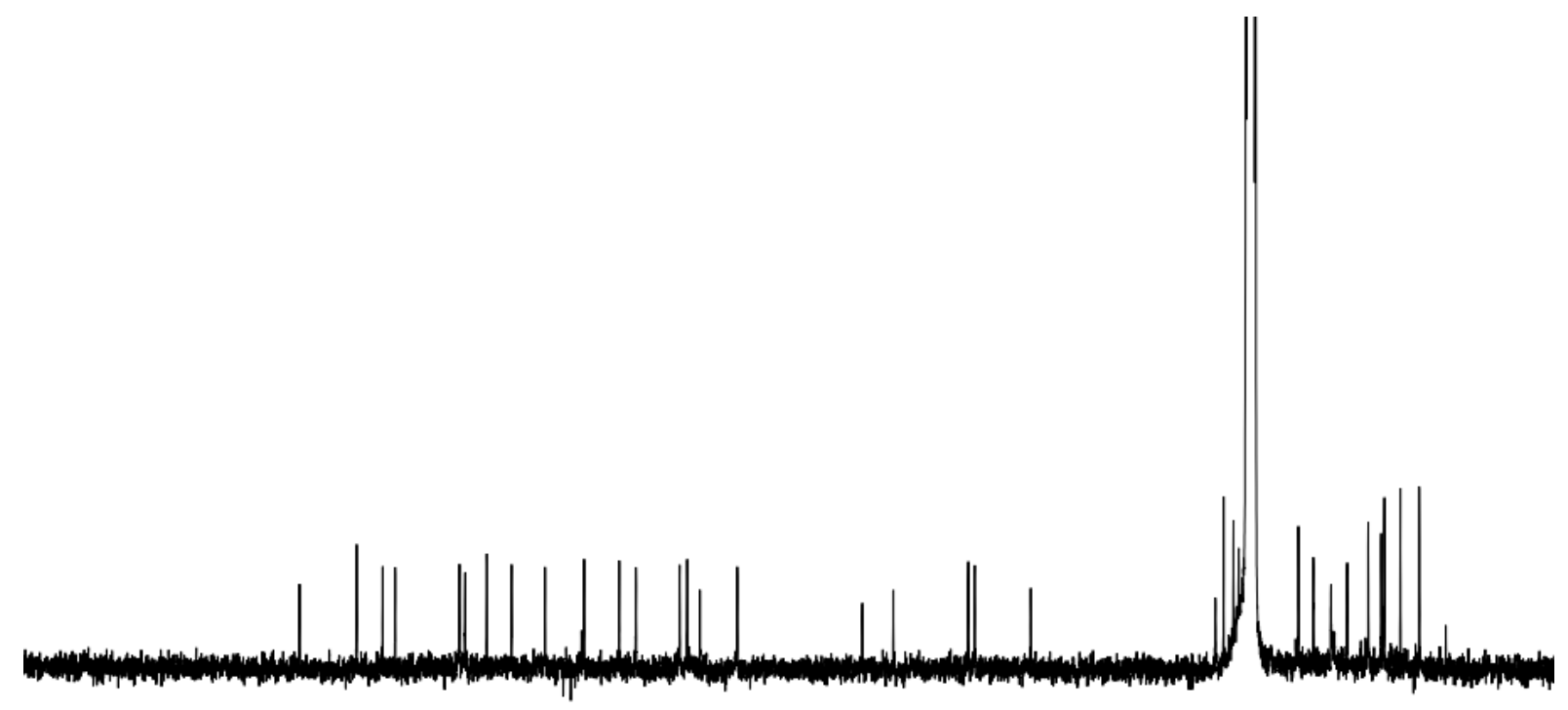

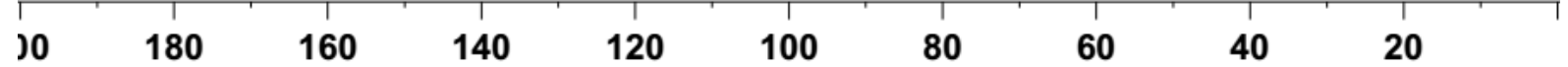

Callyspongiolide 1d (Synthetic Sample 1d, 100 MHz, DMSO- $d 6$ )

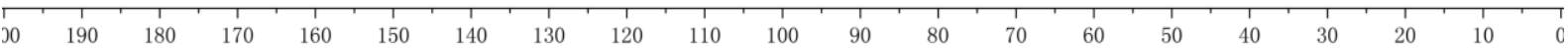




\section{Comparison of ${ }^{13} \mathrm{C}$ NMR Data of Natural, Synthetic Callyspongiolides 1a and 1b}

\begin{tabular}{|c|c|c|c|c|c|}
\hline 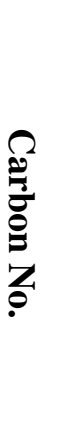 & Sీ & 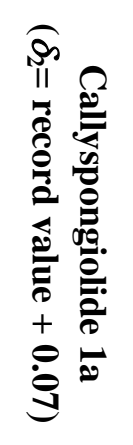 & $\begin{array}{l}\Delta \\
0 \\
\text { II } \\
\text { so } \\
1 \\
0\end{array}$ & 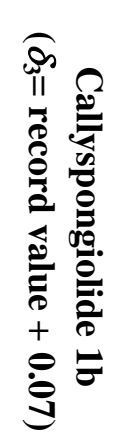 & $\begin{array}{l}\Delta_{n} \\
\text { II } \\
\infty \\
\infty_{0} \\
0\end{array}$ \\
\hline 1 & 164.15 & 164.15 & 0 & 164.15 & 0 \\
\hline 2 & 122.25 & 122.26 & 0.01 & 122.26 & 0.01 \\
\hline 3 & 142.45 & 142.45 & 0 & 142.45 & 0 \\
\hline 4 & 31.29 & 31.27 & -0.02 & 31.28 & -0.01 \\
\hline 5 & 26.85 & 26.83 & -0.02 & 26.84 & -0.01 \\
\hline 6 & 41.07 & 41.05 & -0.02 & 41.05 & -0.02 \\
\hline 7 & 68.32 & 68.28 & -0.04 & 68.31 & -0.01 \\
\hline 8 & 44.12 & 44.11 & -0.01 & 44.14 & 0.02 \\
\hline 9 & 33.23 & 33.23 & 0 & 33.24 & 0.01 \\
\hline 10 & 136.36 & 136.36 & 0 & 136.36 & 0 \\
\hline 11 & 131.98 & 131.99 & 0.01 & 131.98 & 0 \\
\hline 12 & 41.76 & 41.78 & 0.02 & 41.77 & 0.01 \\
\hline 13 & 75.68 & 75.67 & -0.01 & 75.68 & 0 \\
\hline 14 & 139.61 & 139.61 & 0 & 139.61 & 0 \\
\hline 15 & 113.35 & 113.35 & 0 & 113.35 & 0 \\
\hline 16 & 86.34 & 86.35 & 0.01 & 86.35 & 0.01 \\
\hline 17 & 90.41 & 90.41 & 0 & 90.41 & 0 \\
\hline 18 & 106.77 & 106.77 & 0 & 106.77 & 0 \\
\hline 19 & 151.62 & 151.61 & -0.01 & 151.62 & 0 \\
\hline 20 & 43.04 & 43.05 & 0.01 & 43.04 & 0 \\
\hline 21 & 76.53 & 76.52 & -0.01 & 76.53 & 0 \\
\hline 22 & 143.2 & 143.2 & 0 & 143.2 & 0 \\
\hline 23 & 111.68 & 111.66 & -0.02 & 111.68 & 0 \\
\hline 24 & 153.25 & 153.25 & 0 & 153.25 & 0 \\
\hline 25 & 114.33 & 114.32 & -0.01 & 114.33 & 0 \\
\hline 26 & 126.85 & 126.86 & 0.01 & 126.85 & 0 \\
\hline 27 & 120.06 & 120.07 & 0.01 & 120.07 & 0.01 \\
\hline 28 & 24.09 & 24.06 & -0.03 & 24.09 & 0 \\
\hline 29 & 22.4 & 22.41 & 0.01 & 22.4 & 0 \\
\hline 30 & 19.88 & 19.88 & 0 & 19.88 & 0 \\
\hline 31 & 21.98 & 21.99 & 0.01 & 21.99 & 0.01 \\
\hline 32 & 17.4 & 17.41 & 0.01 & 17.41 & 0.01 \\
\hline 33 & 156.66 & 156.66 & 0 & 156.66 & 0 \\
\hline
\end{tabular}


Comparison of ${ }^{13} \mathrm{C}$ NMR Data of Callyspongiolides

(Natural Product and Synthetic Samples 1a and 1b)

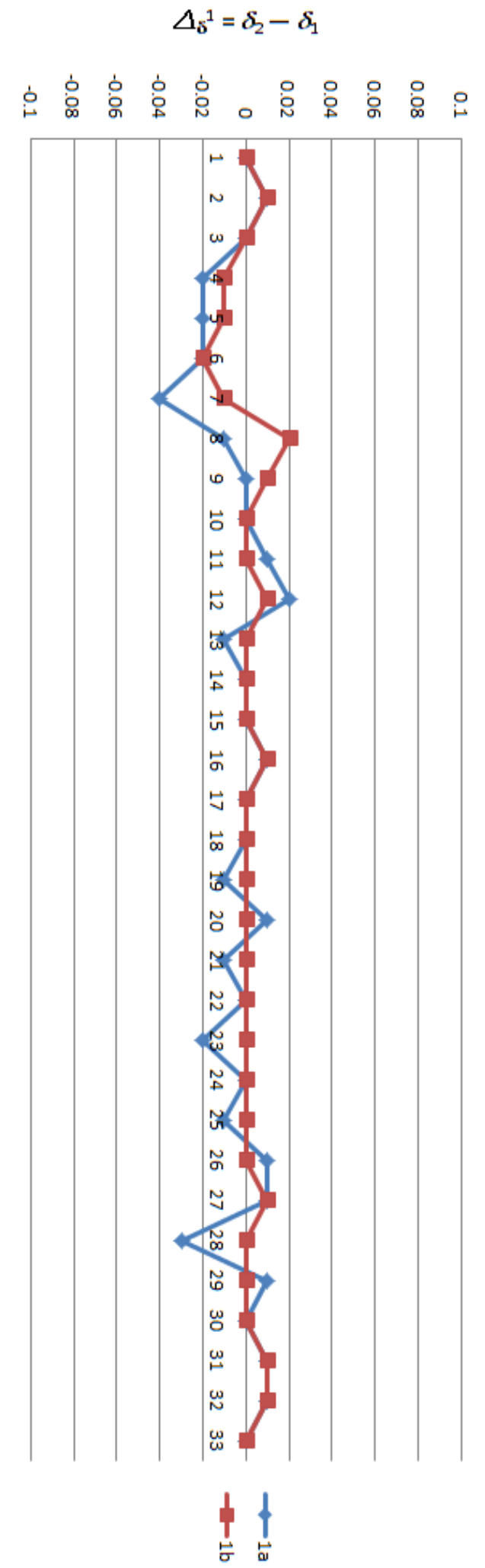


${ }^{1} \mathbf{H}$ NMR $\left(\mathrm{CDCl}_{3}, 500 \mathrm{MHz}\right)$

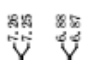

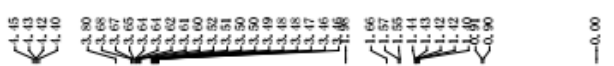
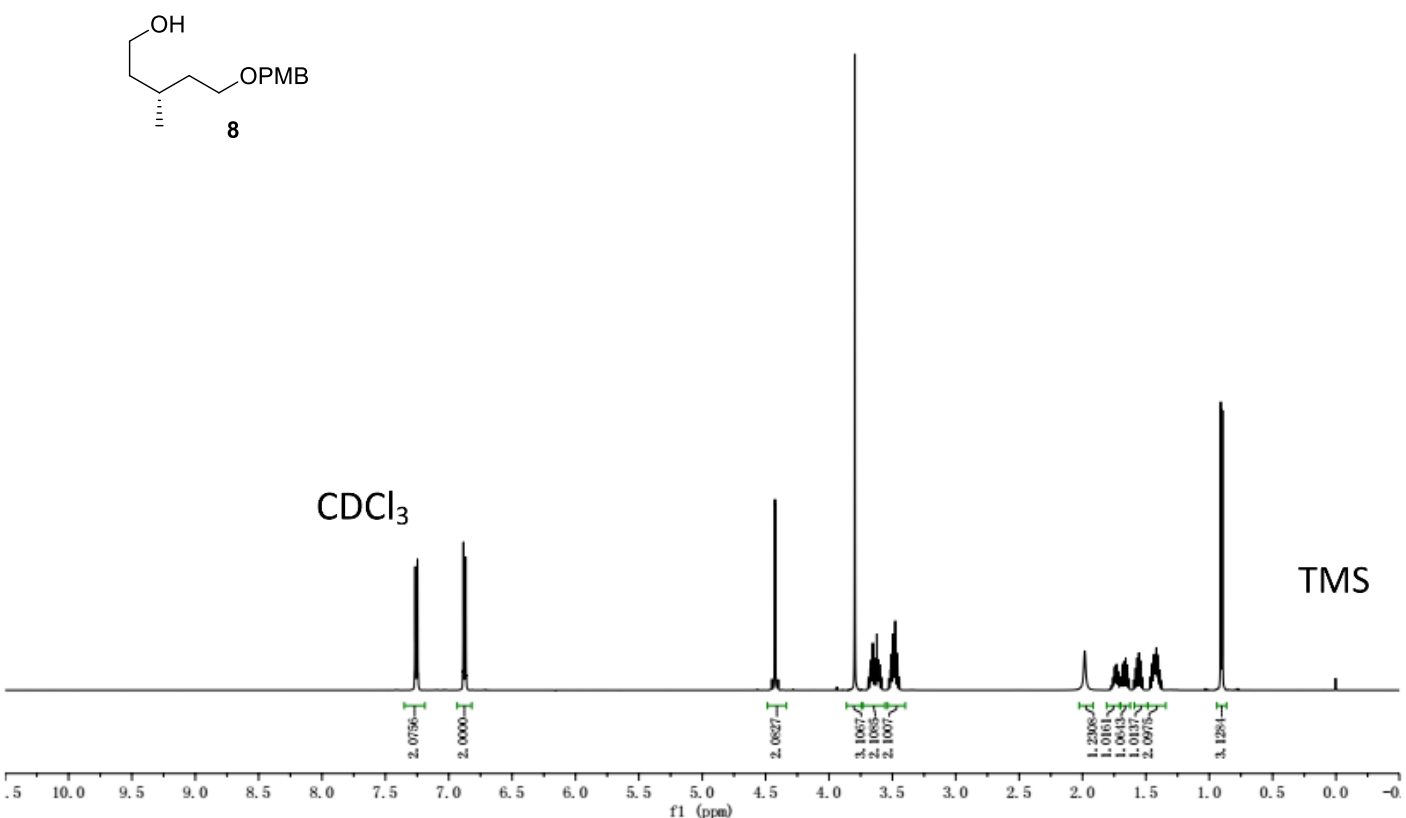

${ }^{13} \mathbf{C ~ N M R}\left(\mathrm{CDCl}_{3}, 125 \mathrm{MHz}\right)$

ㅎํำ

$\begin{array}{lll}\overline{0} & \frac{8}{20} & \frac{8}{2} \\ \frac{\alpha}{1} & \frac{8}{17}\end{array}$

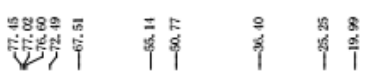
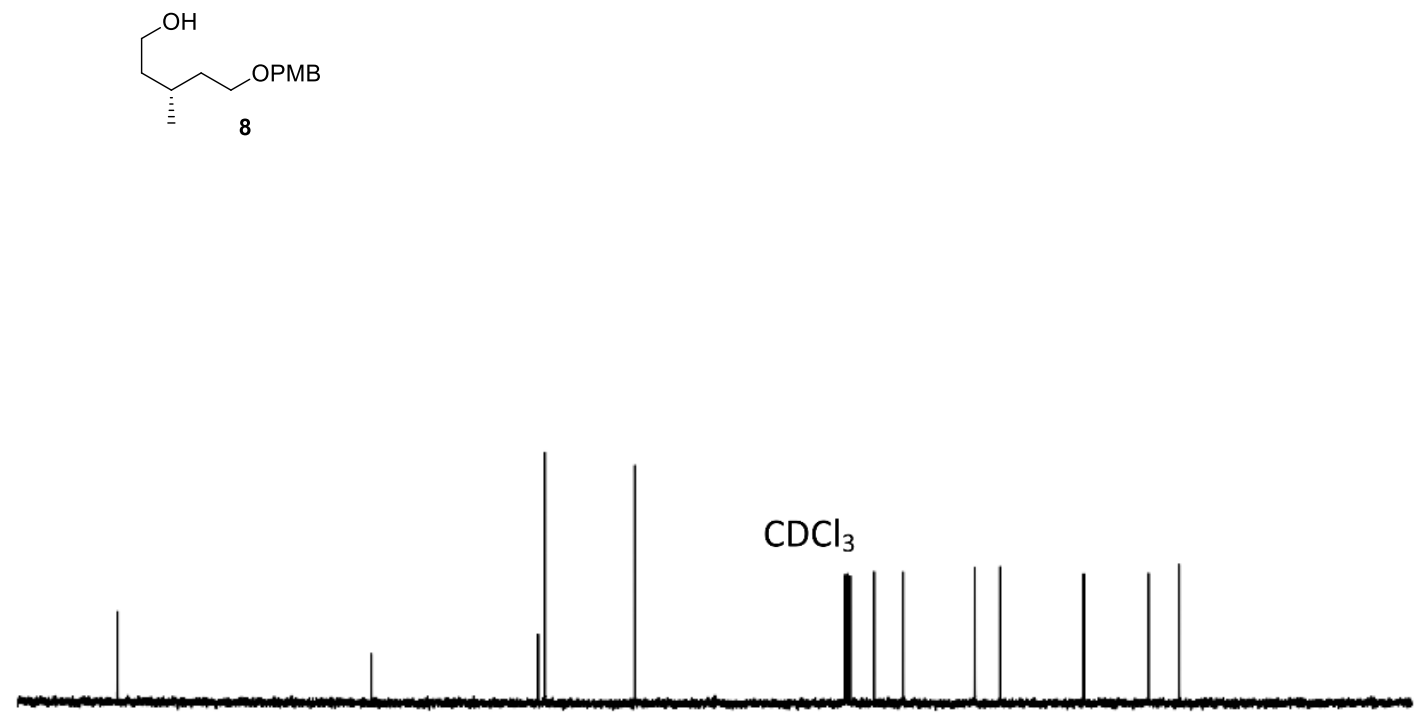

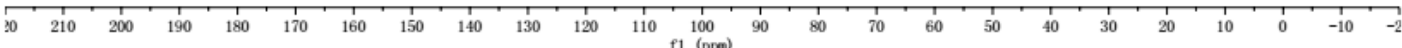


${ }^{1} \mathbf{H}$ NMR $\left(\mathrm{CDCl}_{3}, 500 \mathrm{MHz}\right)$

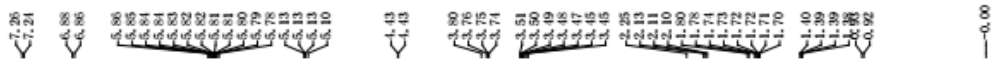

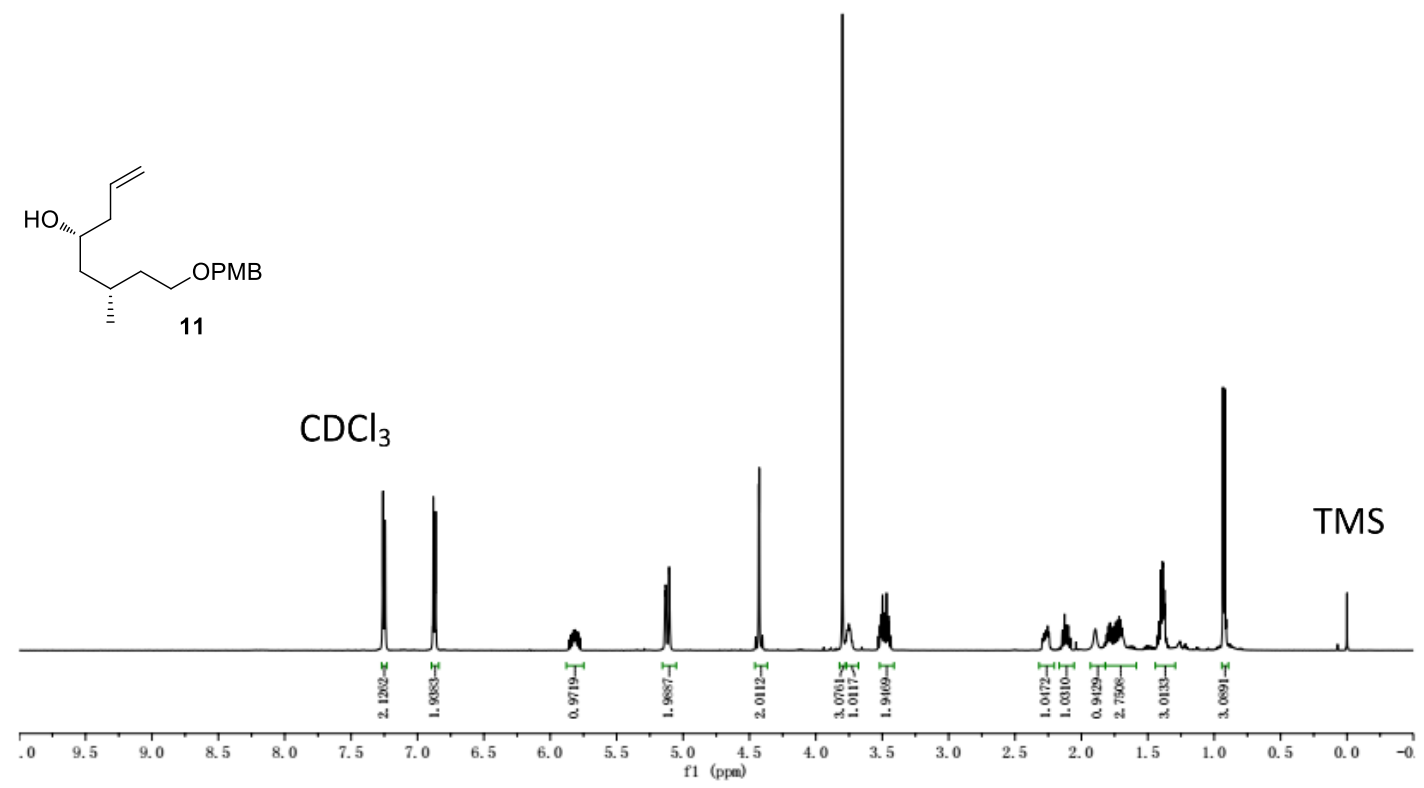

${ }^{13} \mathbf{C} \mathbf{N M R}\left(\mathrm{CDCl}_{3}, 125 \mathrm{MHz}\right)$

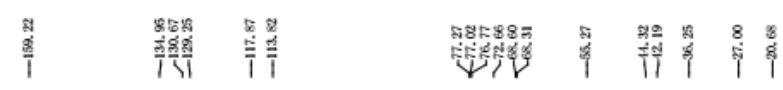

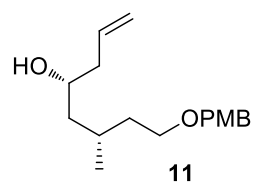

$\mathrm{CDCl}_{3}$

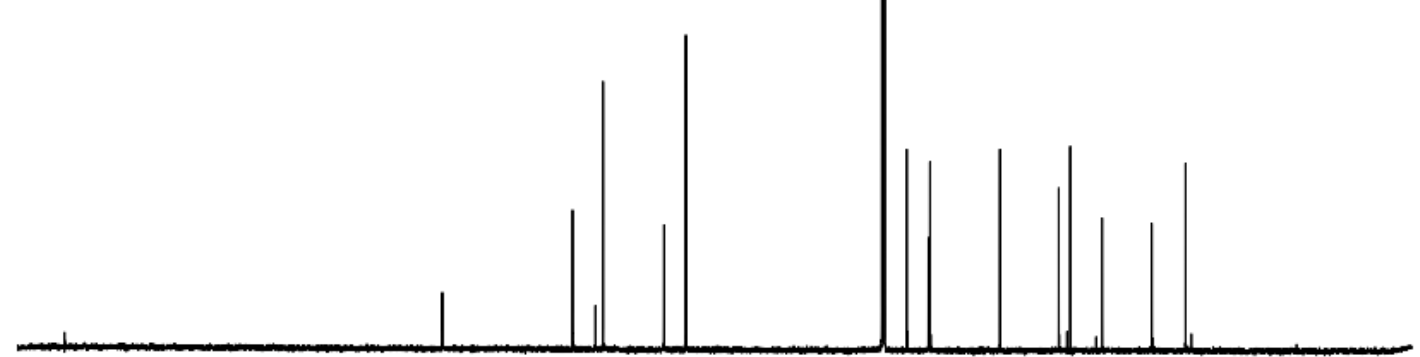

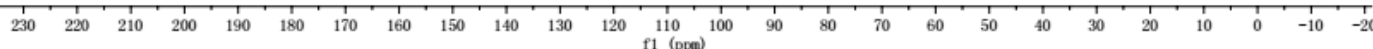


${ }^{1} \mathbf{H} \mathbf{N M R}\left(\mathrm{CDCl}_{3}, 500 \mathrm{MHz}\right)$

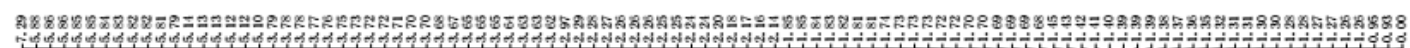
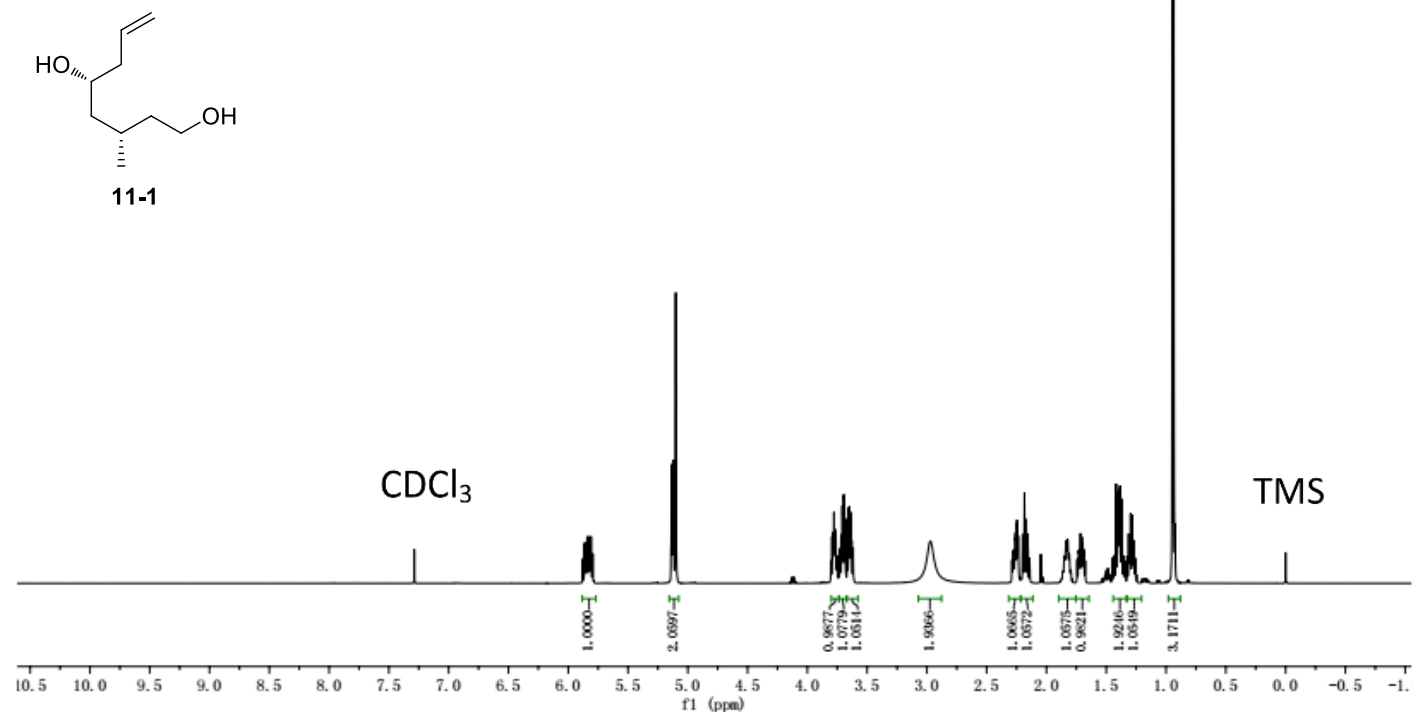

${ }^{13} \mathbf{C} \mathbf{N M R}\left(\mathrm{CDCl}_{3}, 125 \mathrm{MHz}\right)$
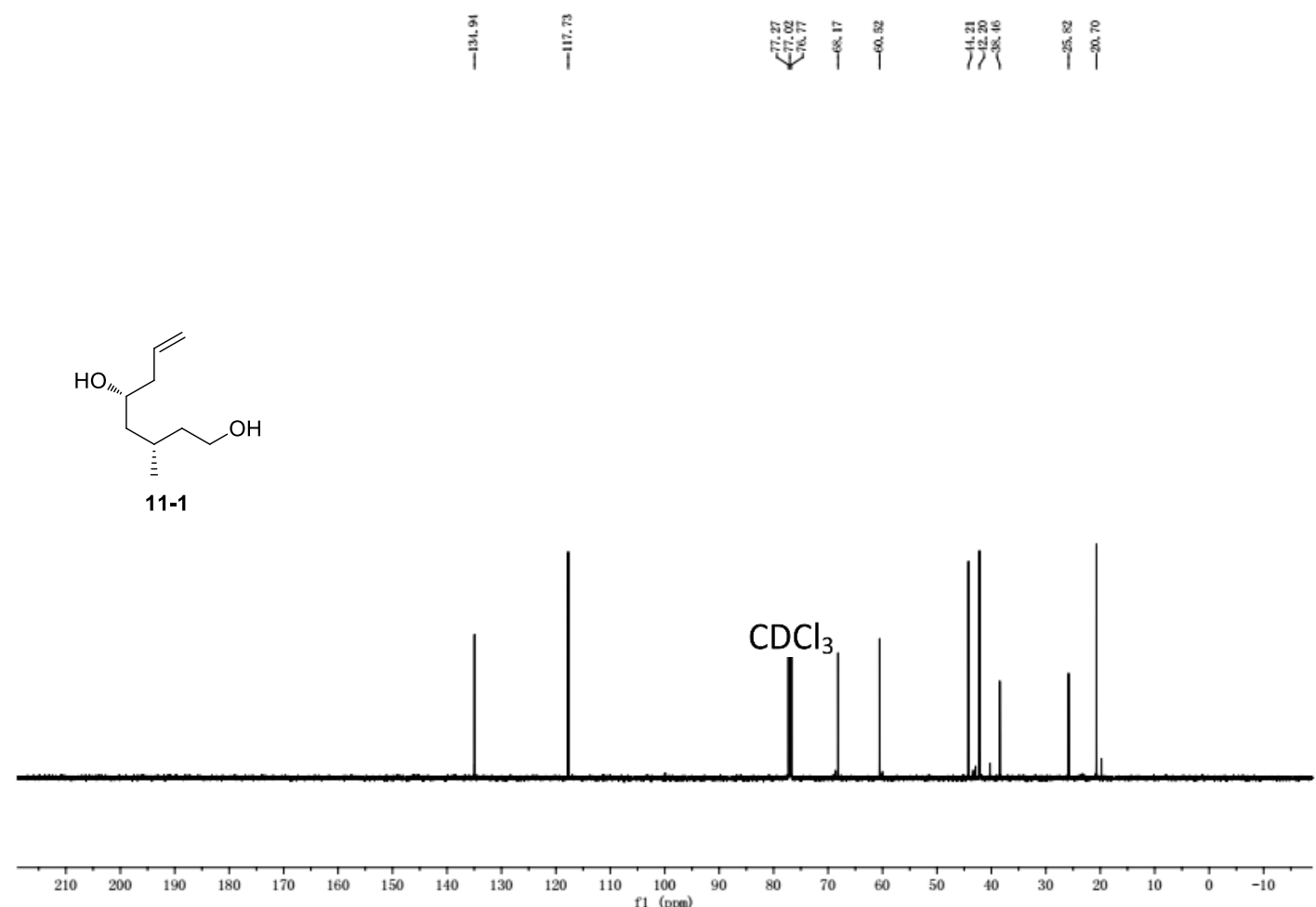
${ }^{1} \mathbf{H}$ NMR $\left(\mathrm{CDCl}_{3}, 500 \mathrm{MHz}\right)$

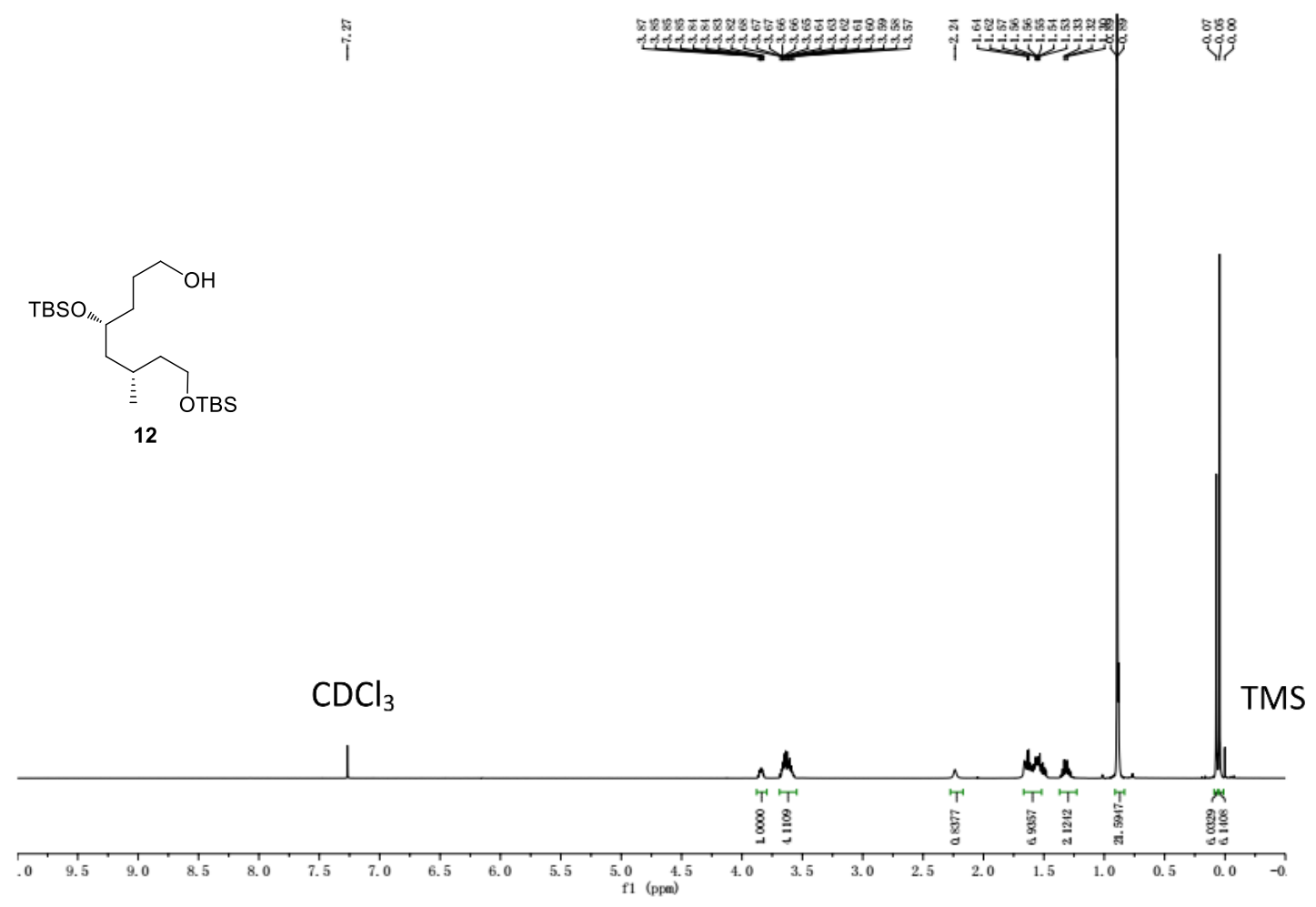

${ }^{13} \mathbf{C} \mathbf{N M R}\left(\mathrm{CDCl}_{3}, 125 \mathrm{MHz}\right)$

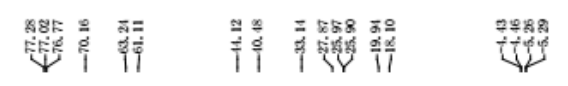

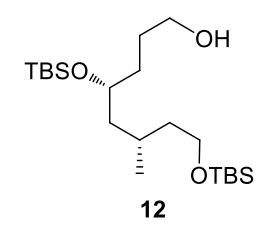

$\mathrm{CDCl}_{3}$

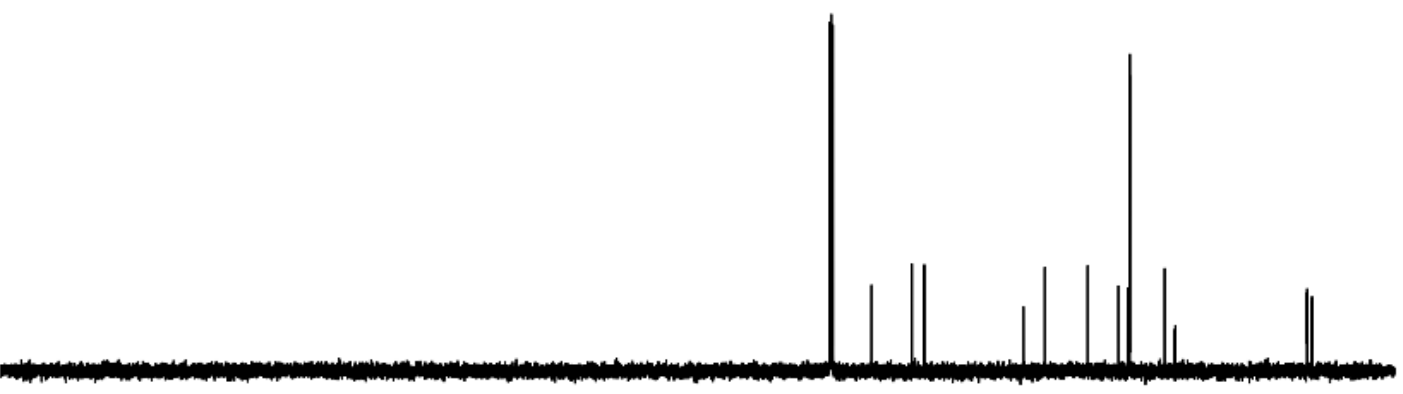

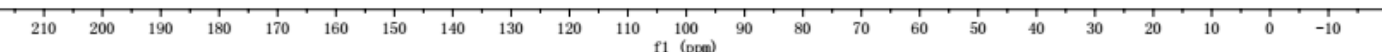


${ }^{1} \mathbf{H} \mathbf{N M R}\left(\mathrm{CDCl}_{3}, 500 \mathrm{MHz}\right)$

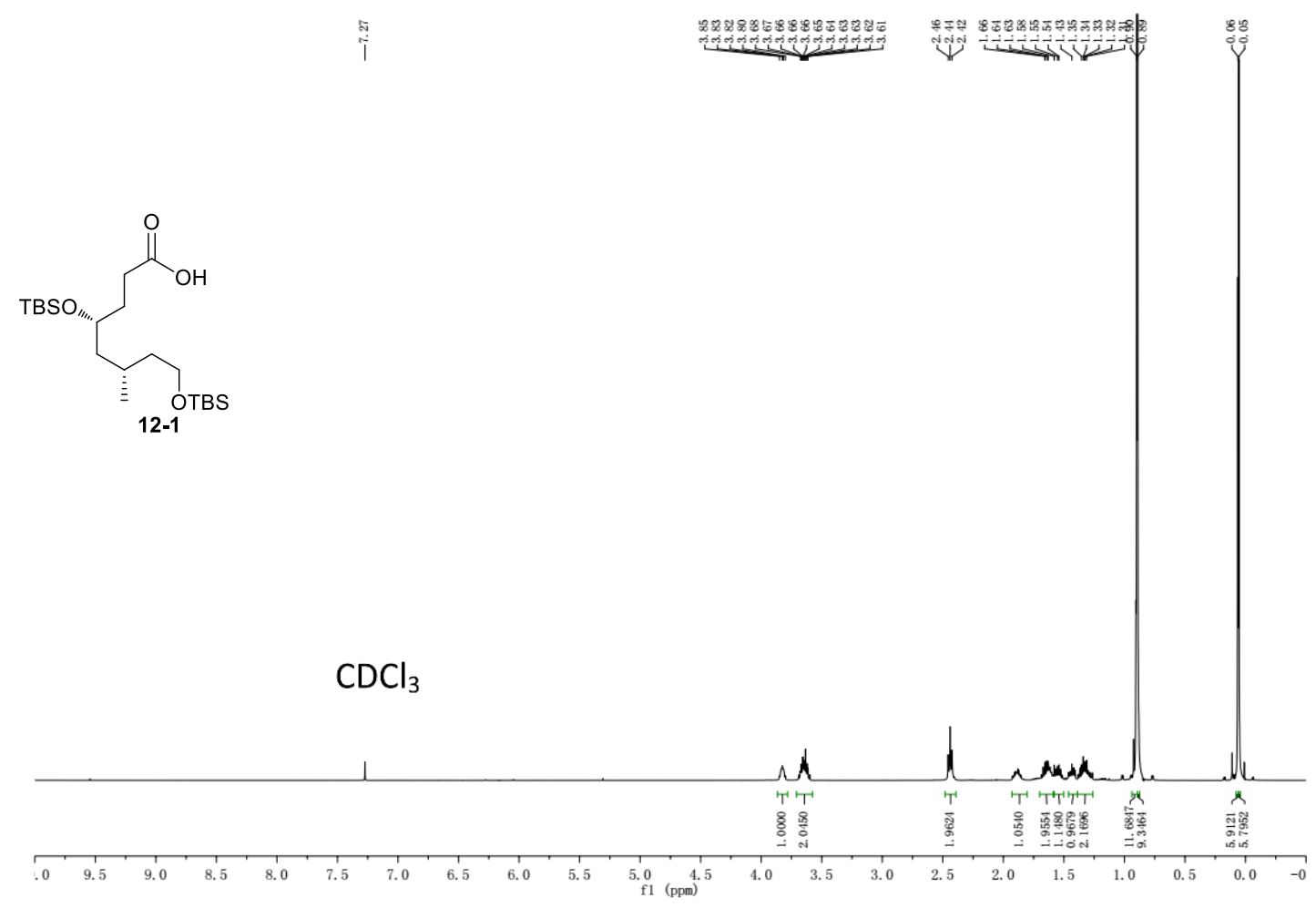

${ }^{13} \mathbf{C}$ NMR $\left(\mathrm{CDCl}_{3}, 125 \mathrm{MHz}\right)$

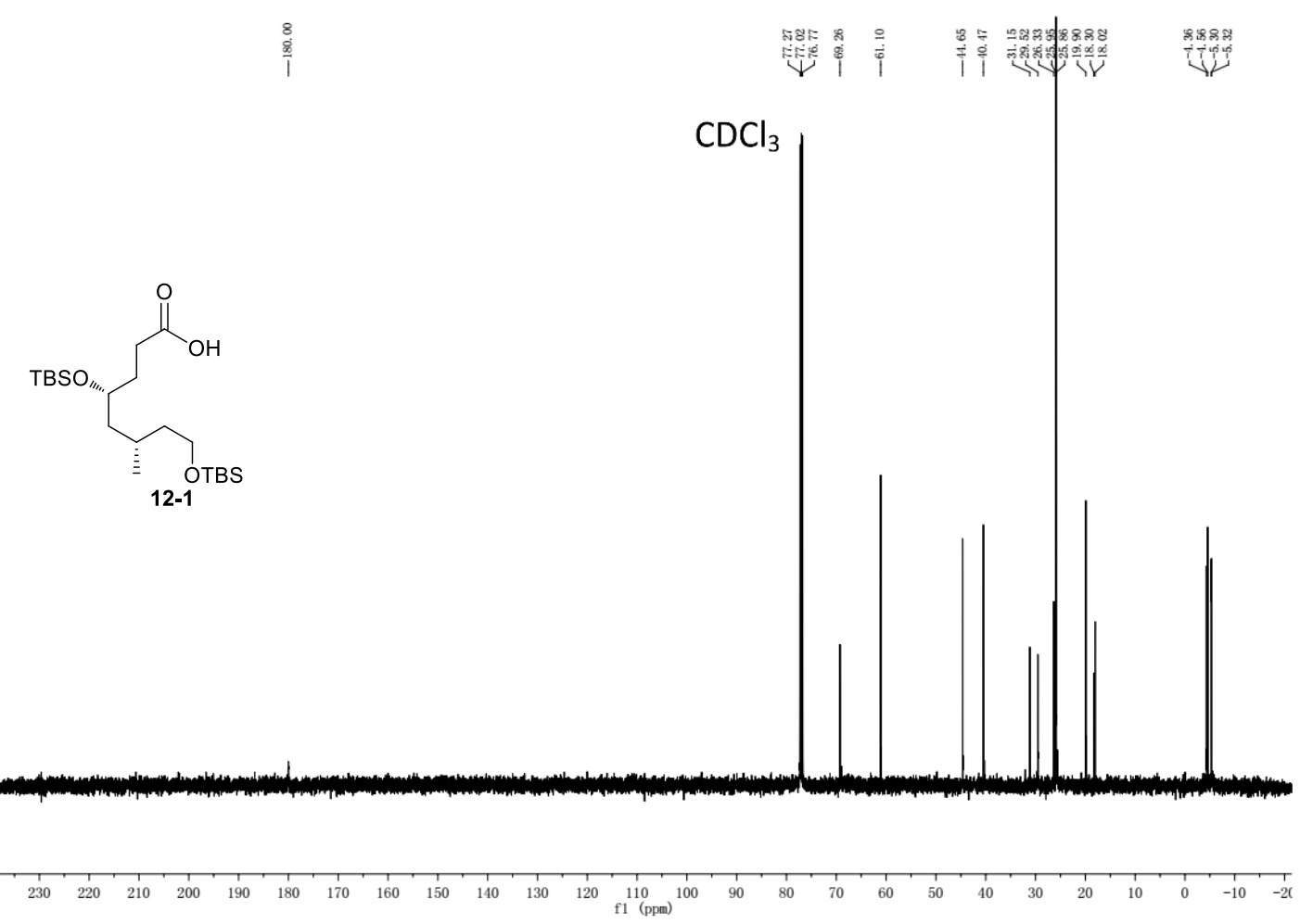


${ }^{1} \mathbf{H}$ NMR $\left(\mathrm{CDCl}_{3}, 500 \mathrm{MHz}\right)$

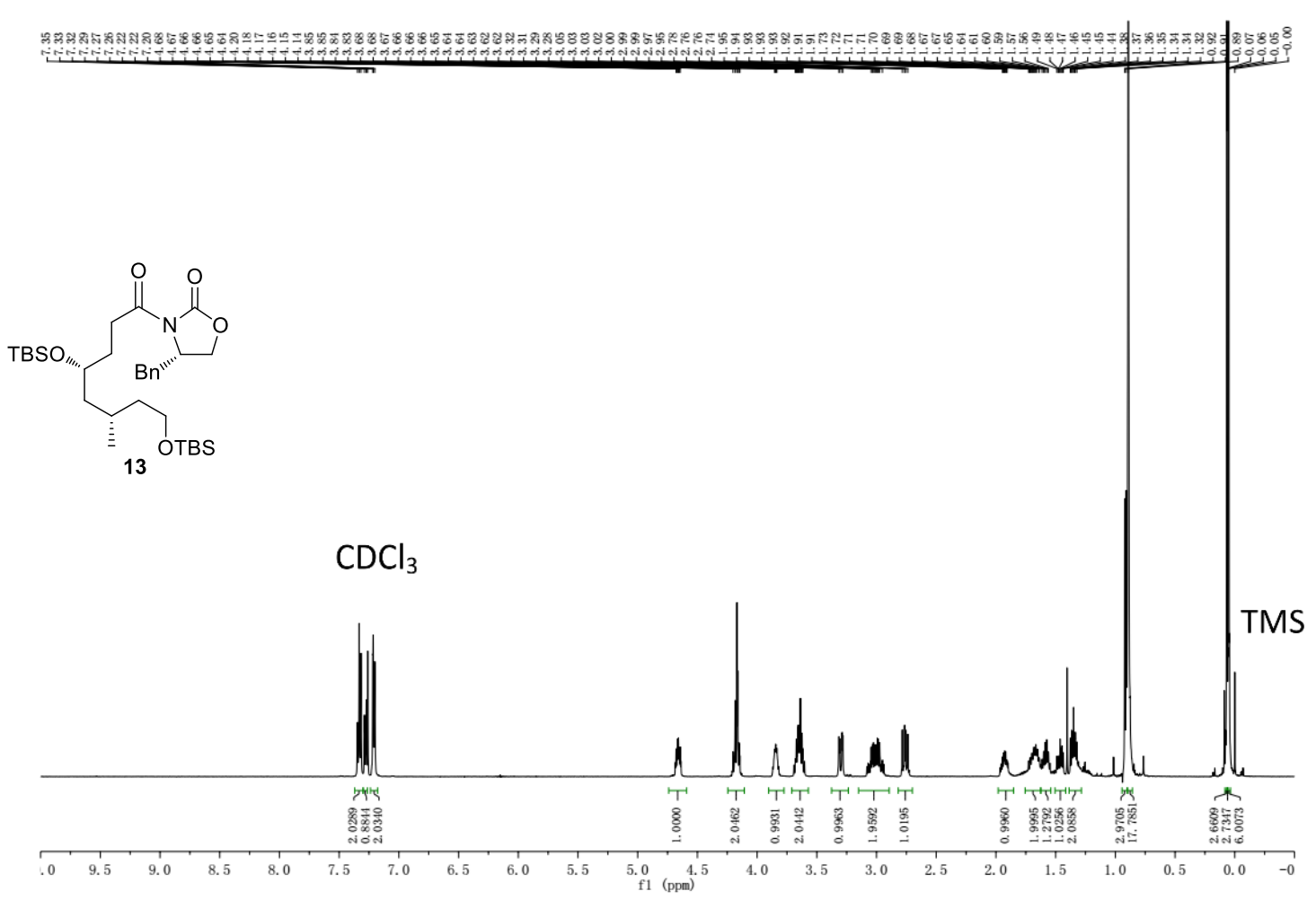

${ }^{13} \mathbf{C}$ NMR $\left(\mathrm{CDCl}_{3}, 125 \mathrm{MHz}\right)$

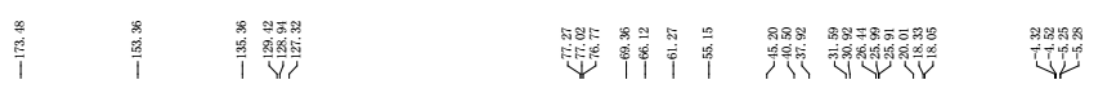

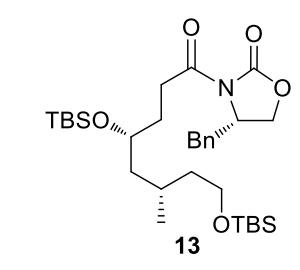

$\mathrm{CDCl}_{3}$

$\begin{array}{lllllllllllllllll}20 & 210 & 200 & 190 & 180 & 170 & 160 & 150 & 140 & 130 & 120 & 110 & 100 & 1 \\ \mathrm{f} 1(\mathrm{ppm}) & 90\end{array}$ 
${ }^{1} \mathbf{H} \mathbf{N M R}\left(\mathrm{CDCl}_{3}, 500 \mathrm{MHz}\right)$

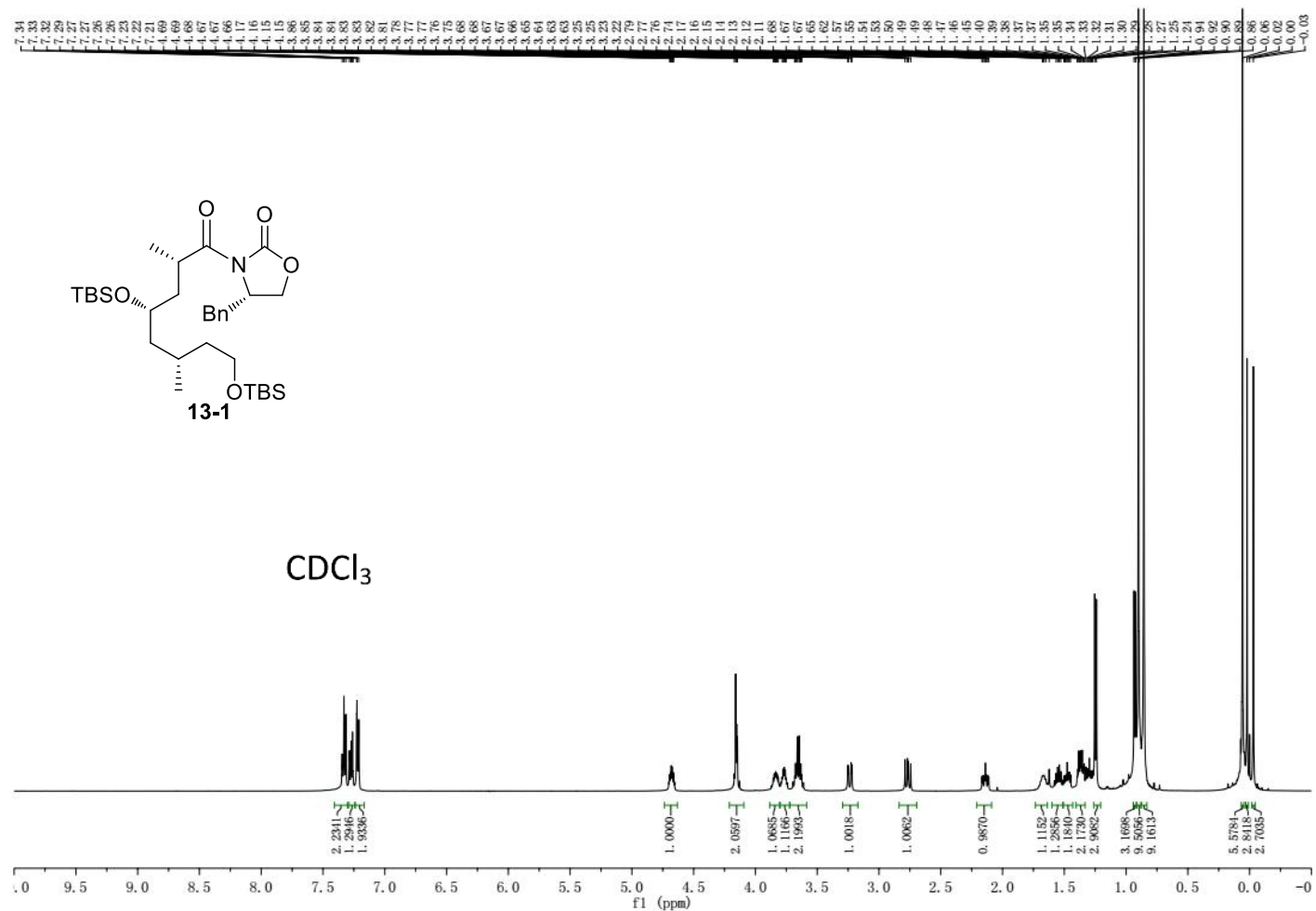

${ }^{13} \mathbf{C} \mathbf{N M R}\left(\mathrm{CDCl}_{3}, 125 \mathrm{MHz}\right)$

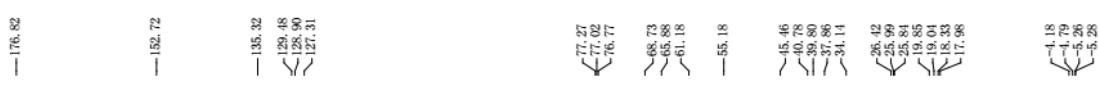

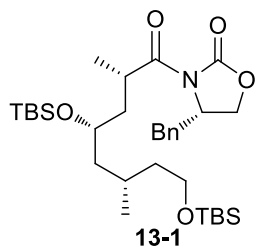

$\mathrm{CDCl}_{3}$

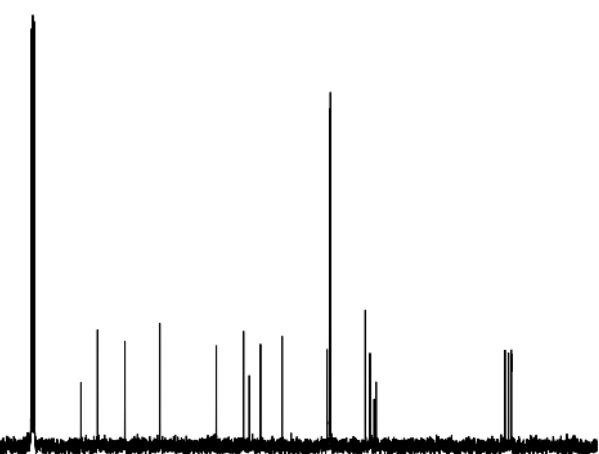

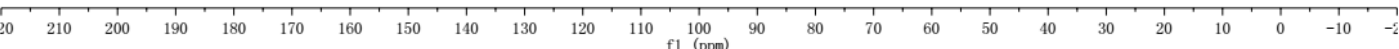


${ }^{1} \mathbf{H}$ NMR $\left(\mathrm{CDCl}_{3}, 500 \mathrm{MHz}\right)$

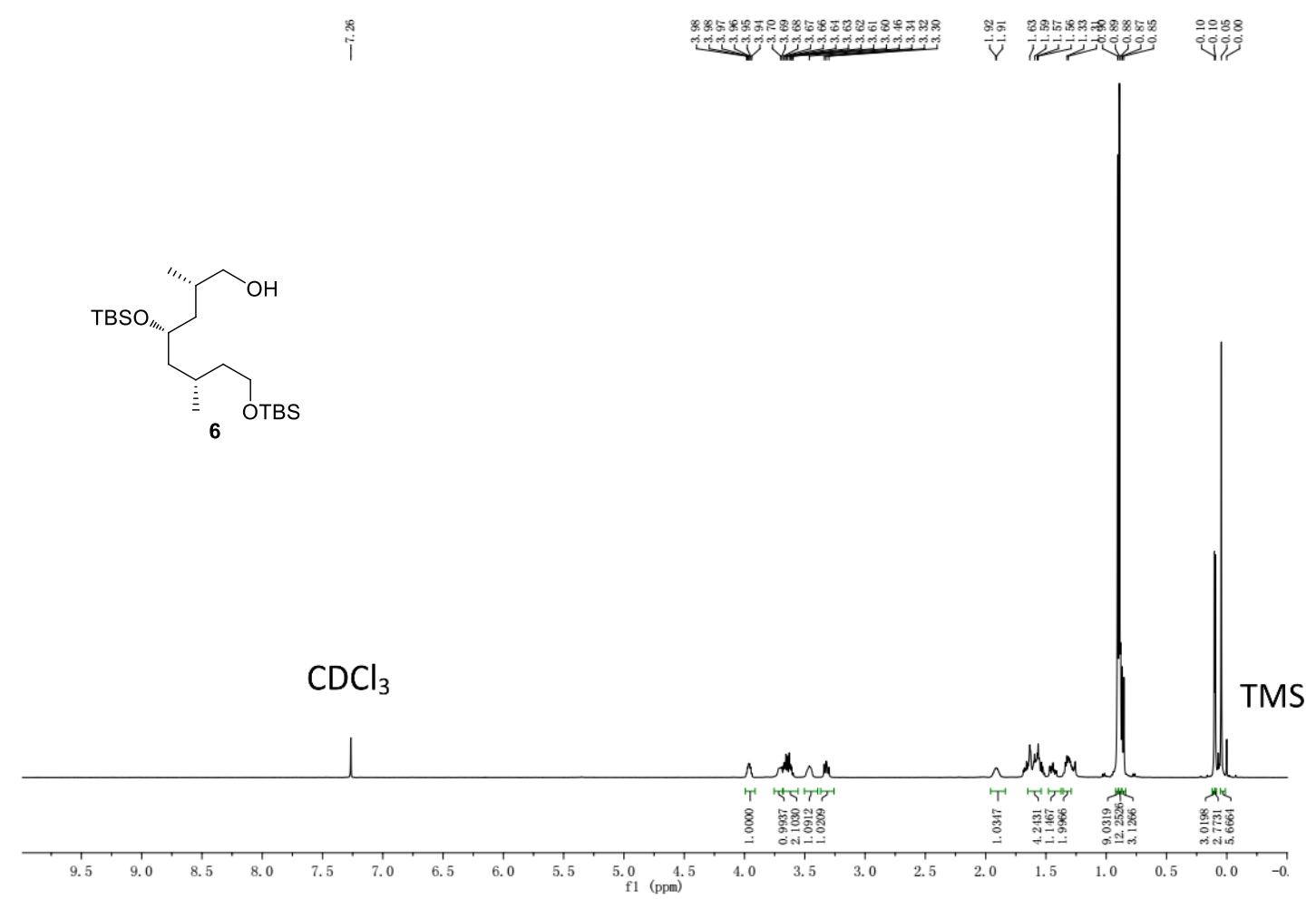

${ }^{13} \mathbf{C}$ NMR $\left(\mathrm{CDCl}_{3}, 125 \mathrm{MHz}\right)$

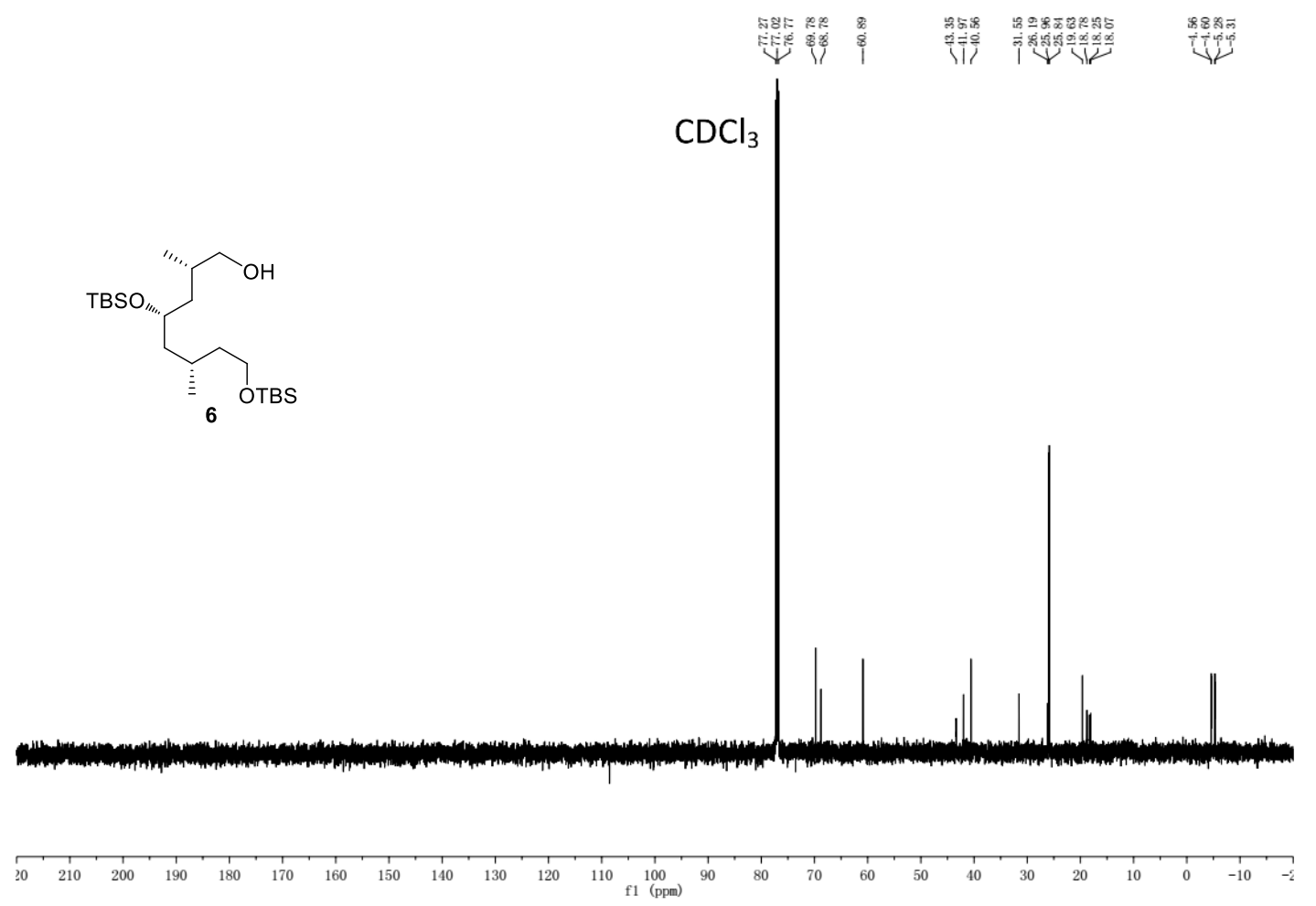


${ }^{1} \mathbf{H}$ NMR $\left(\mathrm{CDCl}_{3}, 500 \mathrm{MHz}\right)$

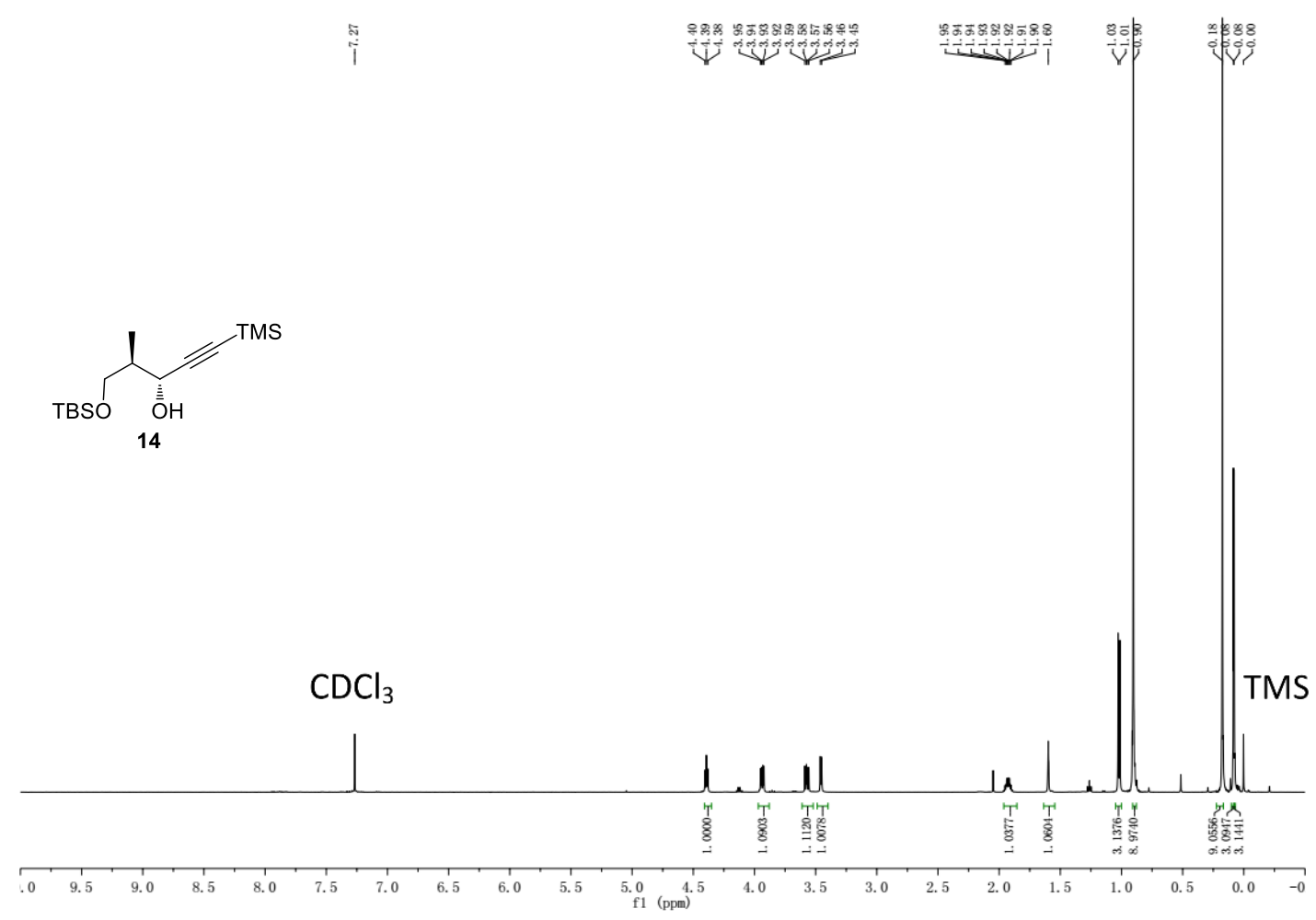

${ }^{13} \mathbf{C} \mathbf{N M R}\left(\mathrm{CDCl}_{3}, 125 \mathrm{MHz}\right)$

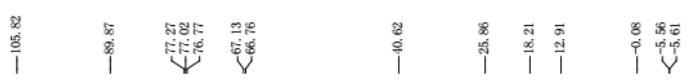

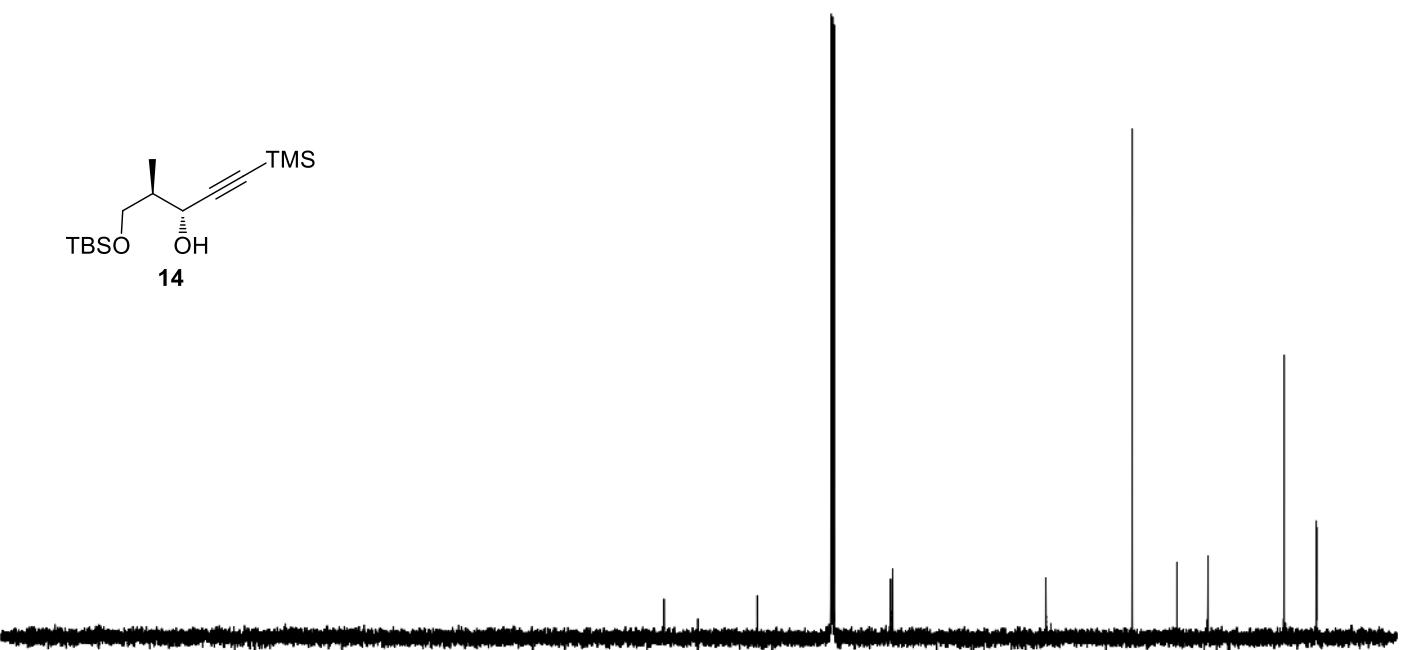

$\mathrm{CDCl}_{3}$

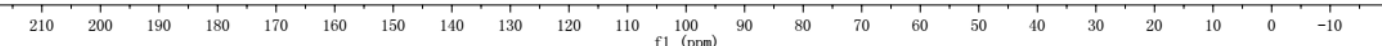


${ }^{1} \mathbf{H} \mathbf{N M R}\left(\mathrm{CDCl}_{3}, 500 \mathrm{MHz}\right)$

8ำ

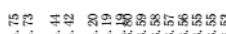

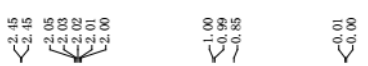

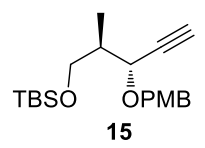

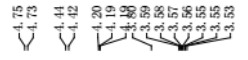

$\checkmark$

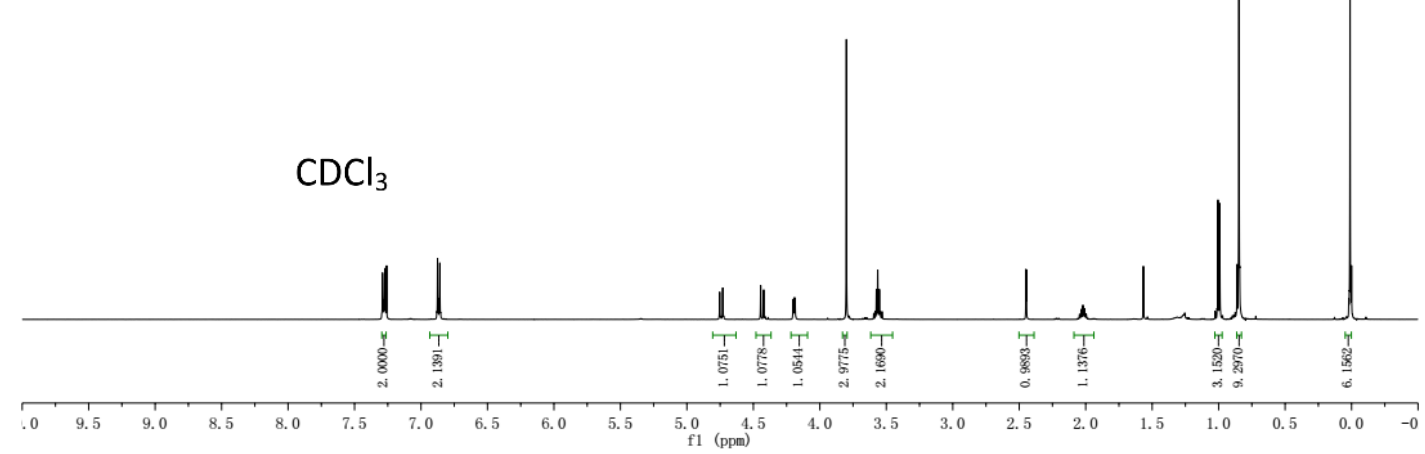

${ }^{13} \mathbf{C}$ NMR $\left(\mathrm{CDCl}_{3}, 125 \mathrm{MHz}\right)$

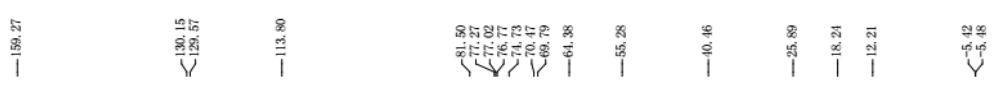
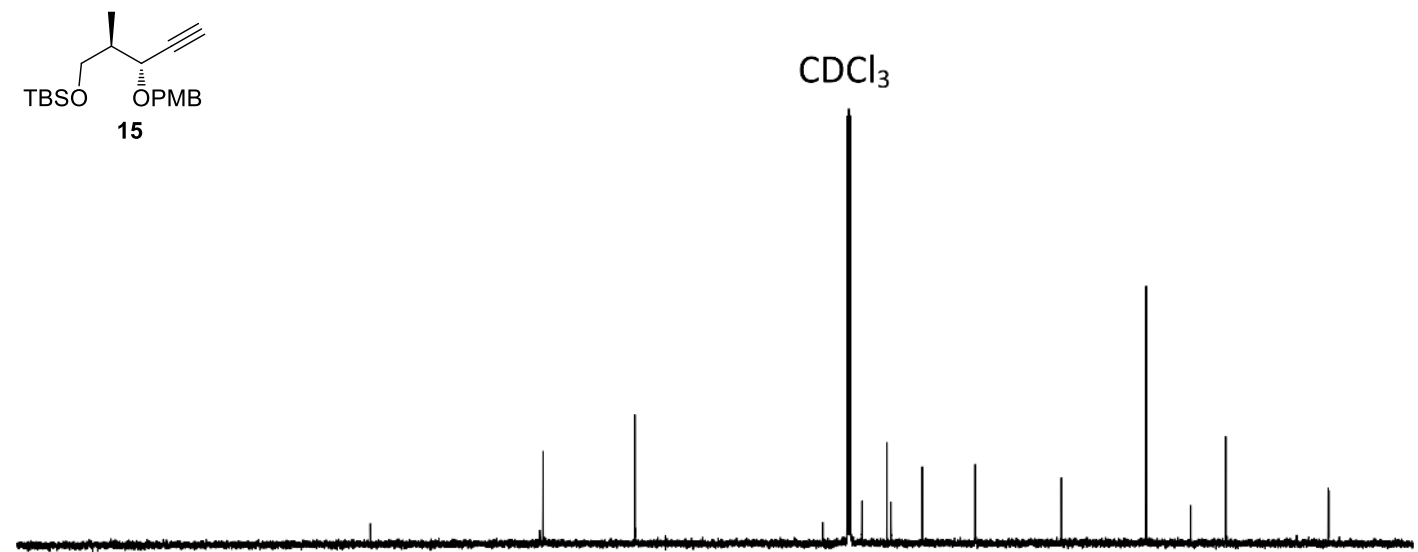

$\begin{array}{lllllllllllll}20 & 210 & 200 & 190 & 180 & 170 & 160 & 150 & 140 & 130 & 120 & 110 & 100 \\ \mathrm{f} 1(\mathrm{ppm}) & 1\end{array}$ 
${ }^{1} \mathbf{H}$ NMR $\left(\mathrm{CDCl}_{3}, 400 \mathrm{MHz}\right)$

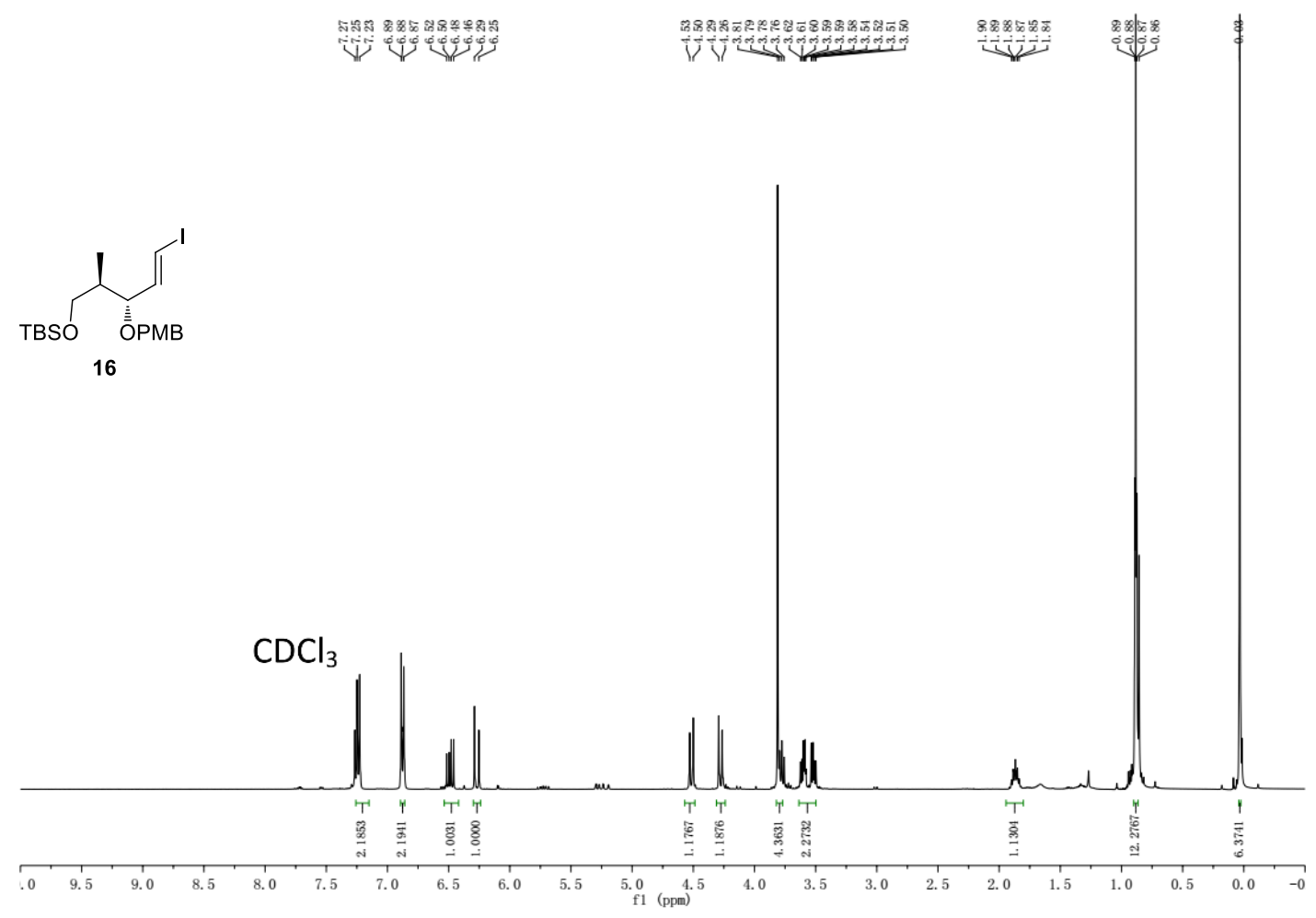

${ }^{13} \mathbf{C ~ N M R}\left(\mathrm{CDCl}_{3}, 100 \mathrm{MHz}\right)$

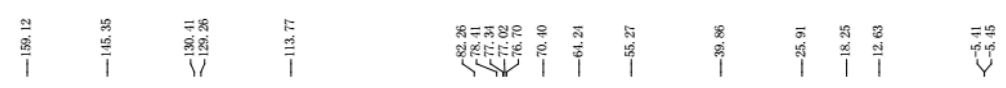
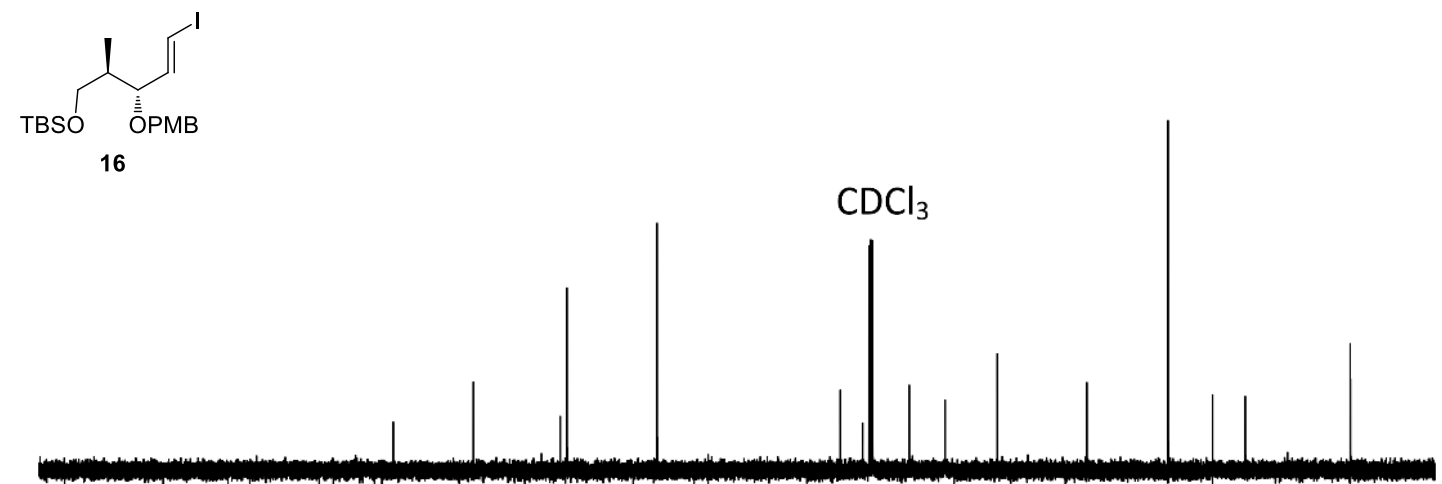

\begin{tabular}{lllllllllllllllllllllllllllll}
20 & 210 & 200 & 190 & 180 & 170 & 160 & 150 & 140 & 130 & 120 & 110 & 100 & 90 & 80 & 70 & 60 & 50 & 40 & 1 & 1 & 1 & 1 & 1 & 1 & 1 & 1 & 1 & 1 \\
\hline
\end{tabular} 
${ }^{1} \mathbf{H}$ NMR $\left(\mathrm{CDCl}_{3}, 400 \mathrm{MHz}\right)$

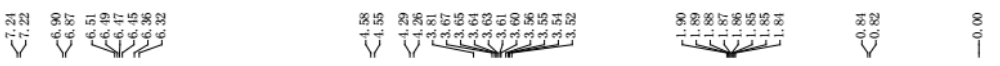
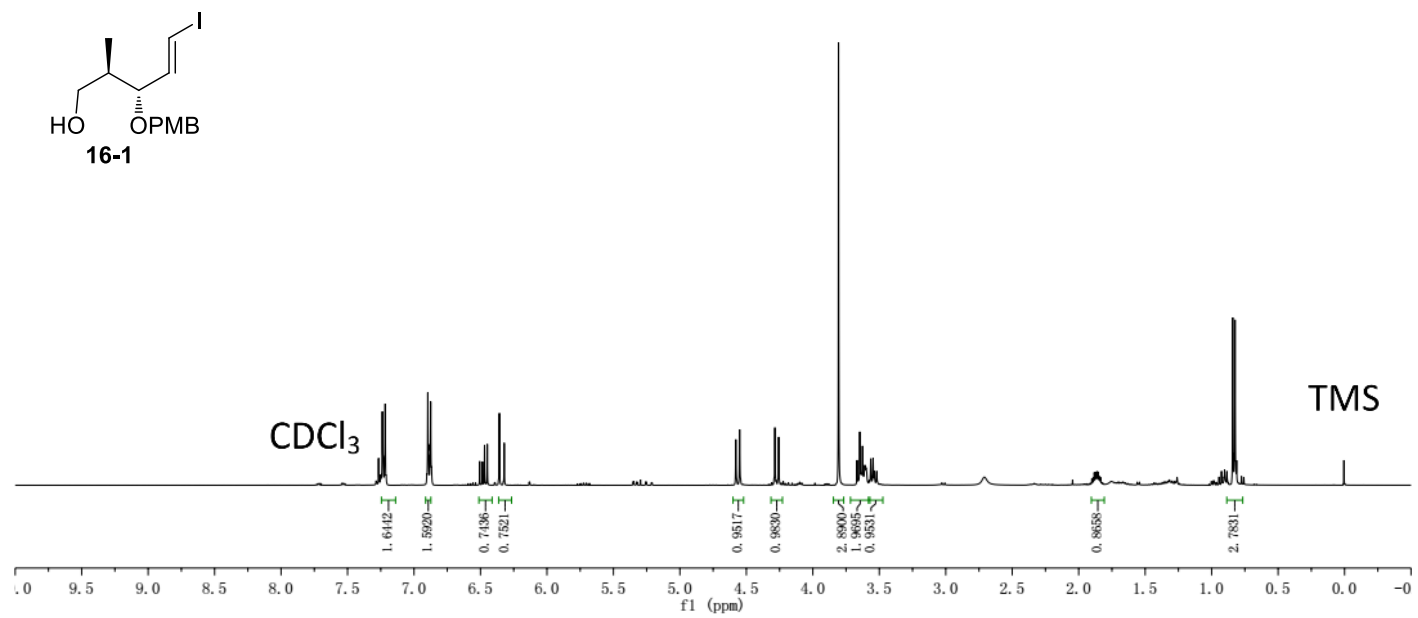

${ }^{13} \mathbf{C ~ N M R}\left(\mathrm{CDCl}_{3}, 100 \mathrm{MHz}\right)$

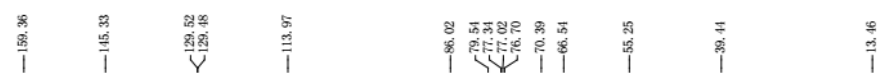

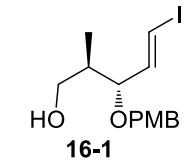

$\mathrm{CDCl}_{3}$

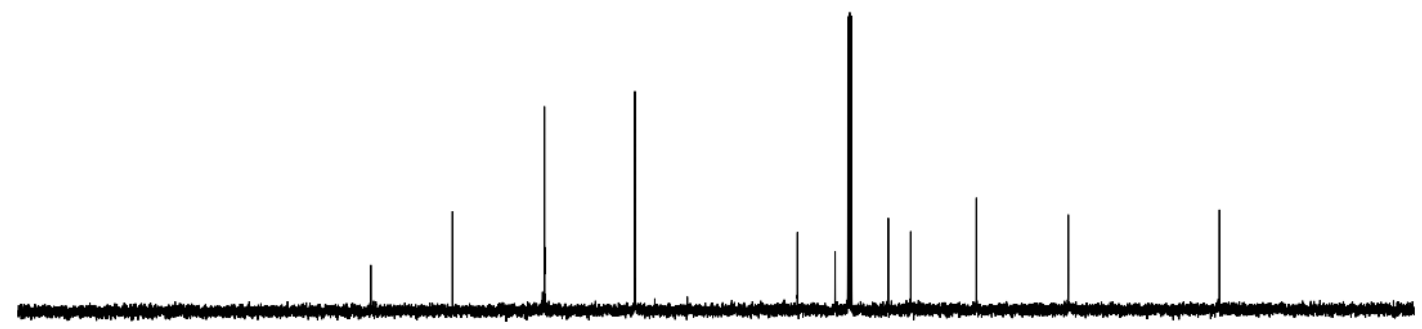

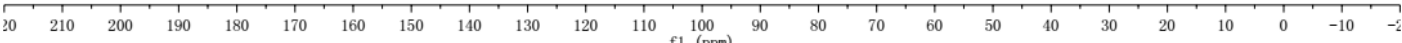


${ }^{1} \mathbf{H}$ NMR $\left(\mathrm{CDCl}_{3}, 400 \mathrm{MHz}\right)$

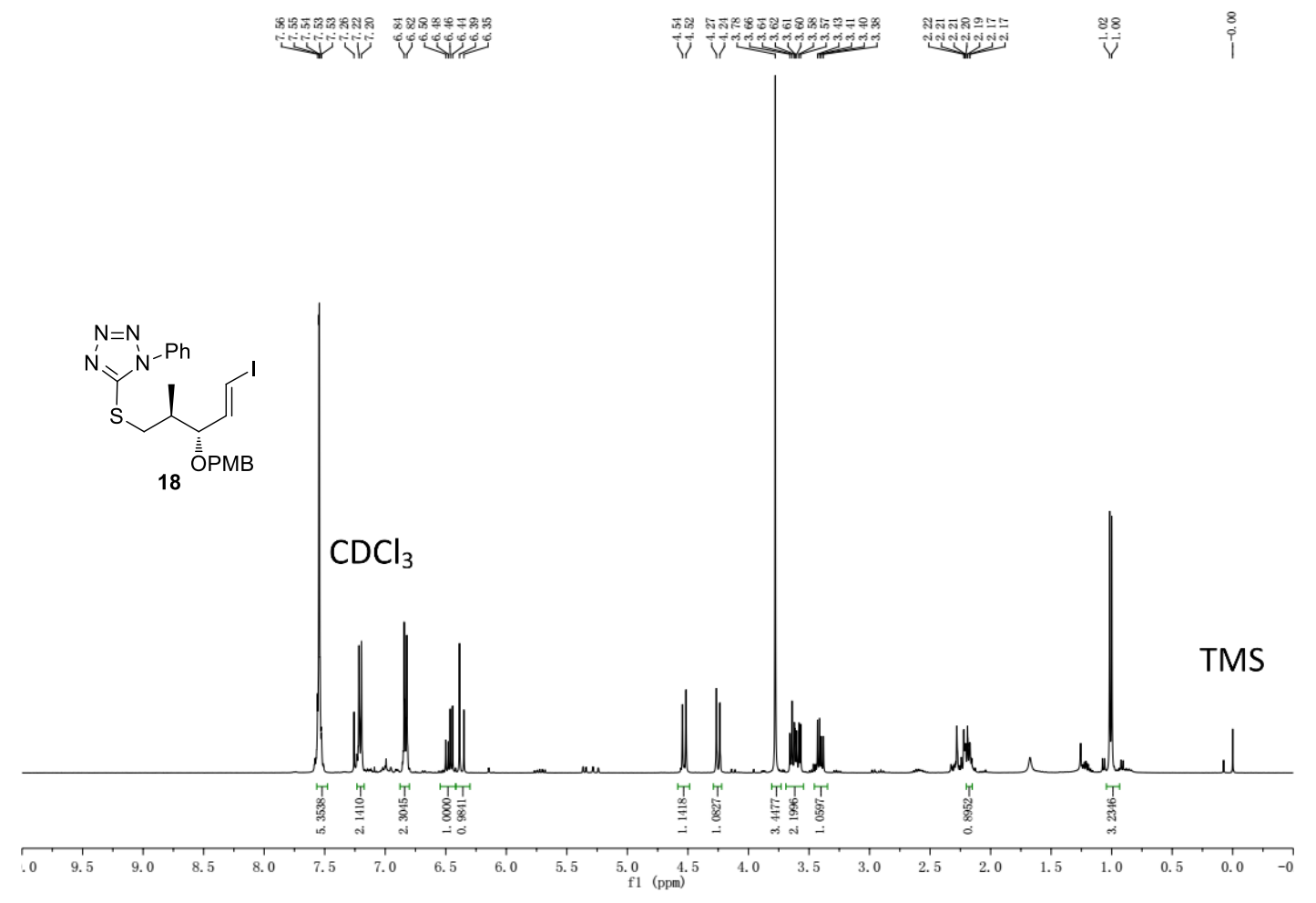

${ }^{13} \mathbf{C} \mathbf{N M R}\left(\mathrm{CDCl}_{3}, 100 \mathrm{MHz}\right)$

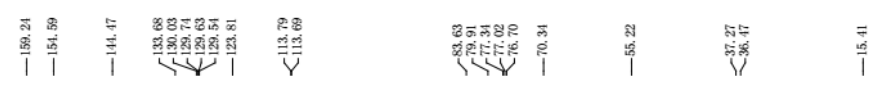

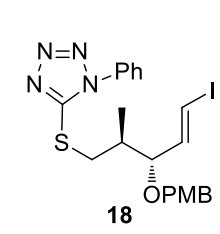

$\mathrm{CDCl}_{3}$

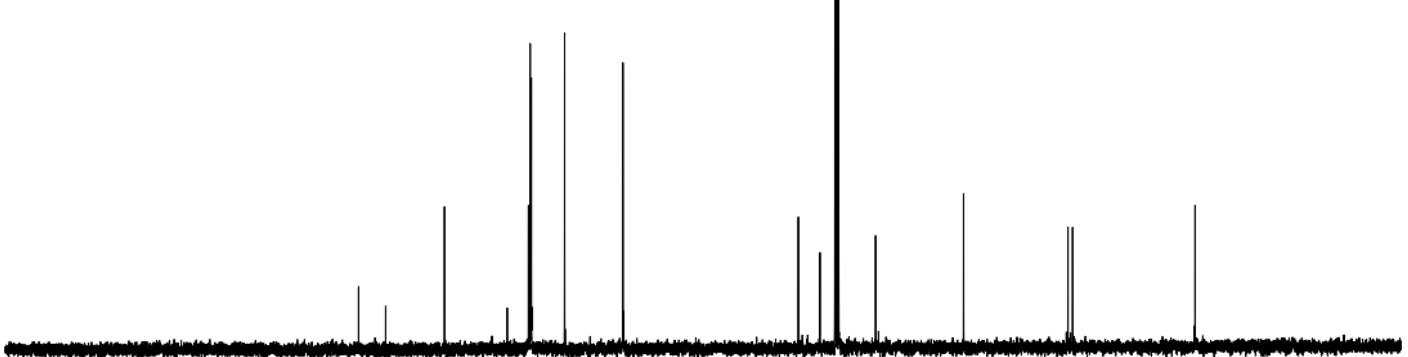

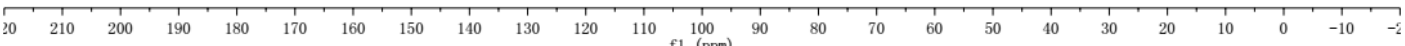


${ }^{1} \mathbf{H} \mathbf{N M R}\left(\mathrm{CDCl}_{3}, 500 \mathrm{MHz}\right)$

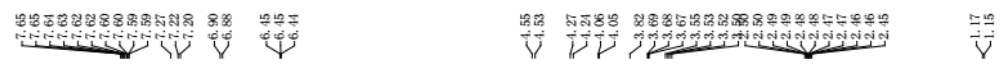
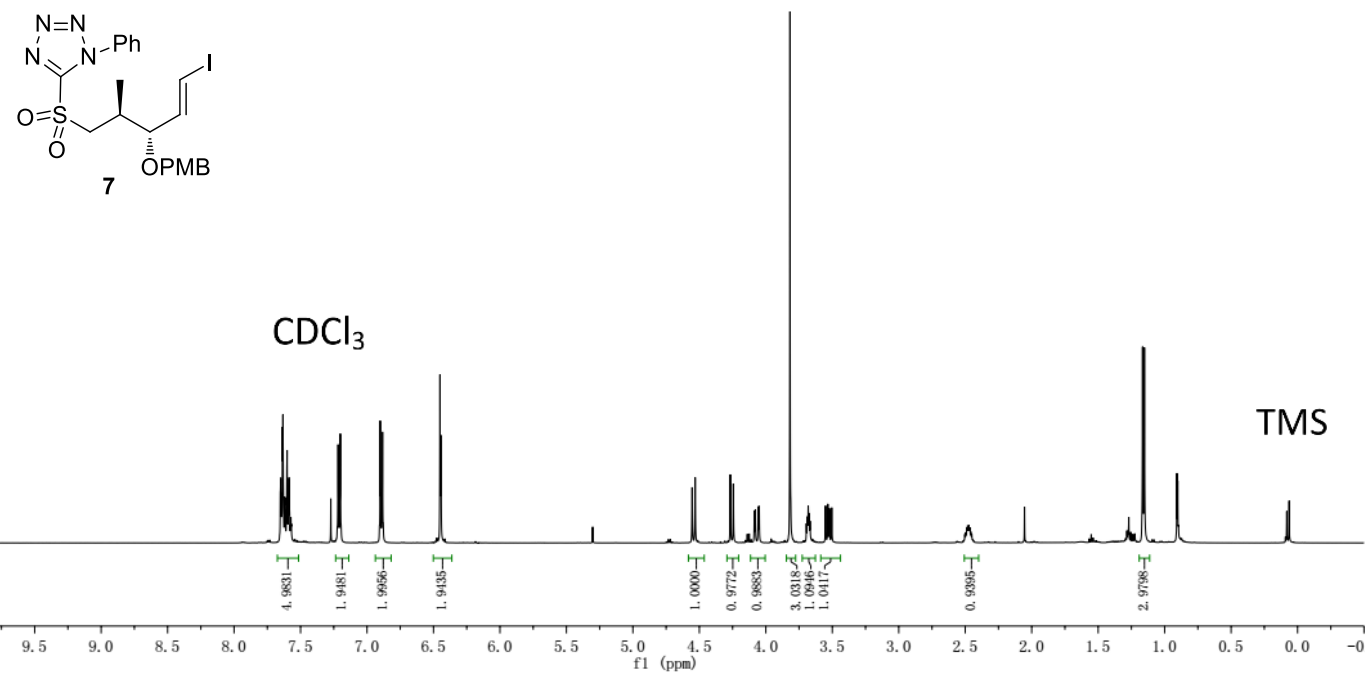

${ }^{13} \mathbf{C ~ N M R}\left(\mathrm{CDCl}_{3}, 125 \mathrm{MHz}\right)$

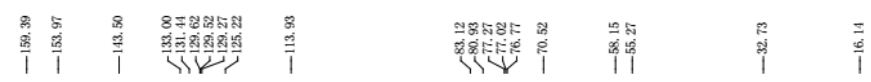

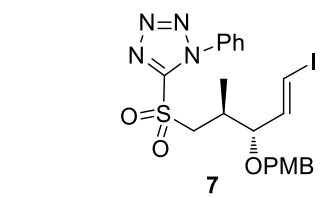

$\mathrm{CDCl}_{3}$
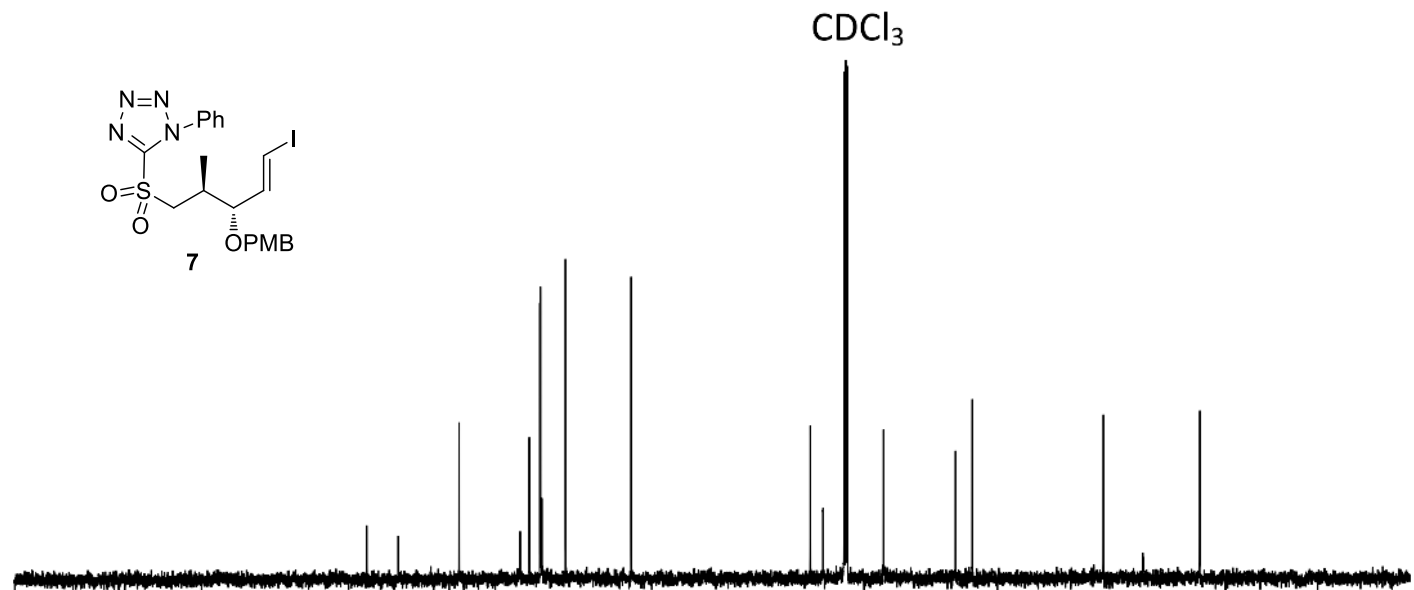

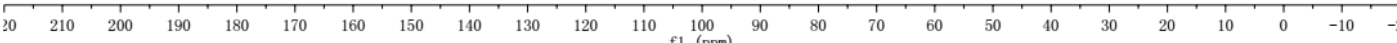


${ }^{1} \mathbf{H} \mathbf{N M R}\left(\mathrm{CDCl}_{3}, 500 \mathrm{MHz}\right)$

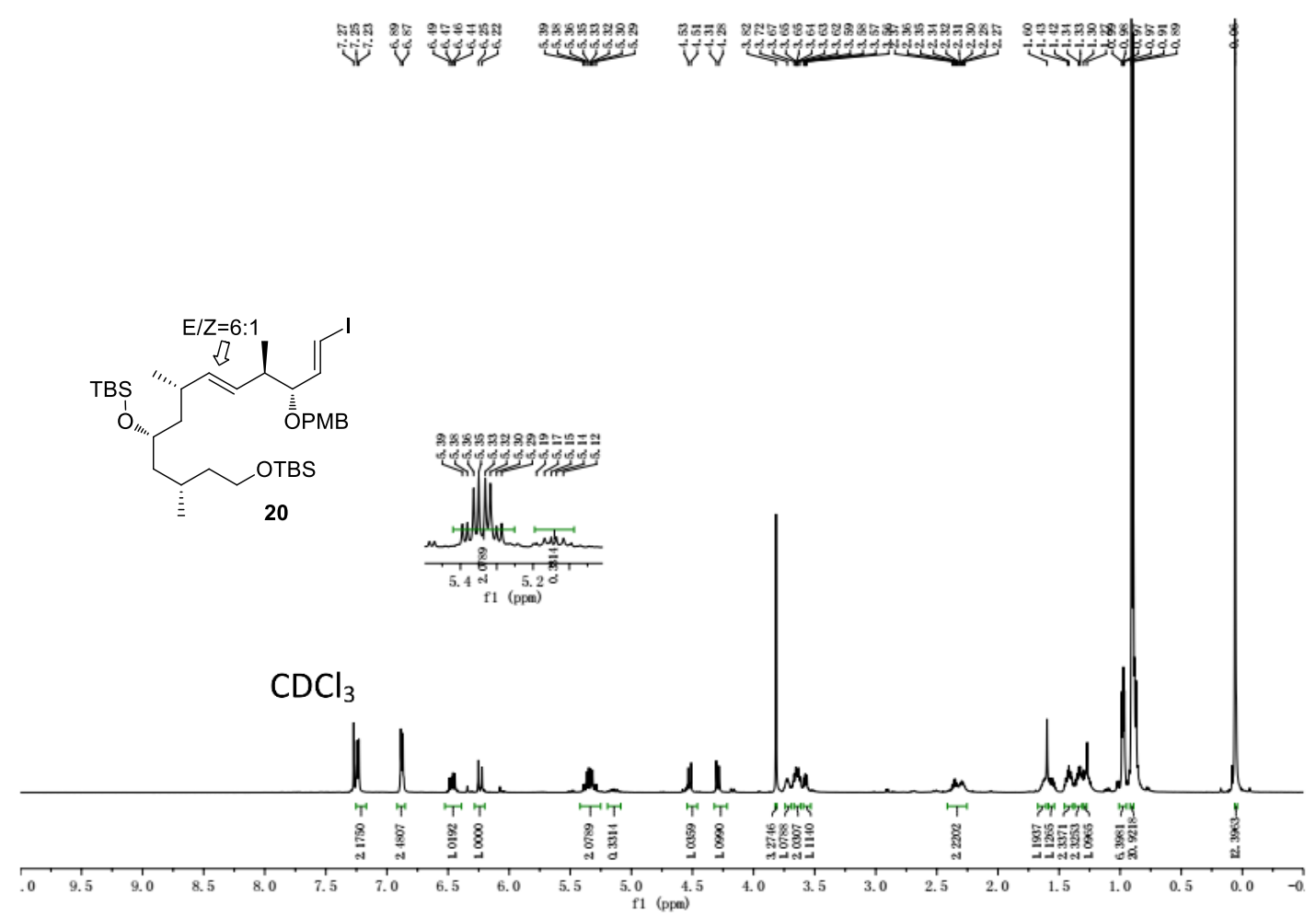

${ }^{13} \mathbf{C} \mathbf{N M R}\left(\mathrm{CDCl}_{3}, 125 \mathrm{MHz}\right)$

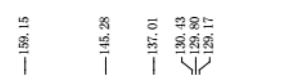

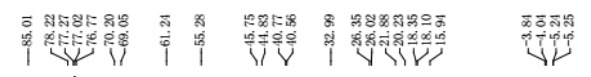

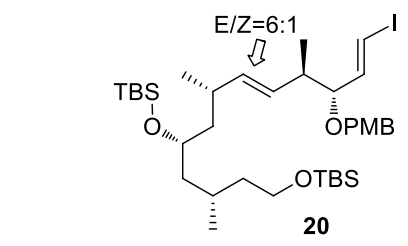

$\mathrm{CDCl}_{3}$

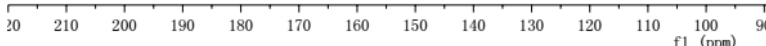


${ }^{1} \mathbf{H} \mathbf{N M R}\left(\mathrm{CDCl}_{3}, 500 \mathrm{MHz}\right)$

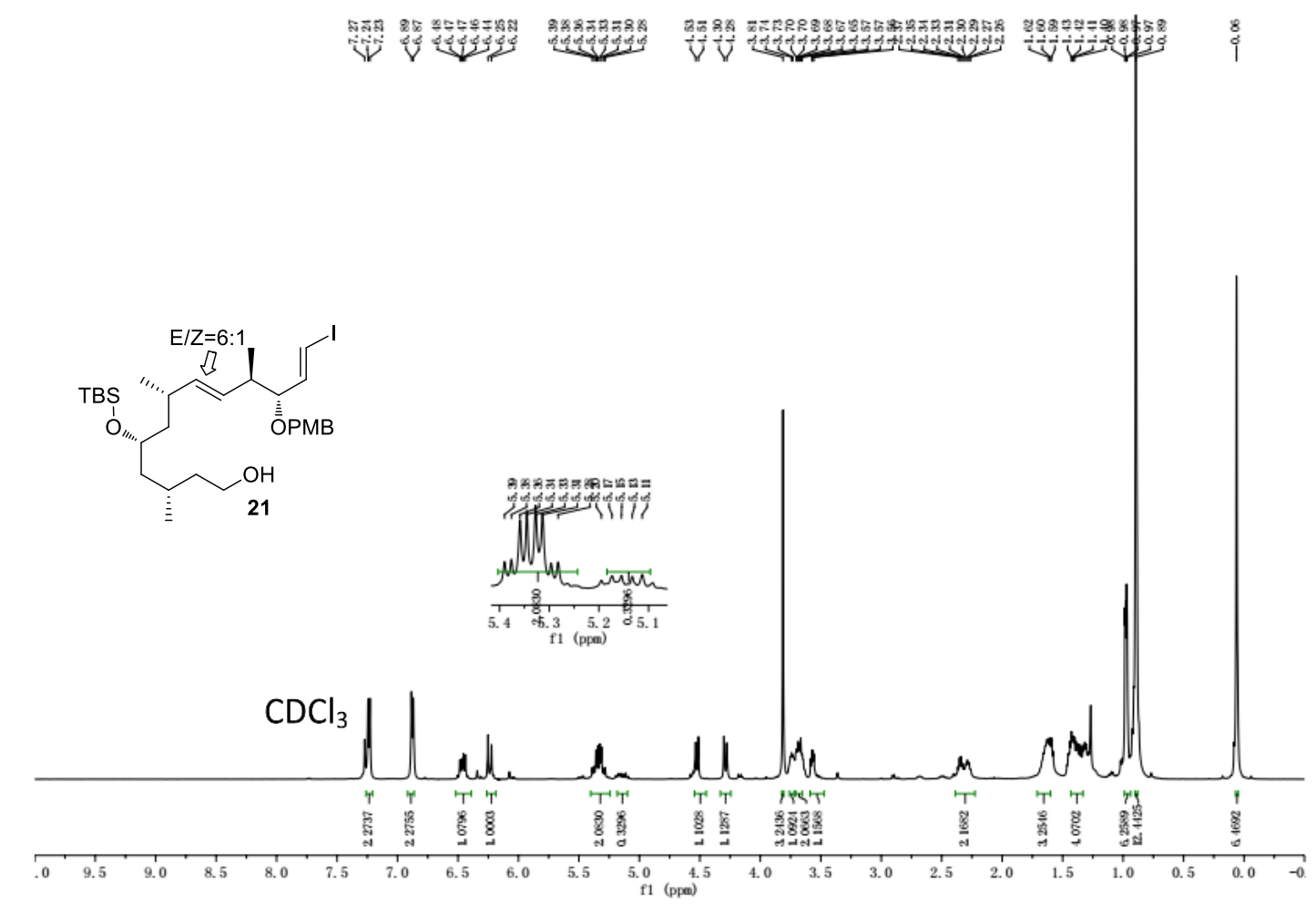

${ }^{13} \mathbf{C ~ N M R}\left(\mathrm{CDCl}_{3}, 125 \mathrm{MHz}\right)$

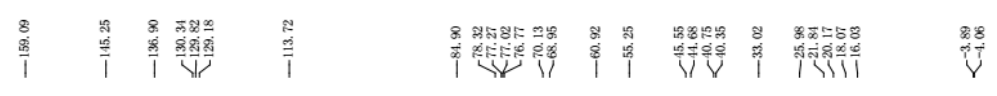
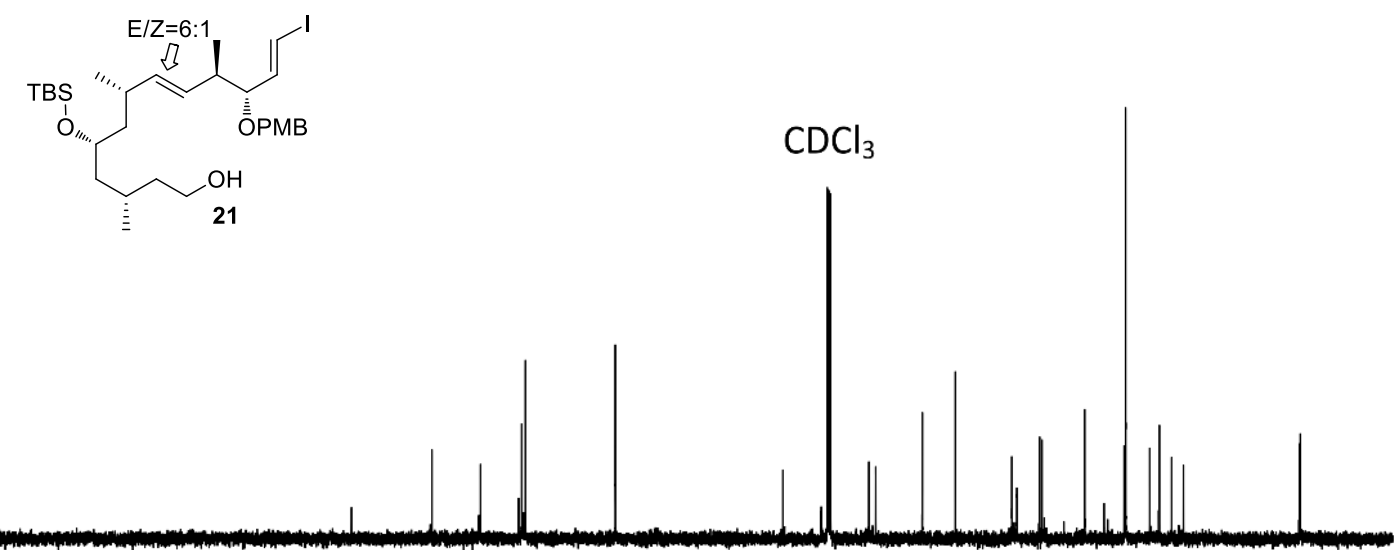

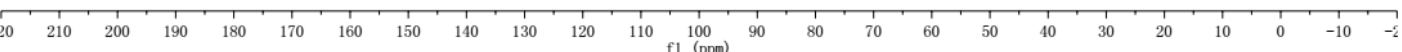


${ }^{1} \mathbf{H}$ NMR $\left(\mathrm{CDCl}_{3}, 500 \mathrm{MHz}\right)$

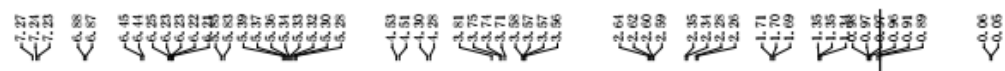
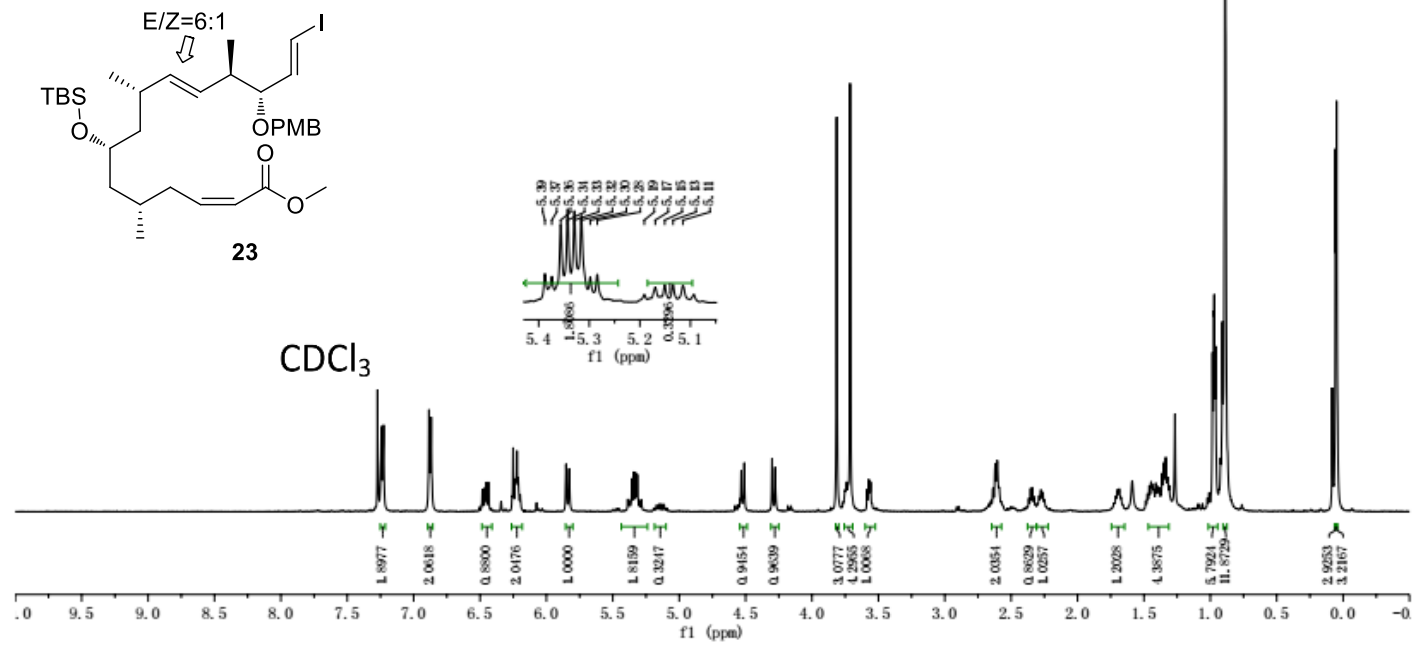

${ }^{13} \mathbf{C} \mathbf{N M R}\left(\mathrm{CDCl}_{3}, 125 \mathrm{MHz}\right)$

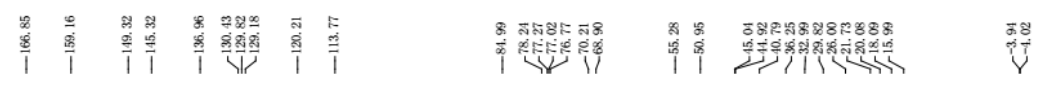

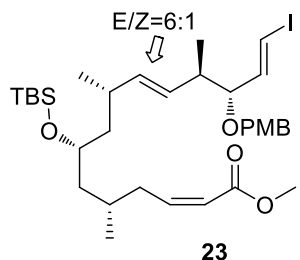

$\mathrm{CDCl}_{3}$

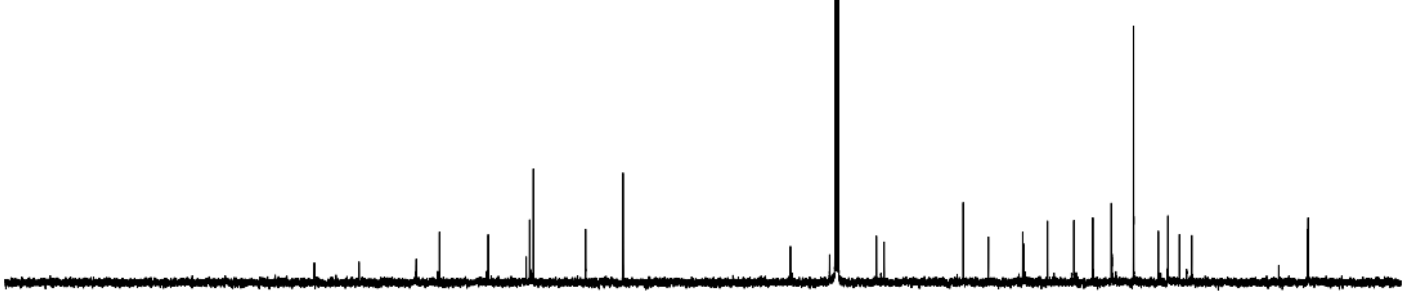

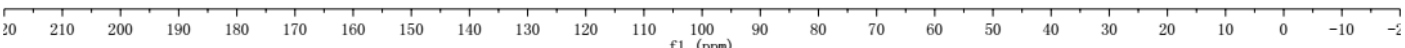


${ }^{1} \mathbf{H}$ NMR $\left(\mathrm{CDCl}_{3}, 500 \mathrm{MHz}\right)$

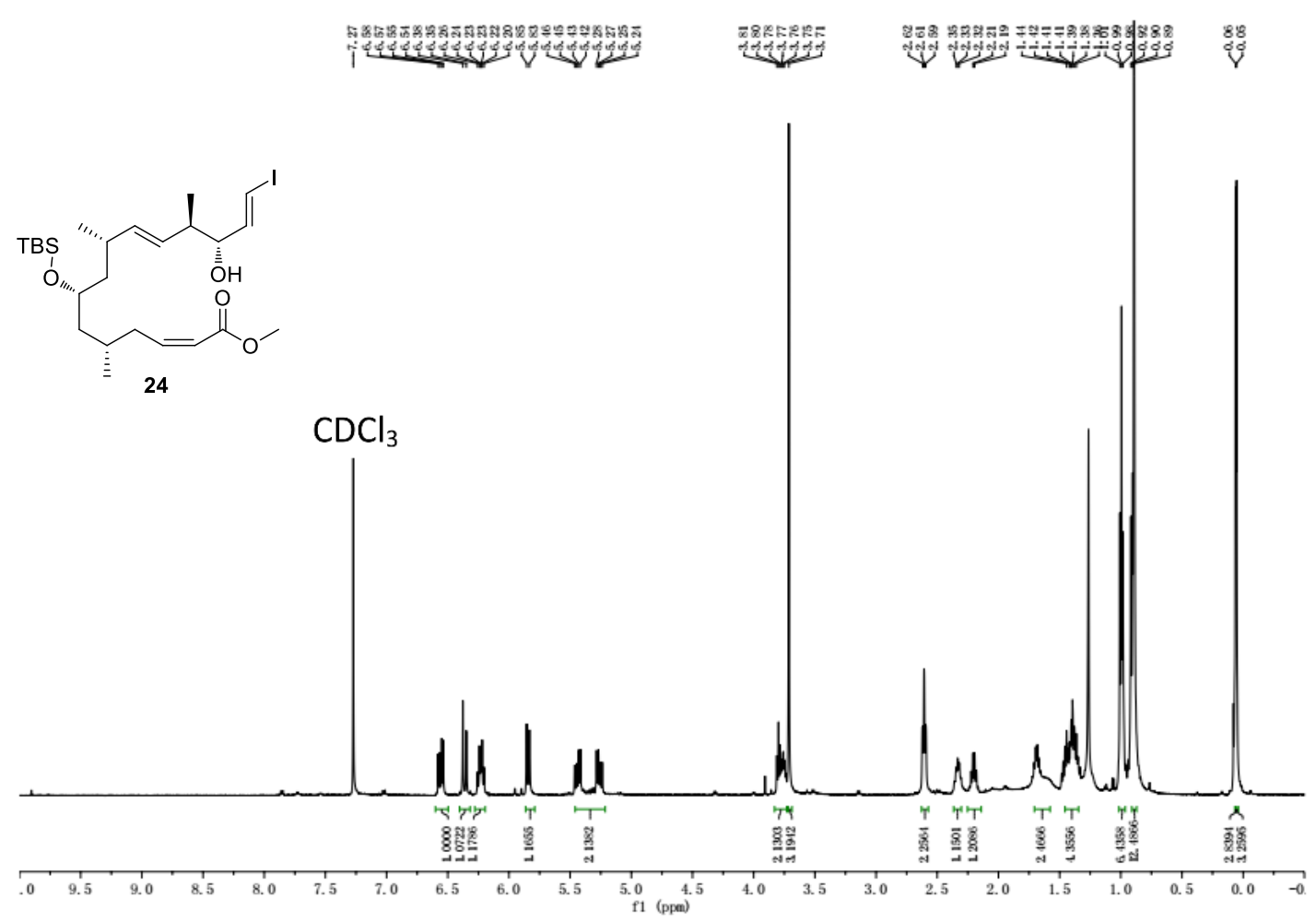

${ }^{13} \mathbf{C} \mathbf{N M R}\left(\mathrm{CDCl}_{3}, 125 \mathrm{MHz}\right)$

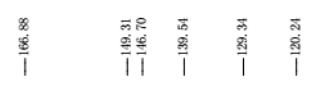

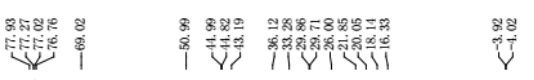
$\mathrm{CDCl}_{3}$

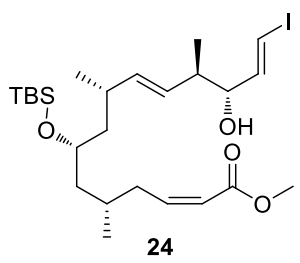

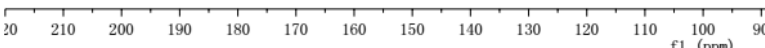


${ }^{1} \mathbf{H}$ NMR $\left(\mathrm{CDCl}_{3}, 400 \mathrm{MHz}\right)$

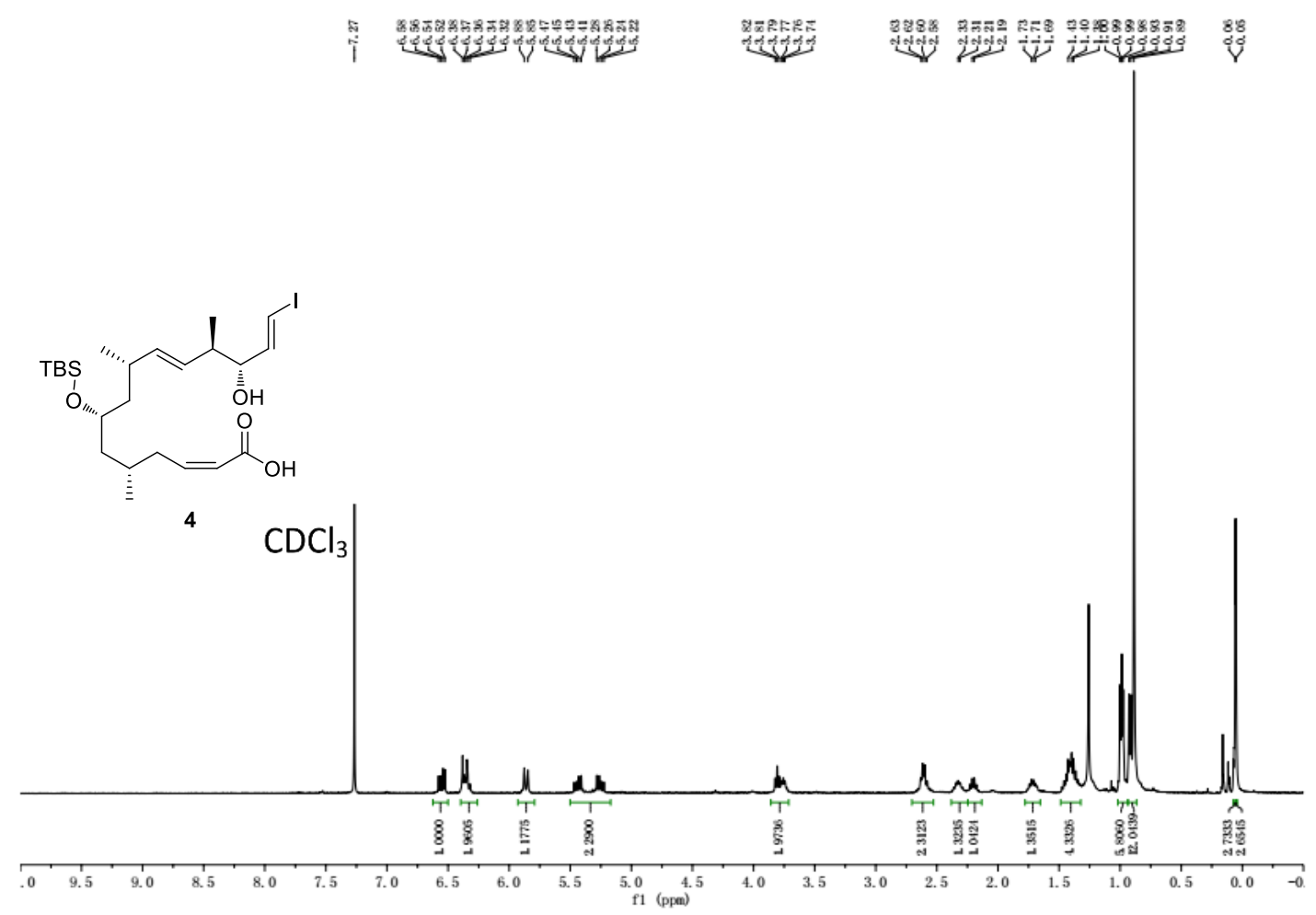

${ }^{13} \mathbf{C ~ N M R}\left(\mathrm{CDCl}_{3}, 100 \mathrm{MHz}\right)$

I 11

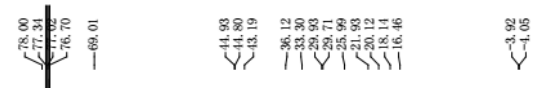

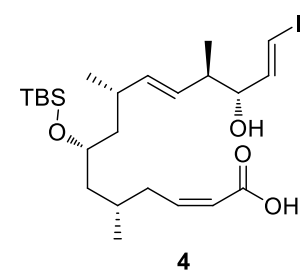

$\mathrm{CDCl}_{3}$

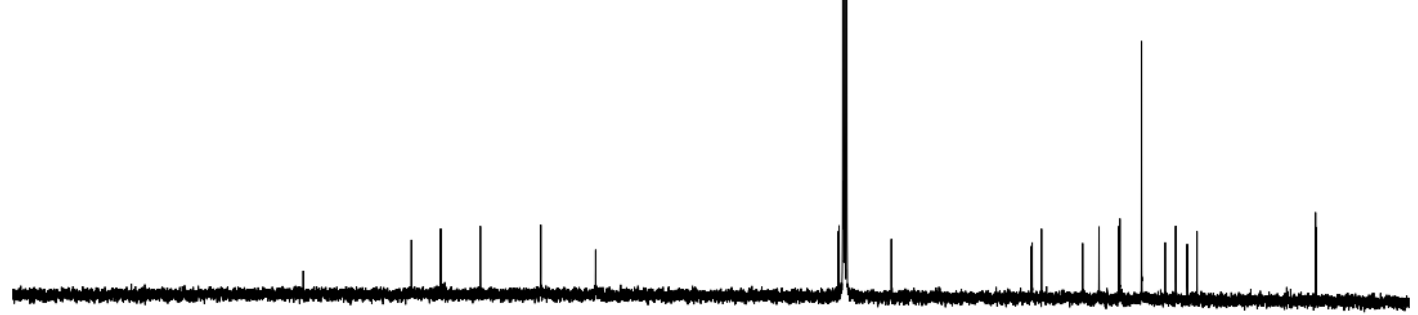

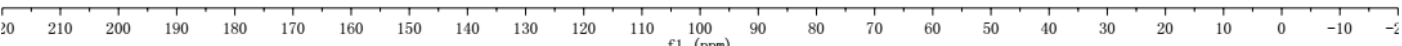


${ }^{1} \mathbf{H}$ NMR $\left(\mathrm{CDCl}_{3}, 400 \mathrm{MHz}\right)$

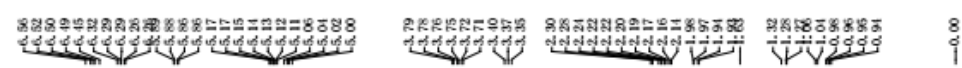
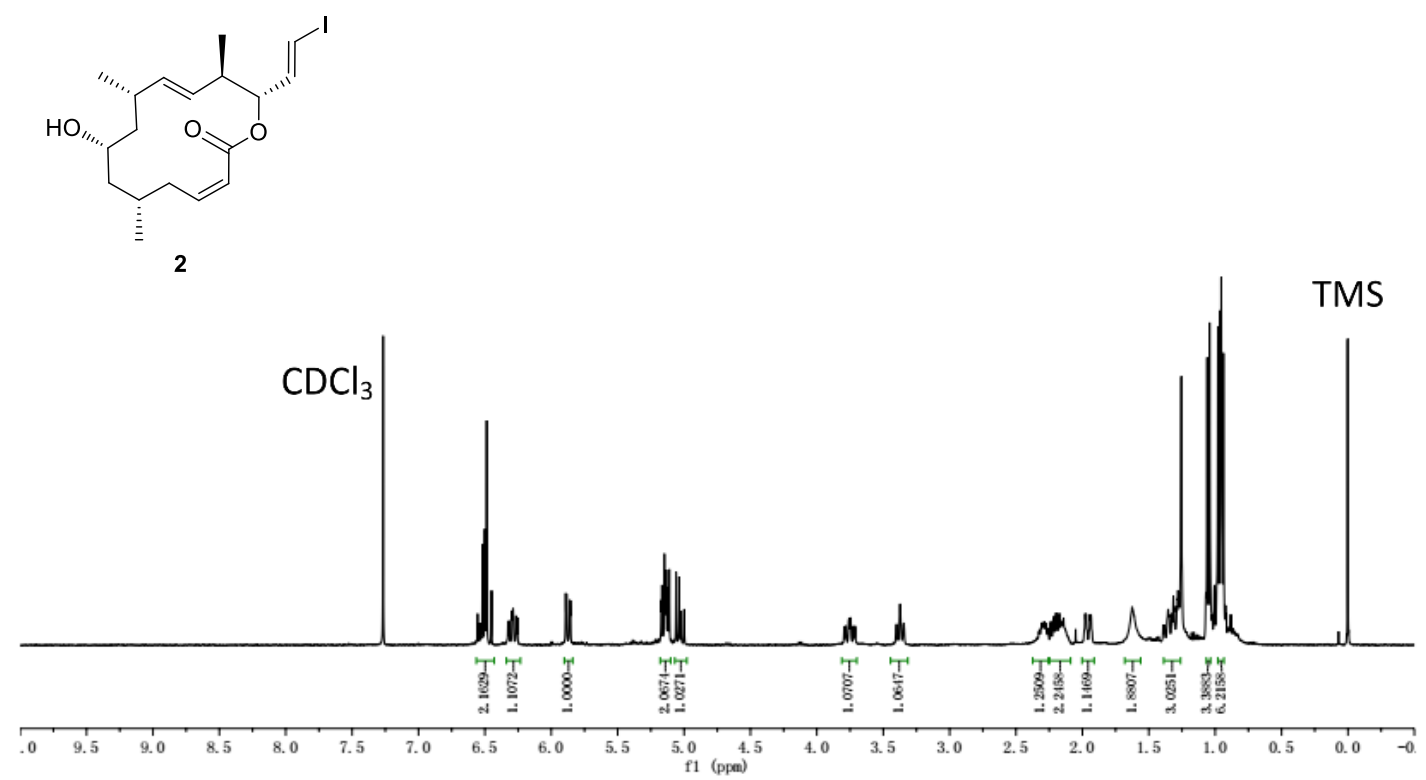

${ }^{13} \mathbf{C}$ NMR $\left(\mathrm{CDCl}_{3}, 100 \mathrm{MHz}\right)$

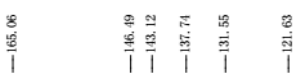

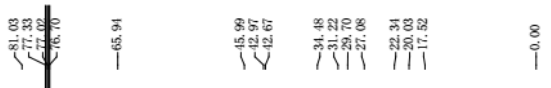

$\mathrm{CDCl}_{3}$

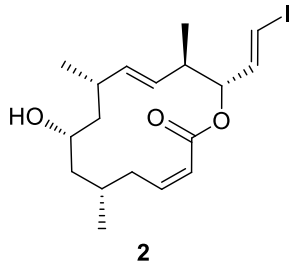

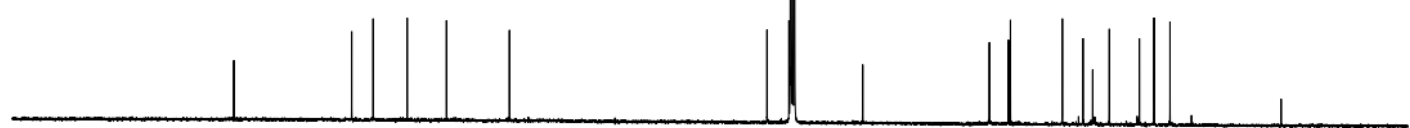

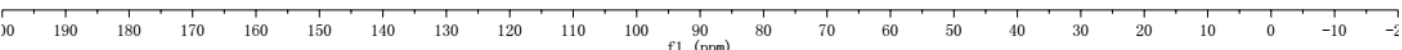


${ }^{1} \mathbf{H}$ NMR $\left(\mathrm{CDCl}_{3}, 500 \mathrm{MHz}\right)$

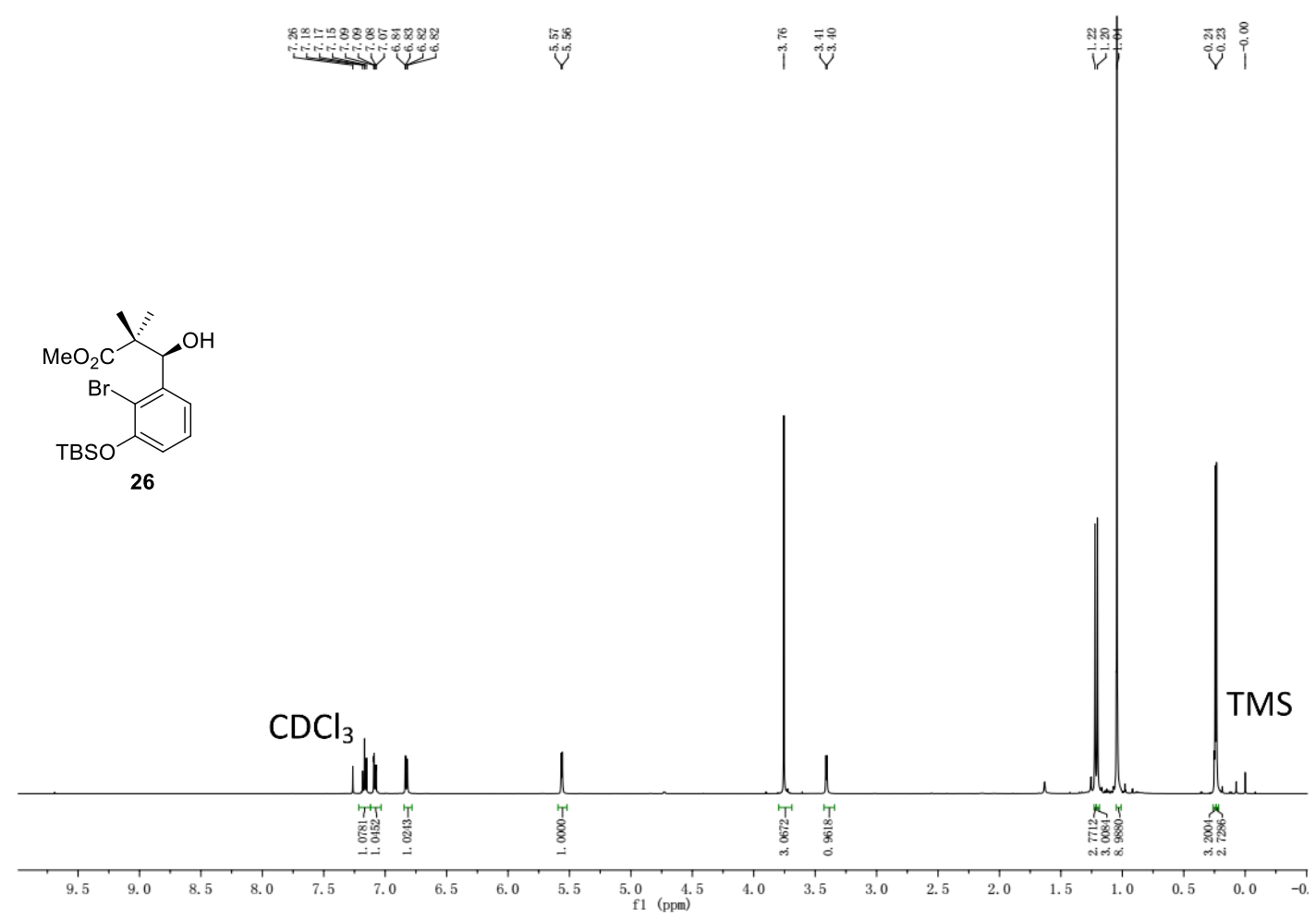

${ }^{13} \mathbf{C ~ N M R}\left(\mathrm{CDCl}_{3}, 125 \mathrm{MHz}\right)$

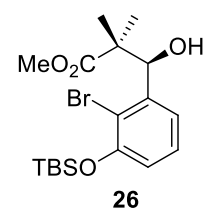

$\mathrm{CDCl}_{3}$

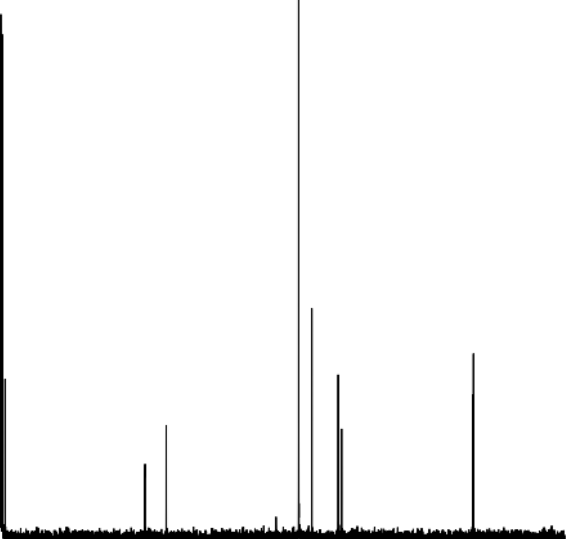

$\begin{array}{lllllll}20 & 210 & 200 & 190 & 180 & 170 & 160\end{array}$

$150 \quad 140 \quad 130$ $\mathbb{1}_{110}^{100} 90$ 
${ }^{1} \mathbf{H} \mathbf{N M R}\left(\mathrm{CDCl}_{3}, 500 \mathrm{MHz}\right)$

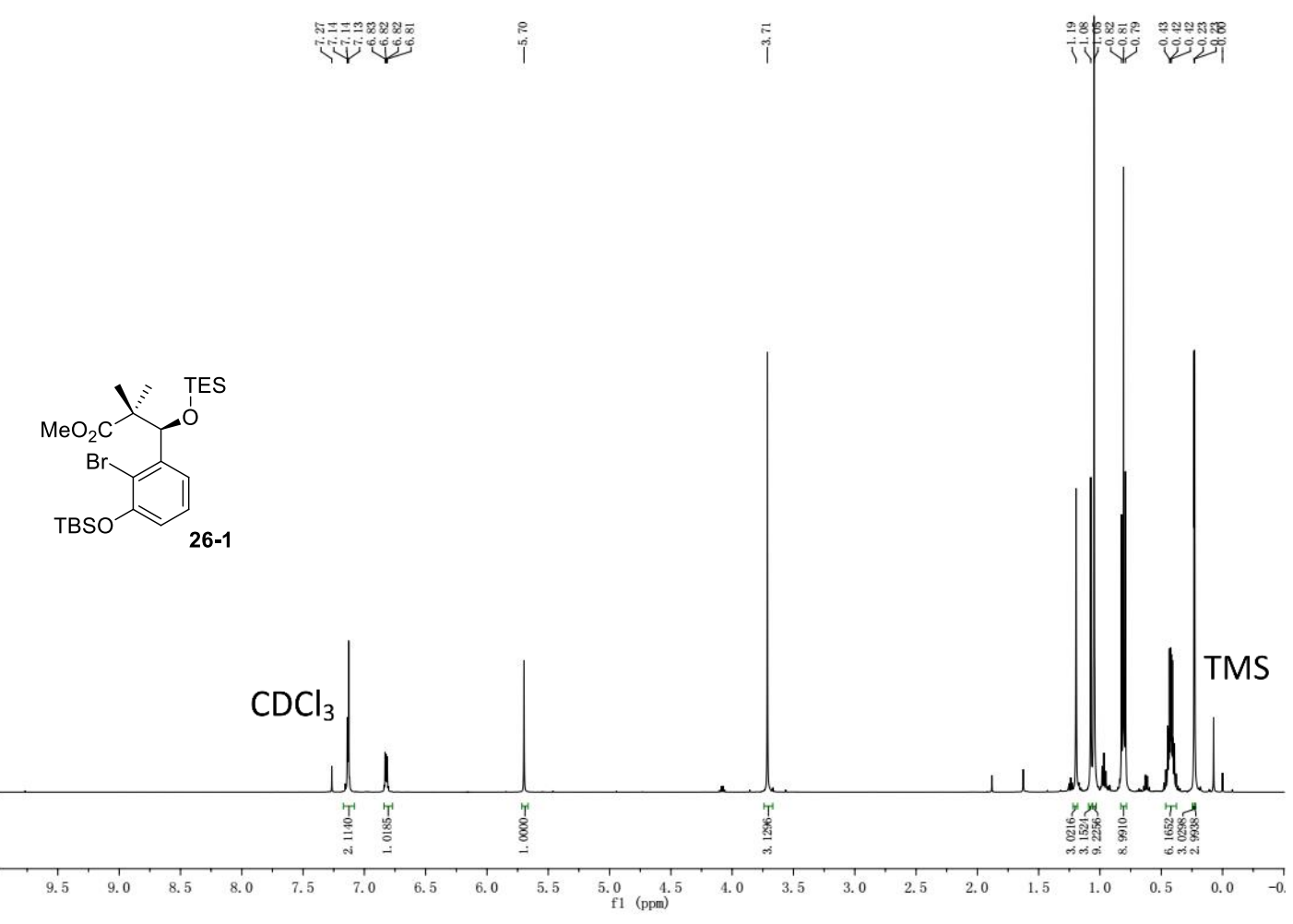

${ }^{13} \mathbf{C ~ N M R}\left(\mathrm{CDCl}_{3}, 125 \mathrm{MHz}\right)$

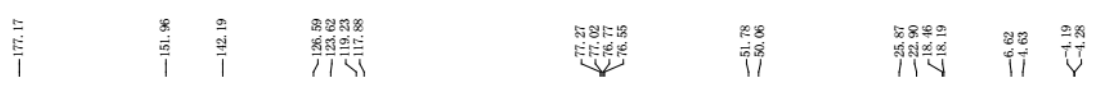
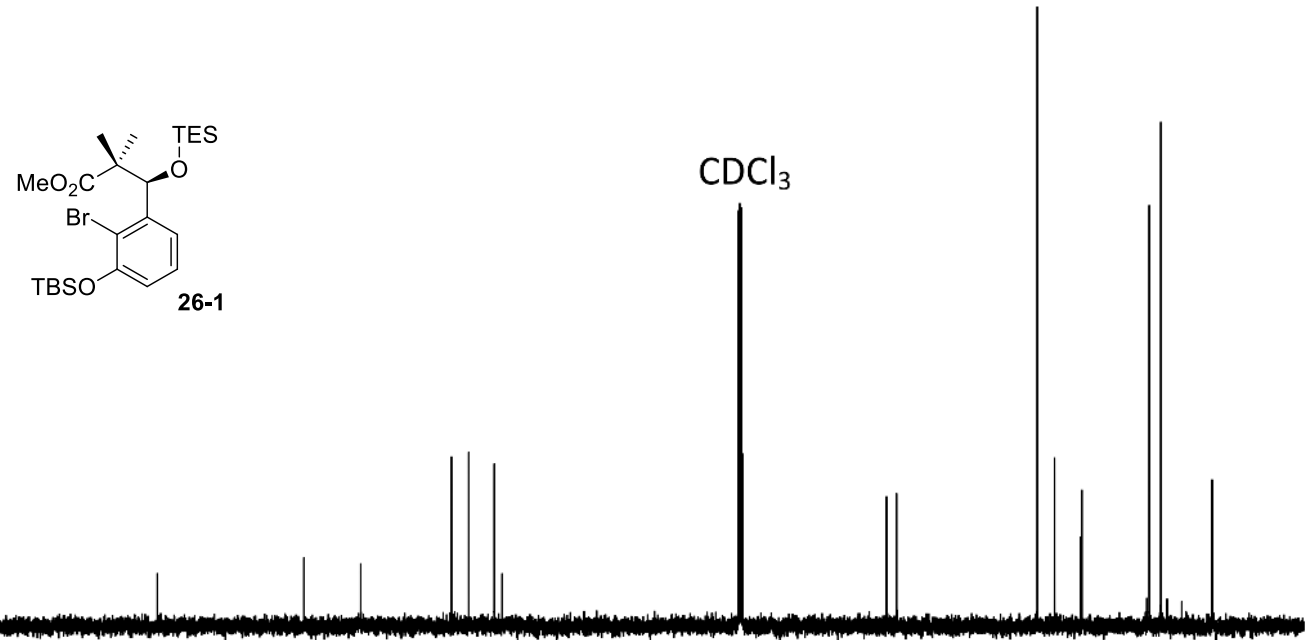

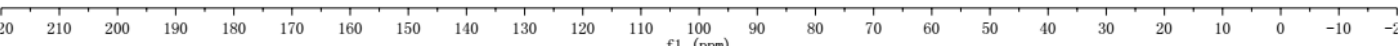


${ }^{1} \mathbf{H}$ NMR $\left(\mathrm{CDCl}_{3}, 500 \mathrm{MHz}\right)$

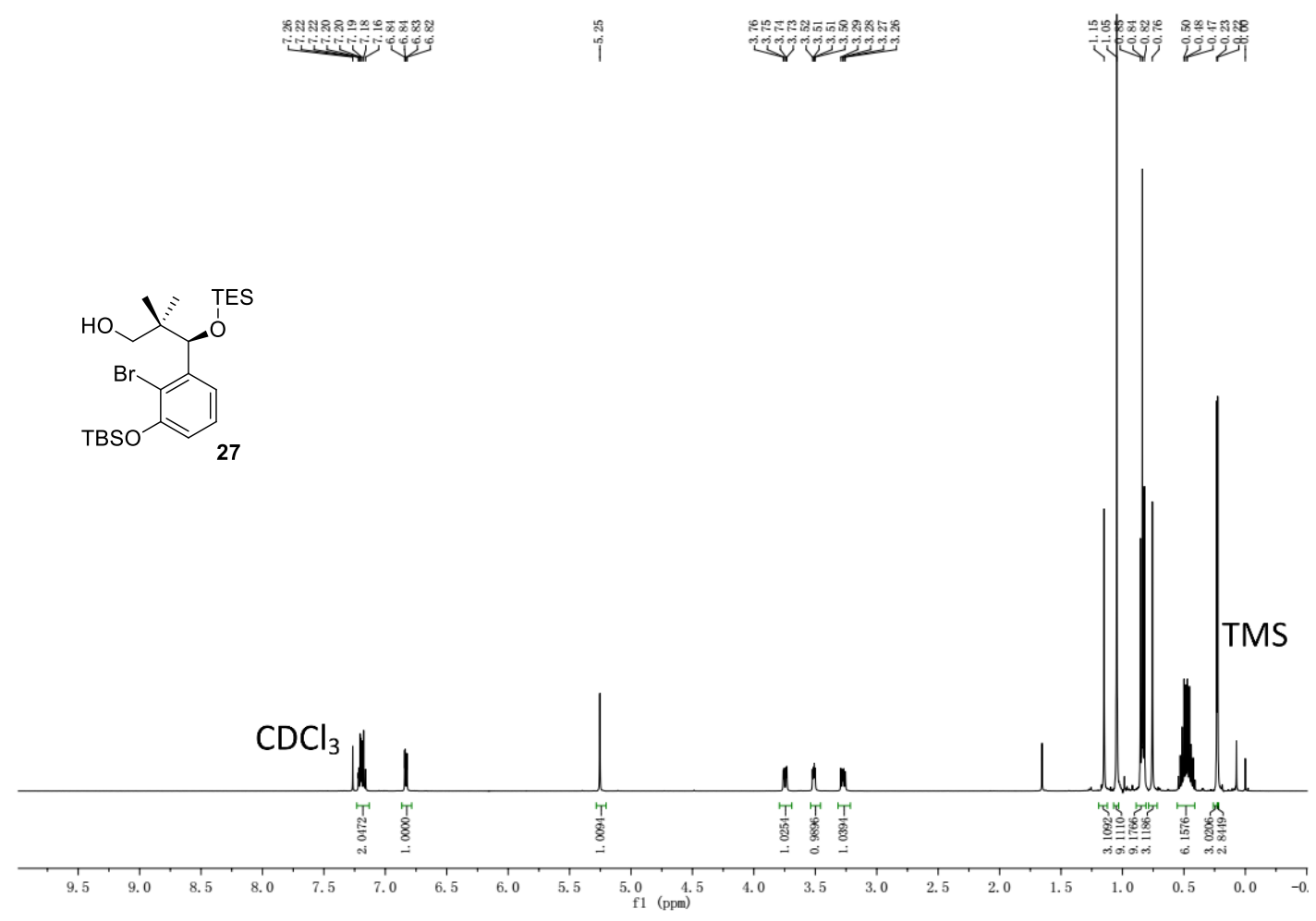

${ }^{13} \mathbf{C ~ N M R}\left(\mathrm{CDCl}_{3}, 125 \mathrm{MHz}\right)$

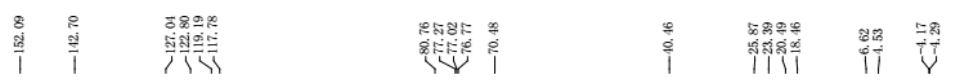

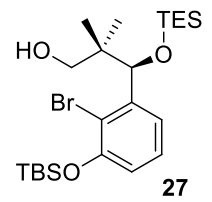

$\mathrm{CDCl}_{3}$

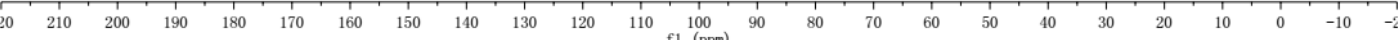


${ }^{1} \mathbf{H} \mathbf{N M R}\left(\mathrm{CDCl}_{3}, 500 \mathrm{MHz}\right)$

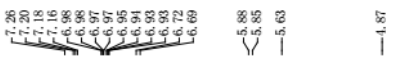
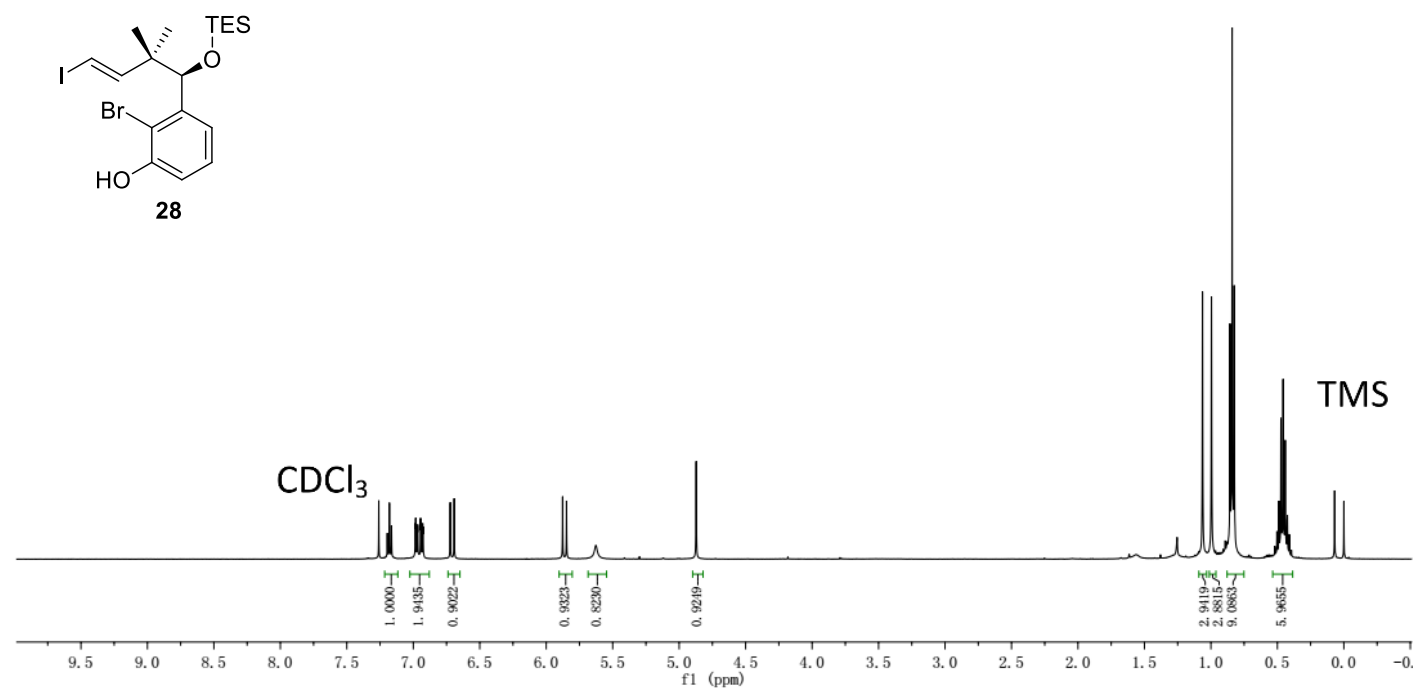

${ }^{13} \mathbf{C}$ NMR $\left(\mathrm{CDCl}_{3}, 125 \mathrm{MHz}\right)$

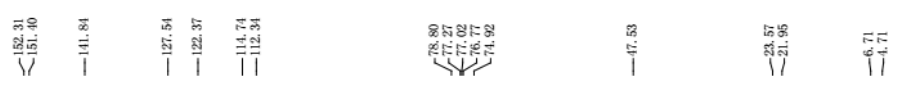

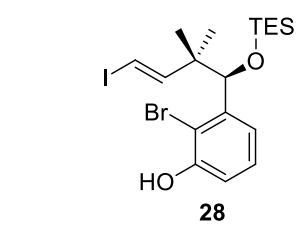

$\mathrm{CDCl}_{3}$

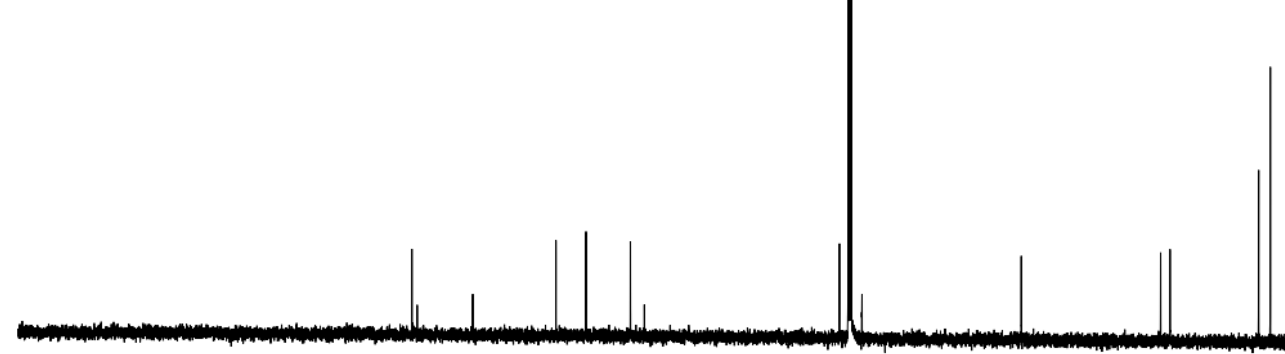

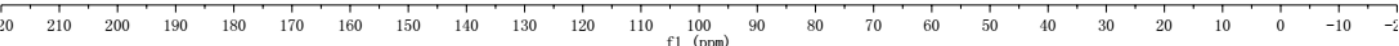


${ }^{1} \mathbf{H}$ NMR $\left(\mathrm{CDCl}_{3}, 400 \mathrm{MHz}\right)$

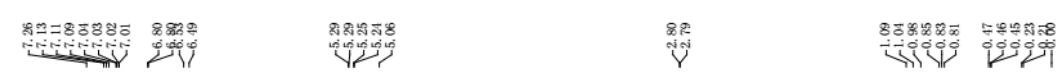
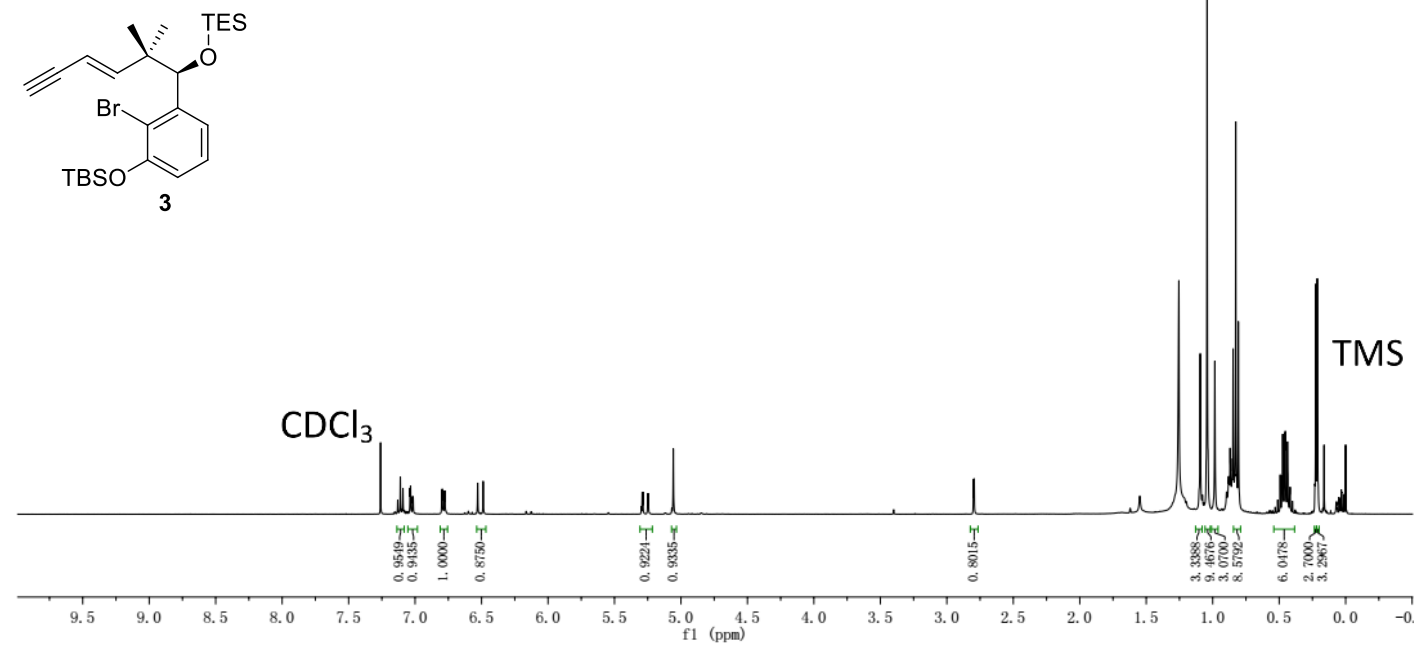

${ }^{13} \mathbf{C}$ NMR $\left(\mathrm{CDCl}_{3}, 100 \mathrm{MHz}\right)$

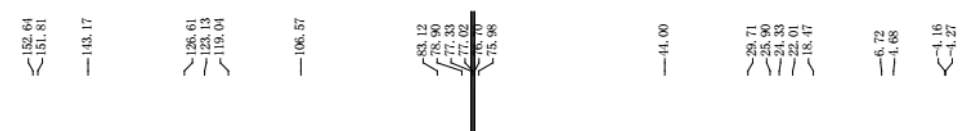

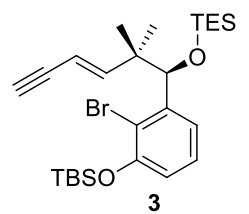

$\mathrm{CDCl}_{3}$

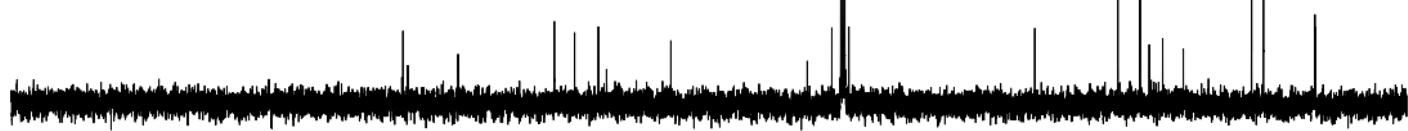

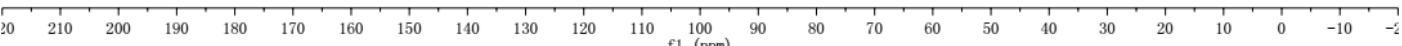


${ }^{1} \mathbf{H}$ NMR $\left(\mathrm{CDCl}_{3}, 500 \mathrm{MHz}\right)$

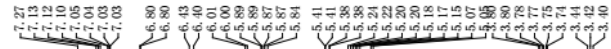

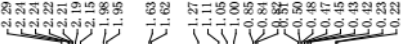<smiles>COC(c1cccc(OC(C)(C)C)c1Br)C(C)(C)C</smiles>

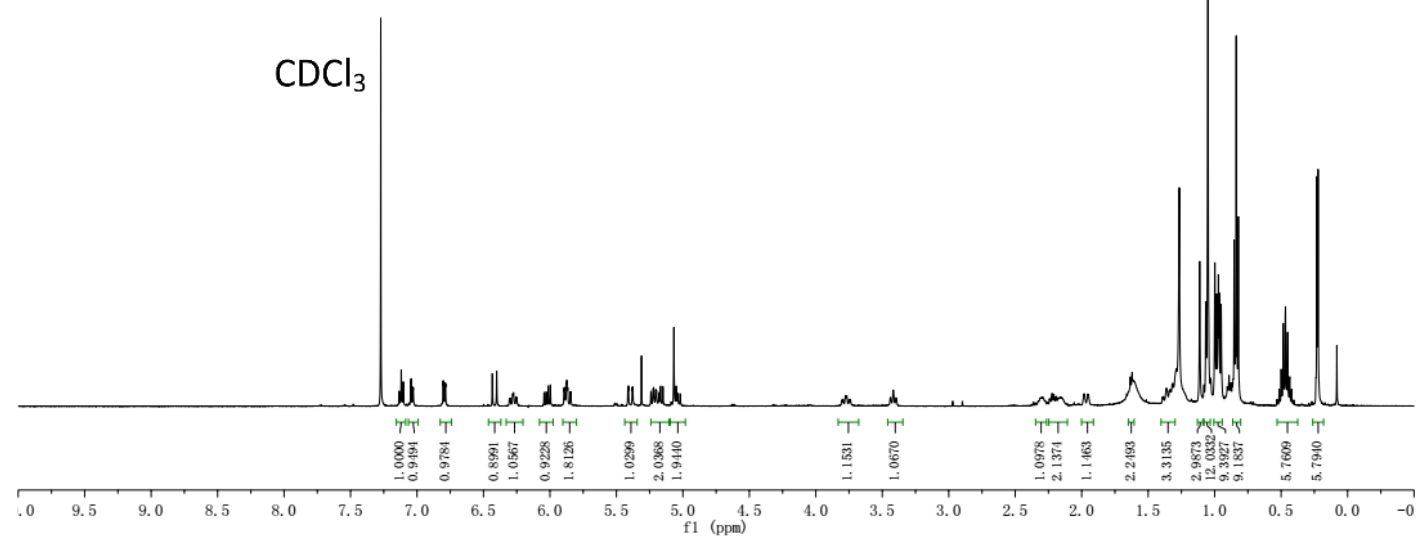

${ }^{13} \mathbf{C ~ N M R}\left(\mathrm{CDCl}_{3}, 125 \mathrm{MHz}\right)$

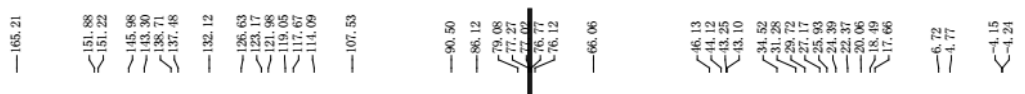

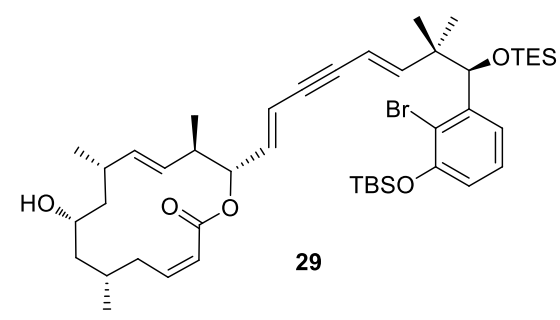

$\mathrm{CDCl}_{3}$

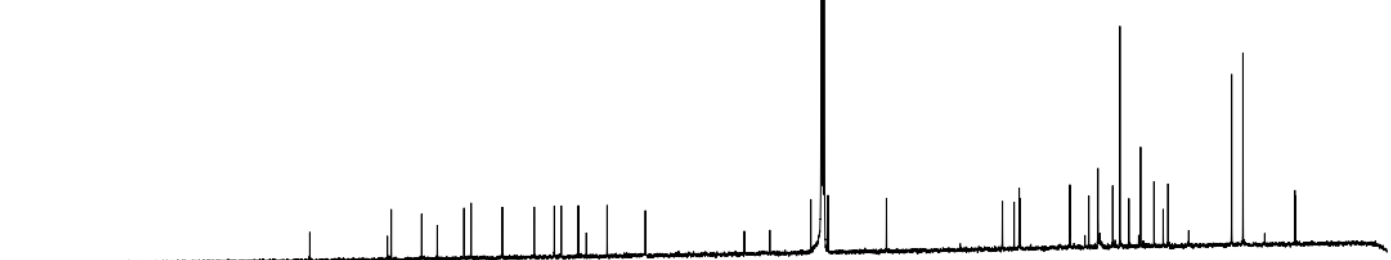

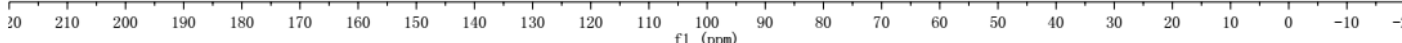


${ }^{1}$ H NMR (DMSO-d6, $400 \mathrm{MHz}$ )

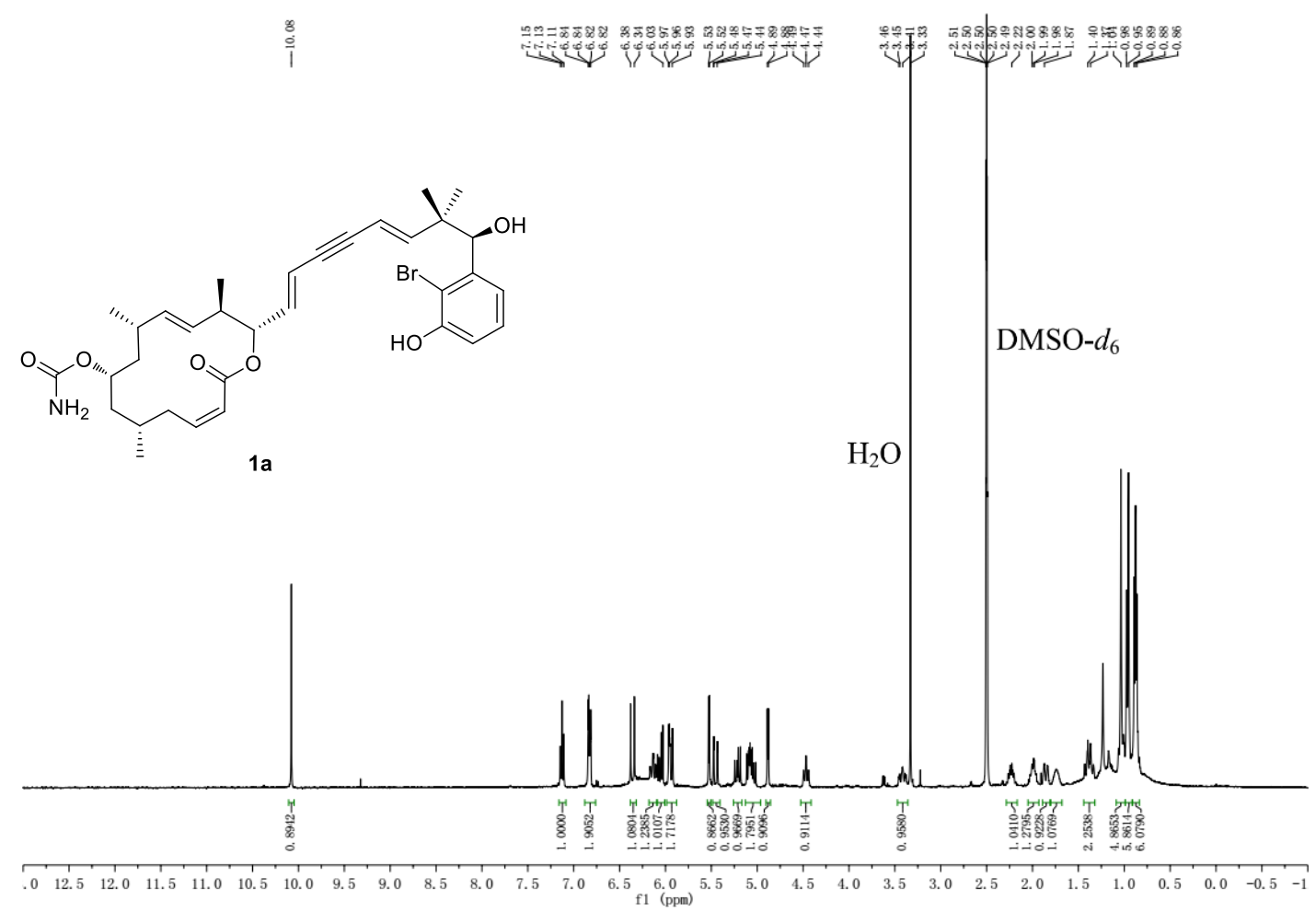

${ }^{13}$ C NMR (DMSO-d6, $100 \mathrm{MHz}$ )

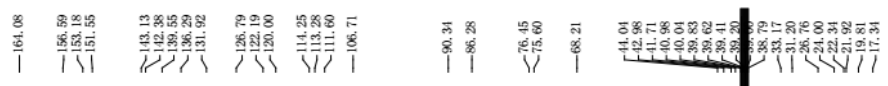

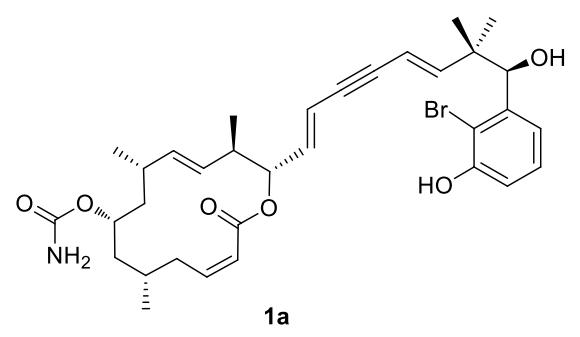

DMSO- $d_{6}$

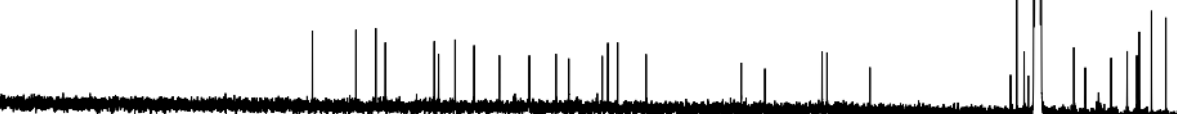

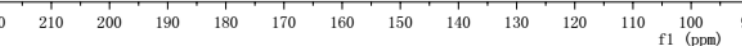


${ }^{1} \mathbf{H}$ NMR $\left(\mathrm{CDCl}_{3}, 500 \mathrm{MHz}\right)$

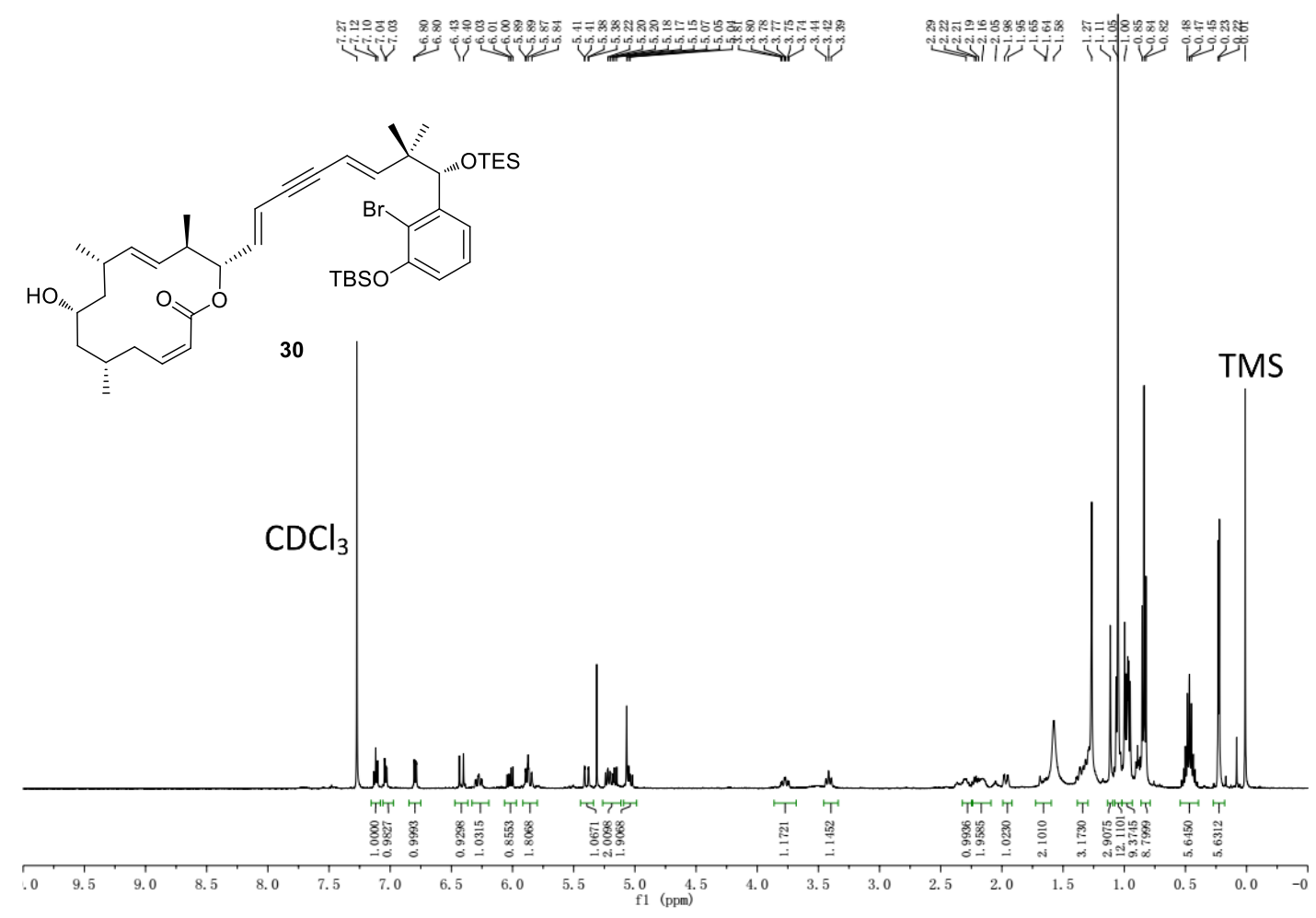

${ }^{13} \mathbf{C}$ NMR $\left(\mathrm{CDCl}_{3}, 125 \mathrm{MHz}\right)$

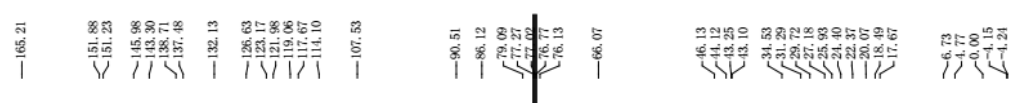

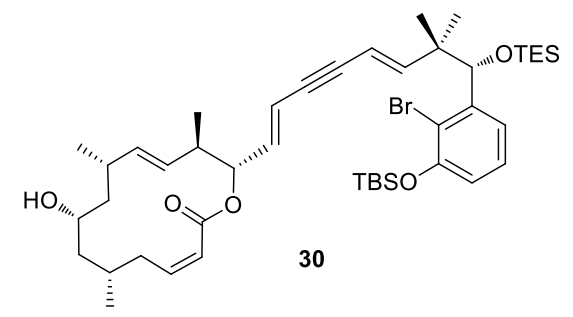

$\mathrm{CDCl}_{3}$

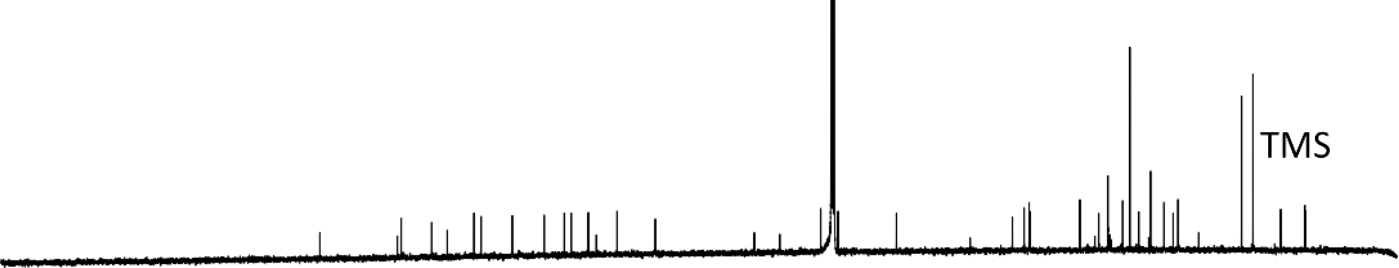

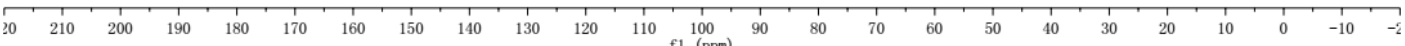


${ }^{1}$ H NMR (DMSO-d6, $\left.400 \mathrm{MHz}\right)$

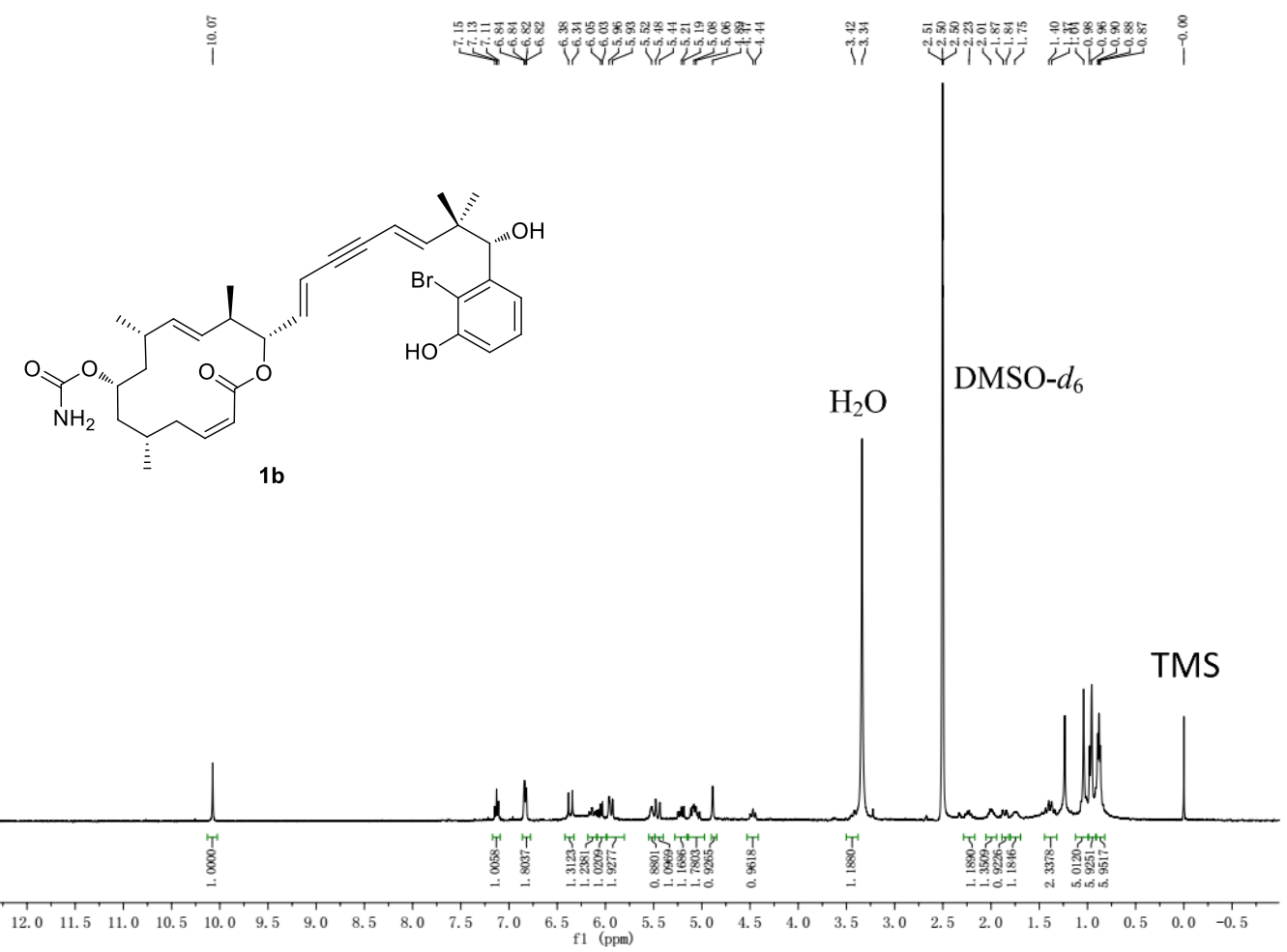

${ }^{13}$ C NMR (DMSO-d6, $\left.100 \mathrm{MHz}\right)$

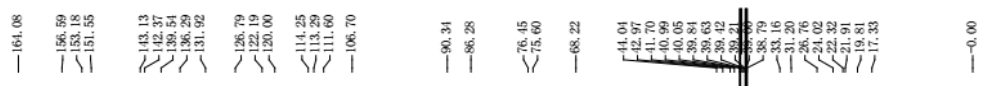

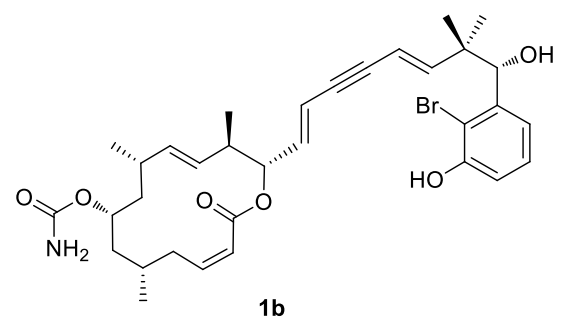

DMSO- $d_{6}$

TMS

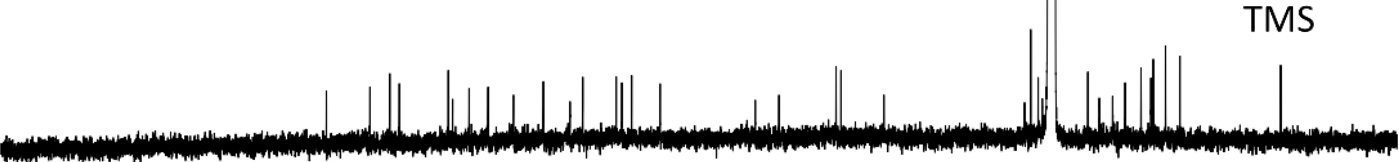

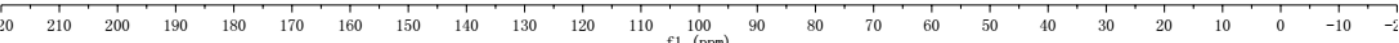


${ }^{1}$ H NMR (DMSO-d6, $400 \mathrm{MHz}$ )

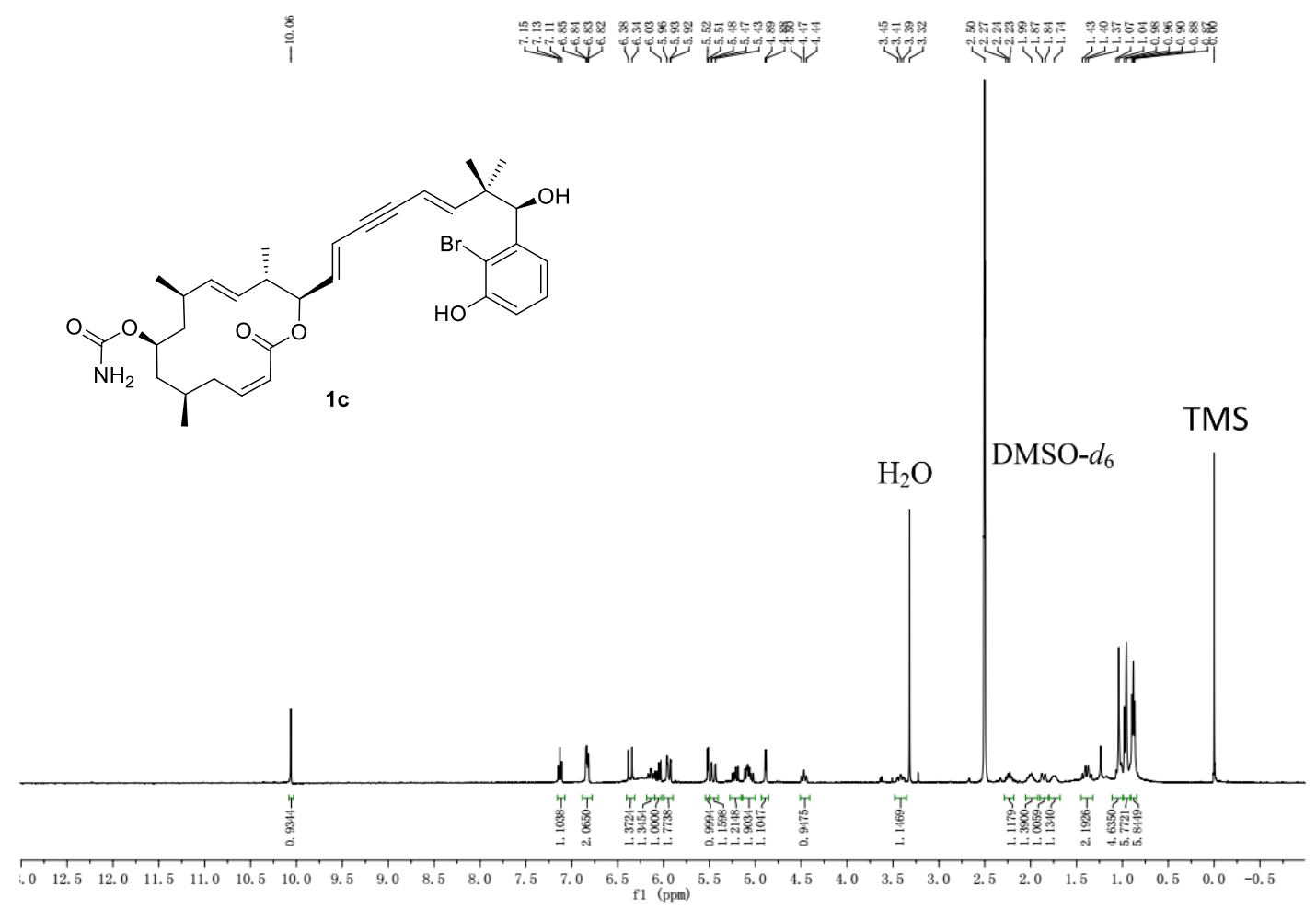

${ }^{13}$ C NMR (DMSO-d6, $100 \mathrm{MHz}$ )

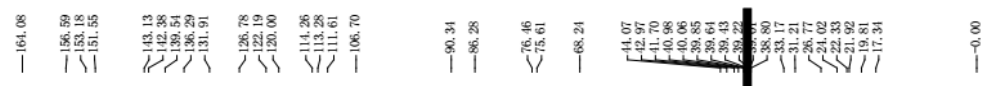

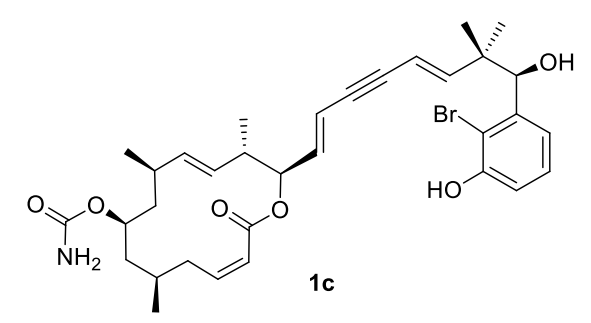

TMS

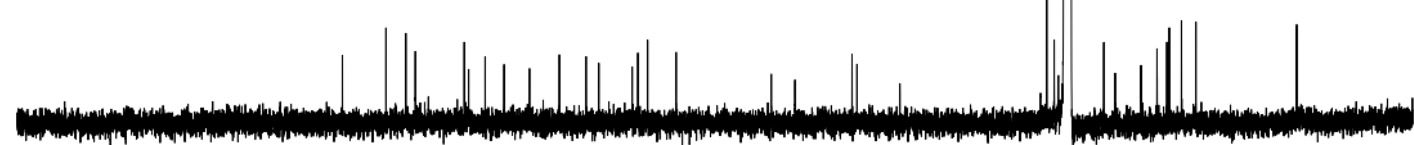

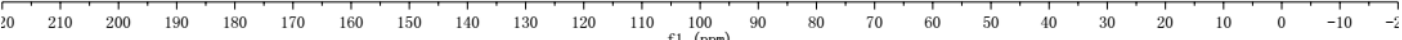


${ }^{1}$ H NMR (DMSO-d6, $400 \mathrm{MHz}$ )

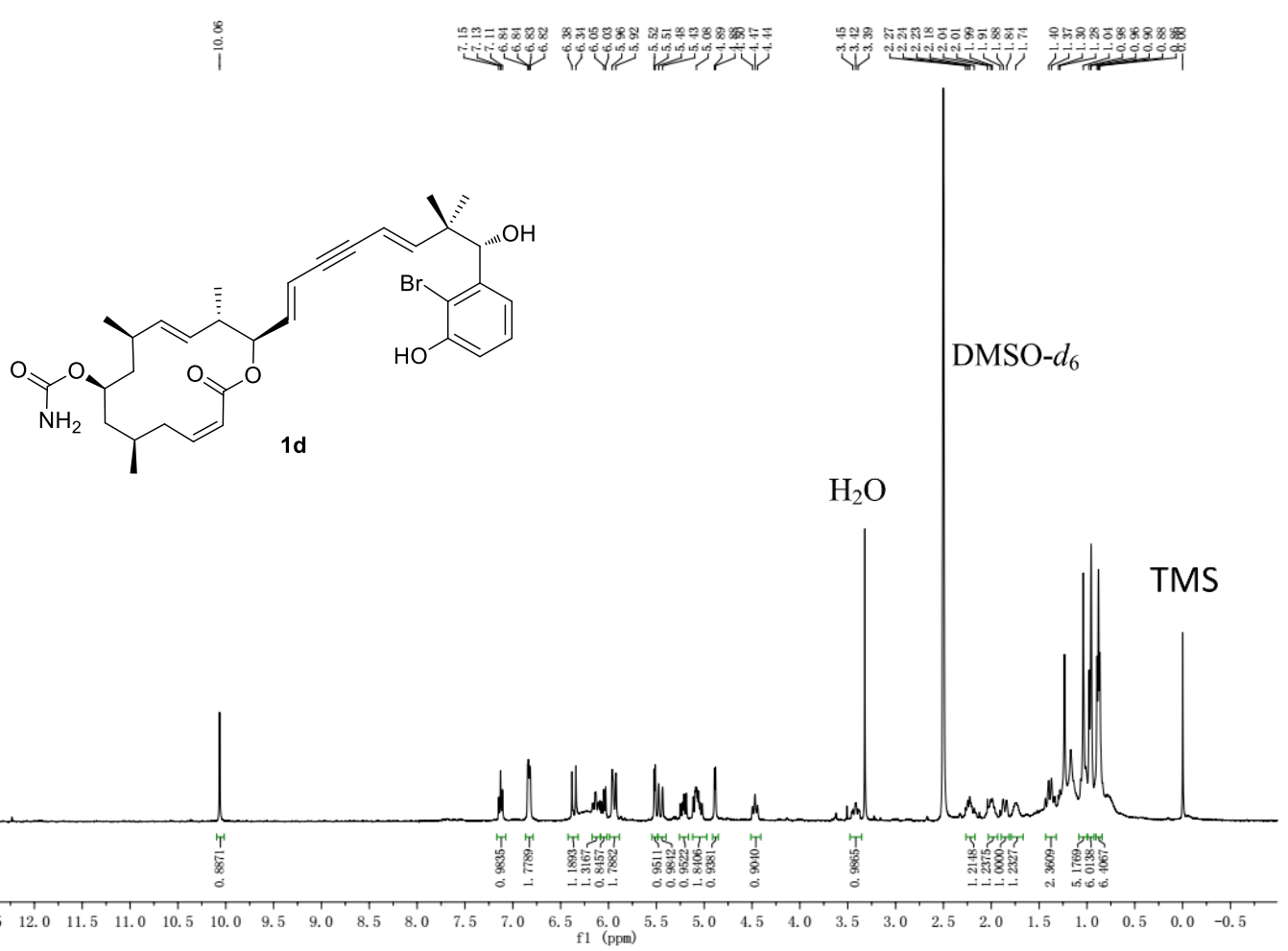

${ }^{13}$ C NMR (DMSO-d6, $100 \mathrm{MHz}$ )

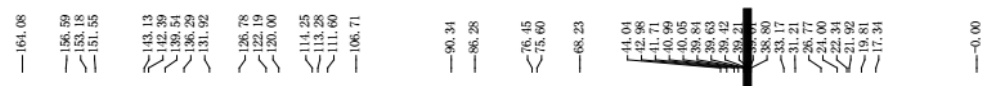

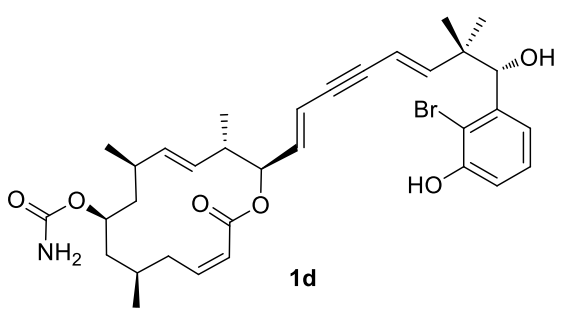

TMS

MSO- $d_{6}$

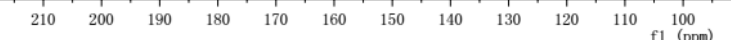

